Florida International University FIU Digital Commons

6-22-2018

\title{
The Effect of Uncertain and Weak Modal Words in 10-K Filings on Analyst Forecast Attributes
}

Myung Sub Kim

MyungSub Kim, mkim013@fiu.edu

DOI: $10.25148 /$ etd.FIDC006848

Follow this and additional works at: https://digitalcommons.fiu.edu/etd

Part of the Accounting Commons

\section{Recommended Citation}

Kim, Myung Sub, "The Effect of Uncertain and Weak Modal Words in 10-K Filings on Analyst Forecast Attributes" (2018). FIU Electronic Theses and Dissertations. 3786.

https://digitalcommons.fiu.edu/etd/3786 


\section{FLORIDA INTERNATIONAL UNIVERSITY}

Miami, Florida

\section{THE EFFECT OF UNCERTAIN AND WEAK MODAL WORDS IN 10-K FILINGS ON ANALYST FORECAST ATTRIBUTES}

A dissertation submitted in partial fulfillment of

the requirements for the degree of

DOCTOR OF PHILOSOPHY

in

BUSINESS ADMINISTRATION

by

Myung Sub Kim

2018 
To: Dean Joanne Li

College of Business

This dissertation, written by Myung Sub Kim, and entitled The Effect of Uncertain and Weak Modal Words in 10-K Filings on Analyst Forecast Attributes, having been approved in respect to style and intellectual content, is referred to you for judgment.

We have read this dissertation and recommend that it be approved.

$\begin{array}{r}\hline \text { Wen-Hsiu Chou } \\ \hline \text { Xiaochuan Huang } \\ \hline \text { Jonathan Milian } \\ \hline \text { Clark Wheatley } \\ \hline \text { Steve Lin, Major Professor }\end{array}$

Date of Defense: June 22, 2018

The dissertation of Myung Sub Kim is approved.

Dean Joanne Li College of Business

Andrés G. Gil

Vice President for Research and Economic Development and Dean of the University Graduate School

Florida International University, 2018 
(C) Copyright 2018 by Myung Sub Kim

All rights reserved. 


\section{DEDICATION}

I dedicate this thesis to my parents, Sung-Il Kim and Soo-Ho Shin. Without their love, support, patience, and understanding, the completion of this work would not have been possible. 


\section{ACKNOWLEDGMENTS}

I thank God for His amazing grace and unchanging love to complete this degree. I wish to thank my wife, Okboon, whose love, support, endurance, and sacrifice enabled me to complete this journey. My two daughters, Lauren and Emily, bring us joy and happiness in times of difficulties and restlessness. I would like to thank the members of my committee for their time, support and guidance: Dr. Clark Wheatley, Dr. Jonathan Milian, Dr. Xiaochuan Huang, and Dr. Wen-Hsiu Chou. I wish to express my deepest gratitude to my advisor, Dr. Steve Lin, for his endless care and support, and excellent guidance through this process. He has been a great mentor and role model scholar during my Ph.D. studies. I would like to thank my professors in the School of Accounting at Florida International University for their encouragement and guidance throughout the last four years. Finally, I want to thank my fellow Ph.D. students in the School of Accounting at Florida International University for their comradeship and friendship. 


\title{
ABSTRACT OF THE DISSERTATION \\ THE EFFECT OF UNCERTAIN AND WEAK MODAL WORDS IN 10-K FILINGS \\ ON ANALYST FORECAST ATTRIBUTES
}

\author{
by \\ Myung Sub Kim \\ Florida International University, 2018 \\ Miami, Florida \\ Professor Steve Lin, Major Professor
}

This study examines the determinants of the use of uncertain and weak modal words in $10-\mathrm{K}$ filings and the effect of these words on analyst forecast attributes. I find that the use of uncertain and weak modal words in 10-K filings is positively (negatively) associated with firm size, volatility of business and operations (firm age and number of business segments). More importantly, after controlling for readability and management tone, I find that the use of uncertain and weak modal words in 10-K filings is associated with greater analyst following, lower forecast dispersion, greater forecast accuracy, and lower uncertainty in analysts' overall and common information environment. The results of this study provide more insights into why management uses uncertain and weak modal words in $10-\mathrm{K}$ filings and how these words in 10-K filings affect analysts' behavior and their forecast outcomes. 


\section{TABLE OF CONTENTS}

CHAPTER

PAGE

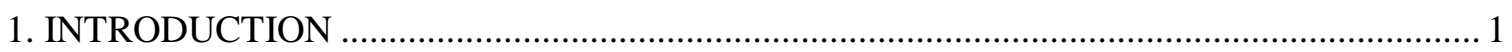

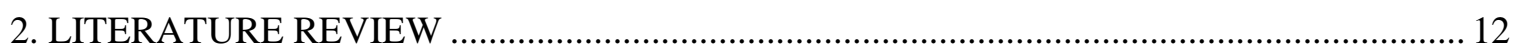

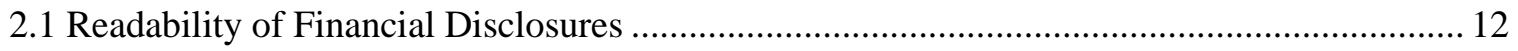

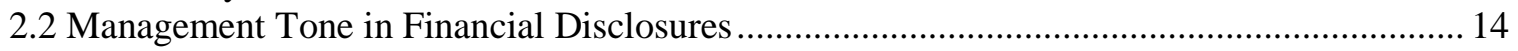

2.3 Uncertain and Weak Modal Words in Financial Disclosures ............................................... 16

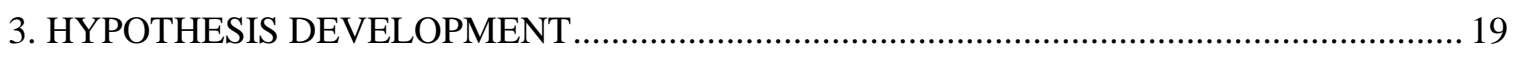

3.1 Determinants of the Use of Uncertain and Weak Modal Words in 10-K

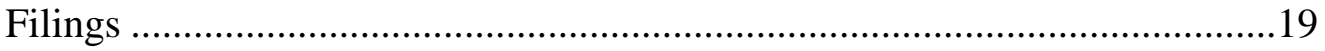

3.2 The Relation between Uncertain and Weak Modal Words in 10-K Filings and Analyst Forecast Attributes ..............................................................20

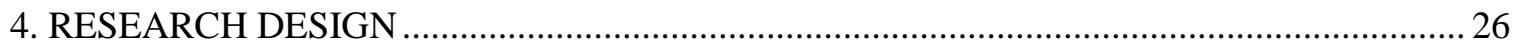

4.1 Determinants of Uncertain and Weak Modal Words in 10-K Filings .............26

4.2 The Effect of the Use of Uncertain and Weak Modal Words in 10-K Filings on Analyst Forecast Attributes ...................................................28

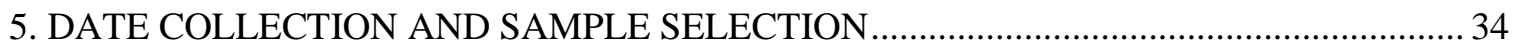

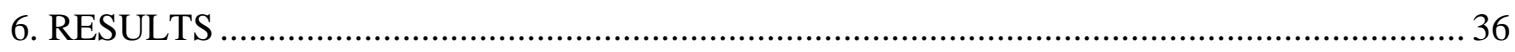

6.1 Determinants of the Use of Uncertain and Weak Modal Words

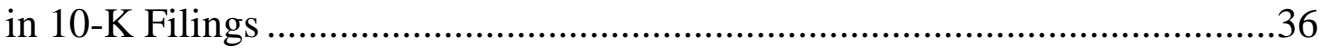

6.2 The Association between the Use of Uncertain and Weak Modal Words in

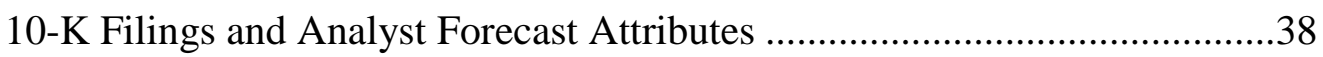

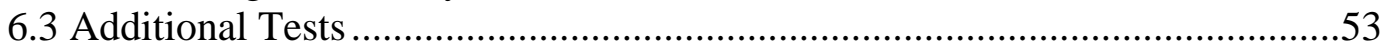

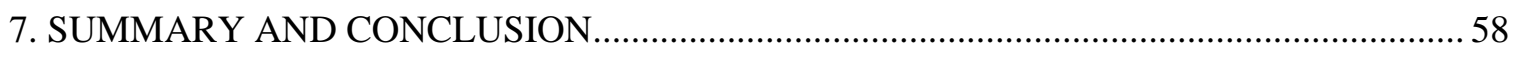

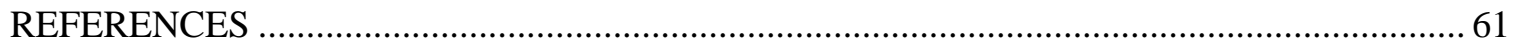

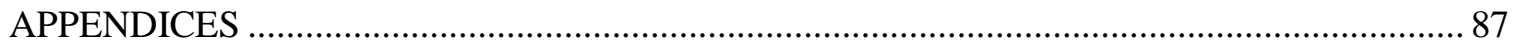

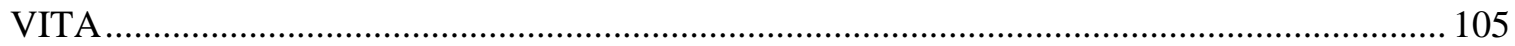




\section{LIST OF TABLES}

TABLE

PAGE

1. Sample Selection 66

2. Descriptive Statistics for the Determinants of the Use of Uncertain and Weak Modal Words in $10-\mathrm{K}$ Filings

3. Correlation Matrix for the Determinants of the Use of Uncertain and Weak Modal Words in 10-K Filings

4. Multivariate Analysis for the Determinants of the Use of Uncertain and Weak Modal Words in the 10-K Filings

5. Descriptive Statistics for the Association between the Use of Uncertain and Weak Modal Words in 10-K Filings and Analyst Forecast Attributes

6. Correlation Matrix for the Association between Analyst Following and the Use of Uncertain and Weak Modal Words in 10-K Filings

7. Multivariate Analysis for the Association between Analyst Following and the Use of Uncertain and Weak Modal Words in 10-K Filings

8. Correlation Matrix for the Association between Analyst Forecast Dispersion and the Use of Uncertain and Weak Modal Words in 10-K Filings

9. Multivariate Analysis for the Association between Analyst Forecast Dispersion and the Use of Uncertain and Weak Modal Words in 10-K Filings

10. Correlation Matrix for the Association between Analyst Forecast Accuracy and the Use of Uncertain and Weak Modal Words in 10-K Filings

11. Multivariate Analysis for the Association between Analyst Forecast Accuracy and the Use of Uncertain and Weak Modal Words in 10-K Filings

12. Correlation Matrix for the Association between Uncertainty in Analysts' Overall

Information Environment and the Use of Uncertain and Weak Modal Words in 10-K Filings ... 81

13. Multivariate Analysis for the Association between Uncertainty in Analysts' Overall

Information Environment and the Use of Uncertain and Weak Modal Words in 10-K Filings ... 82

14. Correlation Matrix for the Association between Uncertainty in Analysts' Common Information Environment and the Use of Uncertain and Weak Modal Words in 10-K Filings ... 84

15. Multivariate Analysis for the Association between Uncertainty in Analysts' Common Information Environment and the Use of Uncertain and Weak Modal Words in $10-\mathrm{K}$ Filings 
16. Correlation Matrix for the Association between Analyst Following and the Use of Uncertain and Weak Modal Words in 10-K Filings: Fog Replacement

17. Multivariate Analysis for the Association between Analyst Following and the Use of Uncertain and Weak Modal Words in 10-K Filings: Fog replacement

18. Correlation Matrix for the Association between Analyst Forecast Dispersion and the Use of Uncertain and Weak Modal Words in 10-K Filings: Fog replacement

19. Multivariate Analysis for the Association between Analyst Forecast Dispersion and the Use of Uncertain and Weak Modal Words in 10-K Filings: Fog Replacement

20. Correlation Matrix for the Association between Analyst Forecast Accuracy and the Use of Uncertain and Weak Modal Words in 10-K Filings: Fog replacement 96

21. Multivariate Analysis for the Association between Analyst Forecast Accuracy and the Use of Uncertain and Weak Modal Words in 10-K Filings: Fog replacement

22. Correlation Matrix for the Association between Uncertainty in Analysts' Overall Information Environment and the Use of Uncertain and Weak Modal Words in 10-K Filings:

Fog replacement

23. Multivariate Analysis for the Association between Uncertainty in Analysts' Overall Information Environment and the Use of Uncertain and Weak Modal Words in 10-K Filings:

Fog replacement

24. Correlation Matrix for the Association between Uncertainty in Analysts' Common Information Environment and the Use of Uncertain and Weak Modal Words in 10-K Filings:

For Replacement

25. Multivariate Analysis for the Association between Uncertainty in Analysts' Common Information Environment and the Use of Uncertain and Weak Modal Words in 10-K Filings: Fog replacement 


\section{CHAPTER 1}

\section{INTRODUCTION}

The SEC introduced the plain English ${ }^{1}$ Rule 421(d) in 1998 to make financial disclosures easier to read and understand for investors, brokers, advisers, and others in the financial services industry. This rule encourages firms to use plain English not only in their prospectuses but also in all SEC documents and communication with shareholders (SEC 1998; Francis 2014; Loughran and McDonald 2014). This new rule has motivated many studies to investigate the effects of the readability of $10-\mathrm{K}$ filings on the usefulness of financial disclosures and the behavior of primary users of these disclosures such as investors and analysts.

Many studies examine and find that disclosure quality significantly affects analyst following and analysts' forecast accuracy and dispersion. More specifically, disclosure quality is measured by various proxies including disclosure scores (Lang and Lundholm 1996; Healy, Hutton, and Palepu 1999), segment disclosures (Botosan and Harris 2000), intangible assets (Barth, Kasznik, and McNichols 2001), a firm's accounting choices (Hopkins, Houston, and Peters 2000; Bradshaw, Miller, and Serafeim 2008), tax law changes (Plumlee 2003), specific financial items that represent earnings quality (Hirst and Hopkins 1998; Hirst, Hopkins, and Wahlen 2004), global diversification (Duru and Reeb 2002), and readability ( $\mathrm{Li}, 2008)$.

\footnotetext{
${ }^{1}$ A Plain English Handbook provided by SEC.gov explains how the issuer can prepare cleaner and more informative documents, and it defines plain English as creating a document that is visually and logically organized and easily understandable. For example, long sentences are fixed by short sentences; passive voice is fixed by active voice. Please find the handbook: https://www.sec.gov/pdf/handbook.pdf.
} 
This dissertation aims to contribute to this line of research by examining the relationship between a firm's financial disclosure and some attributes of analysts' forecasts. The financial disclosure examined in this study is the use of uncertain and weak modal words in financial statements (i.e., 10-K filings). More specifically, this study investigates the impact of using vague language, such as uncertain and weak modal words, in financial statements on analyst behavior and forecast outcomes.

Both the SEC and influential media have often criticized the increasing use of complex language in 10-K filings (Schroeder 2002). Their main concern is that users of financial statements including investors (especially small investors) may not be able to fully understand complex financial information (SEC 1998; Schroeder 2002; Cox 2007). Given the increasing trend of complicated financial disclosures, it is important to examine whether financial analysts require greater knowledge and skills to interpret these complex disclosures or if they can understand and reflect the information contained in complex financial reports into their forecasts (Lehavy, Li, and Merkley 2011). Similar to Lehavy et al. (2011), this study examines the impact of the complexity of a firm's financial disclosures on the attributes of analysts' forecasts. Different from Lehavy et al. (2011) that investigates the impact of readability of financial statements on analysts' forecasts, this study examines the extent to which management's ambiguous language in 10-K filings impacts some attributes of analysts' forecasts after controlling for different measures of readability. More specifically, this study investigates the determinants of usage of ambiguous words in 10-K filings and the association between the use of uncertain and weak modal words in 10-K filings and analysts' subsequent forecast outcomes. To the best of my knowledge, this is the first study to examine this relation in the literature. 
There are various ways to define and measure 'readability' in the literature, but in the context of financial disclosures, it is normally defined as the ability of primary users of financial information such as investors and analysts to assimilate valuation-relevant information from firm disclosures (Loughran and McDonald 2014). The Fog Index, measured by the average sentence length and percentage of complex words, is one of the most commonly used measures for readability in the accounting and finance literature (De Franco, Hope, Vyas, and Zhou 2015) although it is widely criticized for being poorly specified when used to evaluate financial documents. $\operatorname{Li}(2008)$ is the first study to apply the Fog index to examine the impact of the readability of 10-K filings on firm performance and earnings persistence. He finds that 10-K filings of firms with lower earnings have lower readability and $10-\mathrm{K}$ filings with higher readability are more likely to have persistent positive earnings. Many studies have followed Li (2008) to examine the implications of annual report readability for investment efficiency (Biddle, Hilary and, Verdi 2009), investors' responses to information content of annual reports (You and Zhang 2009; Rennekamp, 2012), small versus large investors (Miller 2010), individual investors (Lawrence 2013), management forecasts (Guay, Samuels, and Talyor 2015), and credit rating and cost of debt capital (Bonsall and Miller 2014).

Despite the popularity of the Fog Index in the literature, there has been some criticism of how it identifies 'complex' words. The Fog index defines words with more than two syllables as complex words, which has been criticized for being a poorly designed measure because many words like corporation, agreement, and management are common and reasonably comprehensive in the context of firms' business disclosures even though they have more than two syllables (Loughran and McDonal, 2014). Loughran and 
McDonald (2014) argue that the file size of 10 - $\mathrm{K}$ filings as a gross measure of $10-\mathrm{K}$ readability is straightforward, easy to calculate, readily applicable to other readability research, and more importantly prone to fewer measurement errors. Consistent with these arguments, they find that the $10-\mathrm{K}$ file size outperforms the Fog Index in explaining both unexpected earnings and analyst forecast dispersion. Many recent publications and working papers have used 10-K file size to measure 10-K readability (e.g., Bonsall and Miller 2014; Bratten, Gleason, Larocque, and Mills 2014; Li and Zhao 2014; Ertugrul, Lei, Qiu, and Wan 2017). Although 10-K file size is a reasonable proxy for information complexity of 10-K filings, it may not be suitable for shorter and unvaried disclosure such as press releases and earning conference calls (Loughran and McDonald 2016). Also, both the Fog index and 10-K file size measures do not consider other lexical features of 10-K filings, such as tone and choice of words, which may have significant effects on $10-\mathrm{K}$ readability and be used by managers to strategically deliver valuation-relevant information to market participants. This study aims to further investigate this issue.

There is a growing body of textual analysis research examining the tone and sentiment of firms' written communication with investors (e.g., 10-K filings, earnings press releases, and investor message boards). However, Loughran and McDonald (2016) argue that a lot of textual analysis research (Davis, Piger, and Sedor 2012; Demers and Vega 2014; Frankel, Mayew, and Sun 2010) has focused on a simple positive and negative dichotomy of sentiment analysis. They also argue that positive sentiment appears to have lower power in these studies. Therefore, Loughran and McDonald (2016) suggest exploring other keywords like "uncertain," "litigious," "strong modal," and "weak modal" words to have additional means of parsing sentiment. One relevant example is to examine managers' 
opportunistic word choice of uncertain and weak modal words to hide bad news during conference calls. However, this leads to questions as to when and why firms use these uncertain words, such as approximate, contingent, uncertain, and indefinite, and weak modal words, such as might, could, possible, and maybe, in their 10-K filings and conference calls. Management obfuscation hypothesis states that managers have incentives to obfuscate information when they experience or expect poor performance simply because more complex disclosures take a longer time to process, which will delay market reaction on poor performance (Bloomfield 2002). You and Zhang (2009) find that investors' underreaction to information contained in 10-Ks tends to be stronger for firms with more complex 10-Ks, measured by number of words. However, there is not much research on the incentive and the impacts of using vague language such as uncertain and weak modal words in 10-K filings. This study investigates this issue.

My first research question is, therefore, to investigate the determinants of the use of uncertain and weak modal words in 10-K filings. $\mathrm{Li}$ (2008) examines the determinants of annual report readability, measured by the Fog Index and length of the document. He finds that large firms, volatile business environment, firms with seasonal equity offering and merger-and-acquisition, and Delaware firms (firm age, firms with special items, and number of business segments) have less (more) readable 10-Ks. Lehavy et al. (2011) investigates the association of $10-\mathrm{K}$ readability and analysts' forecast behaviors and find that less readable 10-Ks are positively associated with analyst following, forecast dispersion and error, and uncertainty in analysts' information environment.

Since no prior research has examined the determinants of use of uncertain and weak modal words, I follow both $\mathrm{Li}$ (2008) and Lehavy et al. (2011) to investigate the potential 
determinants of use of uncertain and weak modal words. Using 37,442 observations from Loughran and McDonald's word lists, Compustat financial data, and SDC database for special event data, I predict and find that the use of uncertain and weak modal words in 10$\mathrm{K}$ filings is positively associated with firm size, volatility of business and operations. I further predict and find that the use of uncertain and weak modal words is negatively associated with firm age and number of business segments.

The main research question is to examine the association between the use of uncertain and weak modal words in 10-K filings and some attributes of analysts' forecasts. To examine this relation, I use 25,673 observations from Loughran and McDonald's word lists, Compustat financial data, and I/B/E/S analysts' forecast data. First, I examine the relation between analyst following and the use of uncertain and weak modal words in 10K filings. On the one hand, Lehavy et al. (2011) argue that more complex financial disclosures increase analyst following because increased cost of processing firm's disclosure increases the demand for analysts' services. Therefore, I expect a positive association between the use of uncertain and weak modal words in 10-K filings and analyst following. On the other hand, some prior literature argues that there are additional costs for analysts to cover firms with less readable written communication (Mikhail, Walther, and Willis 1999; Plumlee 2003; Hong and Kubik 2003). I expect that analysts may prefer less ambiguous 10-K filings to produce more reliable forecasts so that they can maintain their reputation. I expect that fewer analysts would pursue tasks of firms with more ambiguous words in 10-K filings. My finding is consistent with the prediction that increased use of uncertain and weak modal words in $10-\mathrm{Ks}$ leads to more analyst following. I report a 
positive and statistically significant relation between number of analysts and the use of ambiguous words in 10-Ks.

Second, I examine whether forecast dispersion is associated with the use of uncertain and weak modal words in 10-Ks. Syntactic complexity driven by uncertain and weak modal words in 10-K filings may lead to higher costs for analysts in processing and interpreting such disclosures. These words create the asymmetric distribution and interpretation of firm information among analysts, leading to more diverse explanations about the firm's disclosures among analysts who follow the same firm. Thus, I expect more dispersion in analysts' reports when 10-K filings contain more uncertain and weak modal words.

However, prior studies find that analyst earnings forecasts become more optimistic when the uncertainty in firms' information environment increases (Ackert and Athanassakos 1997; Das, Levine, and Sivaramakrishnan 1998; Huberts \& Fuller 1995; Lim 2001). Prior literature argues that analysts are more likely to report their earnings forecast with optimistic bias because they want to maintain a good relationship with clients, and this phenomenon occurs more often when uncertainty in clients' information environment increases. I, therefore, expect that more uncertain and weak modal words in 10-K filings increase the uncertainty in firm's information environment; thus, it may cause analysts' forecasts to be consistently upwards and decrease earnings forecast dispersion among analysts. Moreover, analysts may make extra efforts to produce more accurate forecasts when facing more uncertain information environment. My finding is consistent with the idea that analyst forecast dispersion is negatively related to uncertain and weak modal words in 10-K filings, which supports the management-relations and analyst effort 
hypotheses discussed in the hypotheses development section, indicating financial analysts collectively bias their forecasts upward or make extra efforts to produce earnings forecasts when facing more uncertain information environment.

Third, I examine the relation between forecast accuracy ${ }^{2}$ (forecast error) and the use of uncertain and weak modal words in 10-Ks. Lehavy et al. (2011) report that less readable 10-Ks are associated with less accurate forecasts due to increased costs for research and information-processing. I predict ambiguous language in $10-\mathrm{K}$ filings increases costs for research and information-processing and these costs may decrease the accuracy of the forecast. Thus, the use of more uncertain and weak modal words in firms' disclosures may decrease the accuracy of analyst forecasts.

However, there are two theories that can explain the positive association between uncertain and weak modal words in 10-K filings and accurate forecasts. First, analysts may make extra efforts to produce more accurate earnings forecasts. Second, managers may use uncertain and weak modal words to signal analysts and other market participants about the uncertainty of future earnings. My finding is consistent with the idea that forecast accuracy (forecast error) is negatively related to uncertain and weak modal words in $10-\mathrm{K}$ filings which suggests that analysts effectively process 10-Ks with ambiguous words, and are able to produce more accurate forecasts. It is possible that analysts make extra efforts to produce their forecasts when 10-K filings contain more uncertain and weak modal words. Future research needs to use behavioral research methods, such as interviews with analysts, to enhance our understanding of analysts' behavior.

\footnotetext{
${ }^{2}$ Forecast accuracy is defined as the squared value of the difference between the reported earnings in I/B/E/S and the most recent analyst consensus forecast, scaled by stock price 90 days before the consensus earnings forecast.
} 
Fourth, Barron, Byard, Kim, and Stevens (1998) measure uncertainty in private and common (publicly available) information environment using equations with the accuracy, the dispersion, and the number of the analyst. ${ }^{3}$ Employing the Barron et al. (1998)'s measure, Lehavy et al. (2011) measure uncertainty in analysts' overall information environment by the sum of common and idiosyncratic (private) uncertainty among analysts. Lehavy et al. (2011) predict that analyst forecasts for firms with less readable reports will be associated with greater overall uncertainty. Thus, I predict that there will be higher uncertainty in the analysts' overall information environment when firms use more ambiguous words in their $10-\mathrm{K}$ filings. Inconsistent with my prediction, I find that uncertainty in analysts' overall information environment is decreasing in uncertain and weak modal words in 10-Ks, suggesting that managers may use ambiguous language in 10Ks to signal analysts and other market participants about the uncertainty of future earnings.

Finally, following Barron et al. (1998)'s measure, Lehavy et al. (2011) measure common analyst forecast uncertainty by the ratio of common uncertainty to total uncertainty among analysts. In short, it measures the degree to which analysts share a common belief. Lehavy et al. (2011) find a positive relation between common analyst forecast uncertainty and the Fog Index, suggesting publicly available information such as the $10-\mathrm{K}$ becomes more important to analysts relative to private (idiosyncratic) information with more complex 10-K filings. Similarly, I predict that more ambiguous words in 10-K filings increase the degree to which analysts share a common belief such as 10-K filings. This is because more uncertain and weak modal words in 10-Ks make it difficult for

\footnotetext{
${ }^{3}$ The measures and equations in Barron et al. (1998) will be discussed in research design.
} 
analysts to process private information; thus, they may increase the importance of publicly available information such as 10-Ks. Inconsistent with my prediction, I find that uncertainty in analysts' common information environment decreases for firms with increased use of uncertain and weak modal words in firms' 10-K filings. Again, managers may use ambiguous language in 10-Ks to signal analysts and other market participants about the uncertainty of future earnings.

For a robustness test, I replace File_Size with the Fog Index (Fog) to examine if the effect of uncertain and weak modal words in 10-Ks hold for analyst forecast attributes with a different measure of readability $(F o g)$. I employ the Fog Index data from Feng Li's website $^{4}$ for the sample period of 2000 - 2011. The evidence indicates that the Fog replacement does not change the overall results. Interestingly, I also find that the effect of the use of ambiguous language in 10-Ks on analysts' forecast attributes becomes stronger when Fog replaces File_Size (except Analyst Following). One limitation of this additional analysis is inconsistent sample period ${ }^{5}$. Future studies will match the sample period.

This study differs from Li (2008) and Lehavy et al. (2011) in three ways. First, I examine the determinants of the use of uncertain and weak modal words while $\mathrm{Li}$ (2008) examine the determinants of readability. Second, I examine the effect of the use of uncertain and weak modal words in 10-K filings on analyst forecast attributes while Lehavy et al. (2011) examine the association between annual report readability and analyst forecast attributes. Finally, this study examines whether the use of uncertain and weak modal words in 10 -Ks provides significant incremental valuation-relevant information for financial

\footnotetext{
${ }^{4}$ Please check the data from http://webuser.bus.umich.edu/feng/.

${ }^{5}$ Main test sample period is $2000-2016$.
} 
analysts beyond $10-\mathrm{K}$ readability, measured by the Fog index and $10-\mathrm{K}$ file size, and tone management.

Main contributions of this study are threefold. First, this is the first study to examine the characteristics of firms that use uncertain and weak modal words in their $10-\mathrm{K}$ documents. Therefore, this study provides insight into firms' opportunistic word choices in their 10-K filings under firm-specific financial conditions. Second, this is the first study to examine how financial analysts perceive information contained in uncertain and weak modal words in $10-\mathrm{K}$ filings and reflect this information into their decision making. Third, this study is relevant to users of financial disclosures because it provides insight into how vague words in a clients' $10-\mathrm{K}$ impact analyst behavior and forecasts. This is especially important given analysts play a key role as intermediaries between accounting information and investors. Hence, it is important to investigate the extent to which financial analysts interpret the information contained in uncertain and weak modal words and reflect this information into their efforts and research outputs that would directly affect the decision making of market participants.

This dissertation is organized as follows. Chapter 2 provides a summary of the literature review. Chapter 3 discusses hypothesis development. Chapter 4 describes the research design. Chapter 5 describes the data and sample. Chapter 6 presents the empirical results, and Chapter 7 concludes. 


\section{CHAPTER 2}

\section{LITERATURE REVIEW}

This study is related to three areas of accounting and finance research. They are the role of readability, tone management, and the use of uncertain and weak modal words (ambiguous language) in market-based accounting and finance research.

\subsection{Readability of Financial Disclosures}

The first area of research examines the association between annual report/analyst report readability, mostly measured by the Fog index, and earnings quality/analyst forecast attributes. A seminal paper by $\mathrm{Li}$ (2008) examines the impact of annual report readability on firm performance and earnings persistence. He finds that annual reports of firms with lower earnings have lower readability while annual reports with higher readability are more likely to have persistent positive earnings. Many finance and accounting studies use the Fog Index to investigate the readability of annual reports in relation to earnings persistence (Li 2008), investment efficiency (Biddle et al. 2009), and timeliness of price adjustment (Callen, Khan, and Lu 2009). However, only a few studies examine the implications of annual report readability for analyst behavior and the readability of analyst reports. For example, Lehavy et al. (2011) examine the association between readability of 10-Ks and financial analysts' behavior and their financial reports' attributes. Using 10-K filings from SEC's EDGAR database for 1995-2006, they find that analyst reports of firms with less readable 10-K filings are linked with more analyst following and are more informative. Moreover, analyst reports of firms with more complex 10-K filings are associated with 
higher forecast dispersion, less accurate analysts' forecasts, and greater overall uncertainty.

De Franco et al. (2015) use a large text database with analysts' reports from 2002 to 2009 and examine the importance of the readability of analyst reports. They also find that "highability analysts" produce more readable reports and that trading volume reaction increases with more readable analyst reports.

However, many studies argue that the widely used the Fog index, measured by the number of complex words (measured by the syllables) and the average length of sentences, is poorly specified when applied to business documents (e.g., Jones and Shoemaker 1994; Loughran and McDonald 2014, 2016). Also, Loughran and McDonald (2014, 2016) point out that the Fog index does not consider writing style. For example, the value of the Fog index will be identical even though we randomly reorder words in the original sentence to make it incomprehensive. Loughran and McDonald (2014) provide evidence that 10-K file size, as a comprehensive proxy for 10-K readability, appears to outperform the Fog Index when explaining unexpected earnings and analyst forecast dispersion. Hence, it has been increasingly popular to use $10-\mathrm{K}$ file size for measuring annual report readability in accounting and finance research. For example, Ertugrul et al. (2017) find that larger 10-K file size (i.e., a less readable 10-K) decreases loan maturity and increases the probability of collateral requirement. This shows that banks increase their level of monitoring severity for firms with less readable annual reports. This is consistent with the argument made by Loughran and McDonald (2014) that low readability is related to firms' intention to obfuscate mandated earnings-relevant information by burying it in longer documents. In

\footnotetext{
${ }^{6}$ De Franco et al. (2015) define that "high-ability analysts" are more experienced, issue more timely earnings forecasts and more frequent forecast revisions. They are also better ranked by Institutional Investor magazine, and issue more consistent earnings forecasts and recommendations.
} 
sum, previous studies provide evidence indicating that readability is related to the informativeness of annual reports, which affects market participants' behavior although there is a debate on how readability should be measured.

\subsection{Management Tone in Financial Disclosures}

Another relevant research area is to investigate the tone (positive and negative) of the words in the firm's disclosures (e.g., earnings announcements, 10-K, 10-Q, MD\&A, and conference calls) and how investors react to tone management. Loughran and McDonald (2011) develop positive and negative words lists. For example, the positive words in the list are achieve, attain, efficient, improve, profitable, and upturn; negative words in the list are loss, impairment, against, decline, negatives, restated, litigation, and misstatement. Some studies find that managers have incentives to manage their optimistic or pessimistic language at earnings announcements especially for information that is more sensitive to stock prices (e.g. Feldman, Govindaraj, Livnat, and Segal 2009; Davis and Tama-Sweet 2012; Davis et al. 2012; Huang, Teoh, and Zhang 2014; Dermers and Vega 2014). For example, Feldman et al. (2009) find management's tone change in the MD\&A section of $10-\mathrm{Q}$ and $10-\mathrm{K}$ is significantly related to short-window market reactions and excess returns drift around the SEC filing. This study shows that investors seem to consider

this nonfinancial information (e.g., the change of management tone) in addition to quantitative financial information from MD\&A disclosures when making their investment decisions. Davis and Tama-Sweet (2012) find that fast-growing firms and firms that precisely meet or just beat analysts' earnings forecasts report less pessimistic language in their earnings press releases because managers have a greater incentive to report 
strategically when disclosed information is more sensitive to the stock returns. Using 23,000 quarterly earnings press releases between 1998 and 2003, Davis et al. (2012) measure net optimistic language using DICTION software program (counts optimistic and pessimistic words). Their evidence suggests that the managers' use of net optimistic language is positively related to expected future firm performance (e.g., higher ROA) and a significant market reaction. Li (2008) suggests that conference calls may provide a better platform to investigate the relation between linguistic information content and firm performance because unscripted question and answer sessions may provide a full examination of firm disclosure between managers and analysts. Many studies examine and find that the tone of the words used during conference calls affects conference call return and trading volume (e.g., Price, Doran, Peterson, and Bliss 2012; Davis, Matsumoto, and Zhang 2015; Druz, Wagner, and Zeckhauser 2016; Milian and Smith 2017). Price et al. (2012) employ computer-based content analysis to examine the question and answer session in a conference call and find that conference call discussion tone has highly significant explanatory power for initial reaction CARs (Cumulative Abnormal Returns), the post-earnings-announcement-drift, and abnormal trading volume. Also, if uncertainty exists in the firm's cash dividend payout decision, the tone of conference call has more explanatory power for abnormal returns and trading volume. Using the effect of managerspecific factors such as previous career experience (e.g., charitable organization involvement, etc.) and education backgrounds (e.g., MBA, LAW degree, etc.), Davis et al. (2015) find the tone of conference calls is significantly associated with manager-specific factors. Also, they find some evidence that the choice of managers' language influences the investors' interpretation of the firm's financial performance. Milian and Smith (2017) 
examine 16,609 conference calls of S\&P 500 companies and find that the amount of praise by analysts on earnings conference calls is positively related to the earnings surprise and a more significant extent the earnings announcement stock return. These studies, however, are criticized for using an overly simplified positive (optimistic) and negative (pessimistic) dichotomy of sentiment analysis. Loughran and McDonald (2016) argue that tests for positive sentiment appear to have a lower test power because positive sentiment becomes ambiguous when negative information is filled with positive words. ${ }^{7}$ Moreover, these studies do not consider how the tone used in the earnings press releases affects analyst forecast attributes. This study differs from the above studies in that this study examines how the tone (negative and positive) in 10-K filings influences analyst's behavior and forecast outcomes. Overall, studies on tone management find that the tone of the language chosen by management in the earnings press releases is informative for investors although there are some measurement issues with interpreting positive words in financial disclosures.

\subsection{Uncertain and Weak Modal Words in Financial Disclosures}

The third related accounting and finance research area is the use of uncertain and weak modal words in financial disclosures. In addition to readability and tone, ambiguous language in annual reports can be a source of firm risk because it may increase (decrease) informational risk (investors' ability to comprehend financial reports). Loughran and

\footnotetext{
${ }^{7}$ Loughran and McDonald (2016) show an example case, "a careful manager might use $90 \%$ positive words in dismissing an employee." which explains one critical issue with positive and negative tone textual analysis. The manager intended to dismiss the employee but textual analysis will capture more positive words than negative words in the manager's comment.
} 
McDonald (2011) create word lists to reflect ambiguous words in the financial context. For example, the list of uncertain words such as approximate, assume, contingent, depend, and indefinite, expresses imprecision; the list of weak modal words indicates a lack of confidence, and examples are might, could, maybe, depending, and possible. Recent studies find that ambiguous texts of corporate disclosures affect valuation uncertainty. For example, Loughran and McDonald (2011) find a positive relation between the use of uncertain and weak modal words in $10-\mathrm{K}$ filings and the stock return volatility. They perform event studies for report excess returns, abnormal volume, and post-event return volatility and find a significantly negative relation between event period excess returns and the use of uncertain and weak modal words in 10-K filings. Moreover, they find that the use of uncertain and weak modal words in $10-\mathrm{K}$ filings is positively associated with the abnormal trading volume during the event window. There is a positive relation between stock return volatility in the year after 10-K filings and a proportion of uncertain and weak modal words in 10-K filings. Their paper documents that ambiguous words are linked with market reactions around the $10-\mathrm{K}$ filings, abnormal trading volume, and stock return volatility after 10-K filings. Loughran and McDonald (2013) find a positive link between the ambiguous language in S-1 initial public offering (IPO) filings and first-day returns, absolute price revisions, and subsequence volatility. Using a sample of 1,887 completed U.S. IPOs during 1997-2010, they find associations between uncertain words in the Form S-1 and first-day returns, offer price revisions, and volatility. Unlike prior literature which measures firm age, sales, and IPO gross proceeds as ex-ante uncertainty proxies, they use S-1's tone as a direct proxy for measuring ex-ante uncertainty about an IPO's valuation. Ertugrul et al. (2017) find that more ambiguous words in annual reports are related to 
stricter loan contracts and higher stock price crash risk. They find that the frequencies of uncertain and weak modal words in annual reports are positively associated with stricter loan contracts. This finding indicates that the ambiguous words of $10-\mathrm{K}$ filings contain relevant information in assessing firm's risk level and have an effect on both price and nonprice loan terms. Also, they find that high frequency of uncertain and weak modal words in financial disclosures increases the likelihood of a stock price crash risk. This finding is consistent with their prediction that 10-K filings with more ambiguous language are related to higher cost of capital. Overall, their results provide significant evidence that the readability and ambiguous language of 10-K filings are associated with a firm's information-concealing behavior that increases its information risk and cost of capital. Moreover, Loughran and McDonald (2016) suggest, uncertain and weak modal words used in annual reports and earnings press releases are additional means of parsing sentiment, which warrants an excellent future area of research. This study aims to examine the effect of uncertain and weak modal words in 10-K filings on financial analysts' behavior and analyst forecast outcomes. 


\section{CHAPTER 3}

\section{HYPOTHESIS DEVELOPMENT}

\subsection{Determinants of the Use of Uncertain and Weak Modal Words in 10-K Filings}

Li (2008) examines the determinants of annual report readability, measured by the Fog Index and the length of the document. He regresses the Fog Index and the length of annual reports on potential determinants such as firm size, market-to-book, firm age, special items, volatility of business and operations, the complexity of operations, financial complexity, firm events, and incorporation state. Li (2008) finds that larger firms, firms with more volatile business, firms with merger-and-acquisition (M\&A) transactions, and firms incorporated in Delaware state are positively related to the Fog Index (i.e., listed items are associated with less readable $10-\mathrm{K}$ reports). However, his finding suggests that firm age, firms with special items, firms with geographic segments, and firms that are issuing new equity are negatively associated with the Fog Index (i.e., listed items are associated with more readable $10-\mathrm{K}$ reports).

This study examines the determinants of the use of uncertain and weak modal words in 10-K filings. To my knowledge, there is no prior study that examines this issue. Thus, I follow Li (2008)'s method to examine the determinants of the use of these words in 10$\mathrm{K}$ filings. First, I predict that the use of uncertain and weak modal words in $10-\mathrm{K}$ filings is positively associated with firm size, market-to-book ratio, volatility of business and operations. I expect that larger firms normally face more complex and uncertain business environment and therefore are more likely to use uncertain and weak modal words in their 10-Ks. I expect that growth firms (i.e., firms with the higher market-to-book) may also face 
a more uncertain business environment and therefore their financial reports are likely to include more ambiguous words. I also predict that firms facing a volatile business operating environment tend to use more uncertain and weak modal words in their financial disclosures. Second, I predict that the use of uncertain and weak modal words in $10-\mathrm{Ks}$ is negatively associated with firm age, special items, and firm events such as merger-andacquisition (M\&A) and seasoned equity offering (SEO). I predict that older firms may have less information asymmetry and information uncertainty. I also expect firms with more negative special items are more likely to use uncertain and weak modal words in their 10K filings. I expect less ambiguous words in annual reports if a firm expects M\&A or SEO near future. Following Li (2008), I include a Delaware dummy to examine whether firms incorporated in Delaware state use more uncertain and weak modal words in their $10-\mathrm{K}$ filings because Daines (2001) argues that firms in Delaware follow different laws and regulations from similar firms in other states.

\subsection{The Relation between Uncertain and Weak Modal Words in 10-K Filings and Analyst Forecast Attributes}

\subsubsection{Analyst Following}

I have no prediction between the use of uncertain and weak modal words in $10-\mathrm{K}$ filings and analyst following because prior literature provides rather mixed evidence. Some literature argues that less readable (more complex) financial disclosures lead to increased analyst following (e.g., Lehavy et al. 2011). In general, the cost of processing complex accounting information is higher for users of financial statements. However, users of financial information have different levels of abilities to interpret and process the 
information (Indjejikian 1991; Ball 1992). Therefore, financial analysts with their private analysis of firms can make a profit from these differences (Schipper 1991). The greater the cost to users of processing firm's disclosure, the more profit the analysts make. If analysts intend to provide their services to meet this increased demand for processing more complicated financial disclosures, then firms with complicated financial disclosures will have more analyst following (Lehavy et al. 2011). Therefore, I expect a positive association between the use of uncertain and weak modal words in 10-K filings and analyst following.

However, there are additional costs for analysts to cover firms with less readable written communication; such costs include the direct costs of processing information provided by management, research costs, and the adverse impact on analysts' reputation from inaccurate forecasts and recommendations (Mikhail et al. 1999; Plumlee 2003; Hong and Kubik 2003). Prior literature also finds that the cost of potential manipulations attributed to the less readable written communication may discourage analyst following ( $\mathrm{Li}$ 2008; Lang, Lins, and Miller 2004). Only "high-ability" analysts issue more consistent earnings forecast and produce more readable forecast reports (De Franco et al. 2015). Thus, I expect that analysts may prefer to work with more transparent and less ambiguous 10-K filings to produce more reliable earnings forecasts and maintain their reputation. I expect that fewer analysts would pursue tasks of firms with more ambiguous words in $10-\mathrm{K}$ filings.

Due to the mixed results from the prior literature, I predict (in a null hypothesis form),

H1: There is no association between the use of uncertain and weak modal words in firm's 10-K filings and analyst following. 


\subsubsection{Forecast Dispersion and Accuracy}

I also examine how the use of the uncertain and weak modal words in $10-\mathrm{K}$ filings affects analyst earnings forecast dispersion and accuracy as well as uncertainty in firm idiosyncratic (private) or common (public) information environments. Syntactic complexity driven by uncertain and weak modal words in $10-\mathrm{K}$ filings may lead to higher costs for analysts in processing and interpreting such disclosures. Moreover, it influences the dispersion and accuracy of earnings forecasts and the uncertainty in the information environment. Less readable written communication increases analysts' information processing cost. As a result, analysts are more likely to have more diverse perceptions and interpretations of firm disclosures (Shipper 1991; Mikhail et al. 1999; Plumlee 2003; Hong and Kubik 2003). Lehavy et al. (2011) find that less readable 10-K filings are associated with higher analyst forecast dispersion. Since uncertain and weak modal words are ambiguous, the use of these words could increase analyst forecast dispersion. These words create the asymmetric distribution and interpretation of firm information among analysts, leading to more diverse explanations about the firm's disclosures among analysts who follow the same firm. Thus, I expect more dispersion in analysts' reports when 10-K filings contain more uncertain and weak modal words. However, prior studies find that analyst earnings forecasts become more optimistic when the uncertainty in the information environment increases (Ackert and Athanassakos 1997; Das et al. 1998; Huberts and Fuller 1995; Lim 2001). These findings are explained by two theories. The first is the management-relations hypothesis. Lim (2001) finds that analysts may report their earnings forecasts with optimistic bias by expecting favorable treatments and better private information from the client firms. He expects that this action becomes stronger when the 
uncertainty in information environment increases. The other theory focuses on the reputational concerns of individual analysts. Ackert and Athanassakos (1997) suggest that reputational concerns related to optimistic opinion will be smaller when the uncertainty in firm's information environment is higher. This is because optimistic earnings forecast is scrutinized more easily when the uncertainty in firm's disclosures is low and with minute differences among analyst forecasts. Both theories predict that analysts' forecasts may collectively become more optimistic when firms' information environment becomes more uncertain, which may reduce forecast dispersion among analysts. Two other theories can also explain a negative association between the use of uncertain and weak modal words in 10-Ks and forecast dispersion. First, analysts may make extra efforts to produce more accurate earnings forecasts, which in turn reduces forecast dispersion (Chen and Matsumoto 2006; Bradley, Gokkaya, and Liu 2017). Second, managers may use uncertain and weak modal words in $10-\mathrm{Ks}$ to signal analysts and market participants about the uncertainty of future earnings.

Due to the mixed prediction from prior literature, I predict (in a null hypothesis form),

H2: There is no association between the use of uncertain and weak modal words in firm's 10-K filings and the dispersion in analyst earnings forecasts.

Lehavy et al. (2011) predict and find that less readable 10-K filings are associated with less accurate analyst earnings forecasts. They argue that less readable financial disclosures increase costs for research and information-processing, which may decrease forecast accuracy. If the ambiguous language in 10-K filings increases these costs, then I predict that the use of more uncertain and weak modal words in a firm's disclosures may 
decrease the accuracy of analyst consensus forecast after 10-K filings. However, at least two theories that can explain the positive association between uncertain and weak words in 10-K filings and accurate analyst earnings forecasts. First, analysts may make extra efforts to produce more accurate earnings forecasts when facing more uncertain information environment, which in turn reduces forecast error. Second, managers may use uncertain and weak modal words in 10-Ks to signal analysts and market participants about the uncertainty of future earnings, which in turn increases accuracy in analyst earnings forecasts.

Due to the mixed prediction, I predict (in a null hypothesis form),

H3: There is no association between the use of uncertain and weak modal words in firm's 10-K filings and accuracy in analyst earnings forecasts.

\subsubsection{Uncertainty in Analysts' Overall and Common Information Environment}

Barron et al. (1998) measure uncertainty in private and common (publicly available) information environment using equations with the accuracy, the dispersion, and the number of analysts. ${ }^{8}$ Employing Barron et al. (1998)'s measure, Lehavy et al. (2011) measure uncertainty in analysts' overall information environment by the sum of common and idiosyncratic (private) uncertainty among analysts. Lehavy et al. (2011) predict that analyst forecasts for firms with less readable reports will be associated with greater overall uncertainty. There will be higher uncertainty in the analysts' overall information environment when firms use more ambiguous words in their 10-K filings.

Therefore, I predict (in an alternative form),

\footnotetext{
${ }^{8}$ The measures and equations in Barron et al. (1998) will be discussed in research design.
} 
H4: The use of uncertain and weak modal words in firm's 10-K filings may increase in the uncertainty associated with analysts' overall information environment.

Furthermore, Lehavy et al. (2011) find uncertainty in analysts' common (public) information environment is increasing in less readable 10-K filings. Following Barron et al. (1998)'s measure, they measure common analyst forecast uncertainty by the proportion of common uncertainty to total uncertainty among analysts (i.e., the ratio of uncertainty in analyst' common information environment to uncertainty in analysts' overall information environment). In other words, it measures the degree to which analysts share a common belief. Lehavy et al. (2011) find a positive relation between common analyst forecast uncertainty and the Fog Index, suggesting publicly available information such as the $10-\mathrm{K}$ becomes more important to analysts relative to private information with more complex 10K filings. Similarly, I predict that more ambiguous words in $10-\mathrm{K}$ filings may increase the degree to which analysts share a common belief such as $10-\mathrm{K}$ filings. This is because more uncertain and weak modal words in 10-Ks make it difficult for analysts to process private information; thus, they increase the importance of publicly available information such as 10-Ks. Therefore, I predict (in an alternative form),

H5: The use of uncertain and weak modal words in firm's 10-K filings may increase in the uncertainty associated with information common to all analysts. 


\section{CHAPTER 4}

\section{RESEARCH DESIGN}

\subsection{Determinants of Uncertain and Weak Modal Words in 10-K Filings}

I employ Li (2008)'s model to examine the determinants of the use of uncertain and weak modal words in 10-K filings as follows.

$$
\begin{aligned}
& \text { Uncertain }_{i, t} / \text { Weak_Modal } \text { M }_{i, t} \\
& =\beta_{0}+\beta_{1} \text { Firm_Size }_{i, t}+\beta_{2} \text { MTB } B_{i, t}+\beta_{3} \text { Firm_Age }_{i, t} \\
& +\beta_{4} \text { Special_Items }_{i, t}+\beta_{5} \text { Std_Ret }_{i, t}+\beta_{6} \text { Std_Earn }_{i, t}+\beta_{7} \text { Segments }_{i, t} \\
& +\beta_{8} M \& A_{i, t}+\beta_{9} S E O_{i, t}+\beta_{10} \text { Delaware }_{i, t} \\
& +\varepsilon_{i, t}
\end{aligned}
$$

In the above model, I have two dependent variables - Uncertain and Weak_Modal. Uncertain (Weak_Modal) is the proportion (percentage) of uncertain (weak modal) words to the total words in 10-K filings as defined in Loughran and McDonald (2011). Firm_Size is a proxy for firm's operational and business environment. It is defined as the logarithm of the market value of equity at the fiscal year-end and included to explain how the size of a firm influences the use of uncertain and weak modal words in firms' 10 -K filings. I expect larger firms to use more ambiguous language in their financial disclosures because they normally face more uncertain and complex business environment. MTB (market-to-book) is a proxy for potential growth and investment opportunities of firms. It is the ratio of the market value of equity plus book value of liability to the book value of total assets at the fiscal year-end. I expect high $M T B$ firms to use more uncertain and weak modal words in their $10-\mathrm{K}$ filings than do low $M T B$ firms. Older firms are more familiar to users and have 
less information asymmetry. Thus I expect these firms to use less ambiguous language in 10-K filings. Firm_Age in model (1) is the number of years a firm appears in the CRSP monthly stock return database. Special_Items is the amount of special items divided by the book value of assets. I predict that firms with more negative special items ${ }^{9}$ probably experience more unusual events which may lead to more ambiguous word usage in their financial disclosures. I measure firm-specific stock return and earnings volatility for business or operation volatility. Std_Ret is the standard deviation of the monthly stock returns in the prior year and Std_Earn is the standard deviation of the operating earnings during the past five fiscal years ${ }^{10}$. Segments is a proxy for complexity of operations using the logarithm of the number of business segments. I create two dummy variables to measure special firm events such as merger-and-acquisition $(M \& A)$ and Seasoned Equity Offering (SEO). I use the SDC Platinum M\&A database for the $M \& A$ and the SDC Global New Issues database for the $S E O . M \& A$ equals 1 for firms that engage in $M \& A$ as an acquirer in a specific firm-year and 0 otherwise. SEO equals 1 for firms that have the seasoned equity offering in a specific firm-year and 0 otherwise. Delaware is a dummy variable equal to 1 if firms are incorporated in the state of Delaware and 0 otherwise. According to Daines (2001), firms that are incorporated in Delaware follow different corporate laws and investor protections, have more takeover bids, and are valued higher than similar firms in other states. Thus, I include this dummy to examine if firms in Delaware have more ambiguous language in their 10-K filings.

\footnotetext{
${ }^{9}$ Special items are more likely to be negative than positive due to accounting standards.

${ }^{10}$ I only include observations that have at least 3 years data.
} 


\subsection{The Effect of the Use of Uncertain and Weak Modal Words in 10-K Filings on Analyst Forecast Attributes}

H1 predicts the relation between analyst following and the use of uncertain and weak modal words in 10-K filings. I estimate the following regression for $\mathrm{H} 1$.

$$
\begin{aligned}
\text { \#Analysts }_{i, t} & =\beta_{0}+\beta_{1} \text { Uncertain }_{i, t}+\beta_{2} \text { Weak_Modal }_{i, t}+\beta_{3} \text { File_Size }_{i, t} \\
& +\beta_{4} \text { Pos_Tone }_{i, t}+\beta_{5} \text { Neg_Tone }_{i, t}+\beta_{6} \text { Firm_Size }_{i, t}+\beta_{7} \text { Growth }_{i, t} \\
& +\beta_{8} \text { Segments }_{i, t}+\beta_{9} \text { F_Inst }_{i, t}+\beta_{10} 10 K_{-} \text {News }_{i, t}+\beta_{11} \text { Adv }_{i, t} \\
& +\beta_{12} \text { R\&D }_{i, t}+\beta_{13} \text { Std_Ret }_{i, t} \\
& +\varepsilon_{i, t}
\end{aligned}
$$

Following prior literature (e.g., O'Brien and Bhushan 1990; Brennan and Subrahmanyam 1995; Lehavy et al. 2011), \#Analysts is the number of analysts included in the first I/B/E/S consensus earnings forecast after 10-K filings. My variables of interest are Uncertain and Weak_Modal.Uncertain (Weak_Modal) is the proportion of uncertain (weak modal) words to the total words in 10-K filings as defined in Loughran and McDonald (2011). Due to a high correlation between Uncertain and Weak_Modal, I separate the two variables and run two different regressions so that I can capture any incremental effect of each variable. To investigate an incremental effect of uncertain and weak modal words in 10-K filings over readability and tone management on analyst following, I include variables for the 10-K file size (File_Size), positive (Pos_Tone) and negative (Neg_Tone) tone. The 10-K file size (File_Size) is a simple readability proxy that outperforms the Fog Index in that it effectively measures how managers convey valuation-relevant information to analysts and investors (Loughran and McDonald 2014). Management's use of positive and negative tone is relevant in this analysis because this study examines how management tone influences 
analysts' behavior and forecast attributes. As defined by Loughran and McDonald (2011), Pos_Tone (Neg_Tone) is the proportion of positive words (negative words) to the total number of words in 10-Ks.

In model (2), I follow Lehavy et al. (2011) with respect to control variables. Firm_Size is a proxy for firm's operational and business environment. It is the logarithm of the market value of equity at the fiscal year-end. This variable explains how firm size influences the use of uncertain and weak modal words in 10-K filings. I expect that larger firms use more words of an ambiguous nature in their financial disclosures. Growth is the difference in sales volume between the current year and prior year divided by prior year sales volume. I control for sales growth (Growth) because Barth et al. (2001) argue that high-growth firms may increase analyst following due to investor interest and the potential for future investment opportunities. They also argue that, due to the uncertain business operational environment, high-growth firms may lead an analyst to less accurate and more dispersed earnings forecast. I measure the complexity of operations using the logarithm of the number of business segments (Segments) from the Compustat Segment File (Bradshaw et al. 2008). Following (Bhushan 1989, Brennan and Subrahmanyam 1995, and Frankel, Kothari, and Weber 2006), I include \%_Inst to examine the level of institutional holdings. These studies find a positive relation between institutional ownership and analyst following and information content of forecasts. Also, Institutional ownership may increase analyst forecast accuracy and decrease forecast dispersion due to the enhanced information environments. \%_Inst is the percentage of a firm's shares that are held by institutional investors from the most recent quarter before $10-\mathrm{K}$ filing from the $13 \mathrm{~F}$ disclosures. $10 \mathrm{~K}$ _News is defined as two-day event window for market-adjusted return to control the 
informativeness of the 10-K filing. Like Barth et al. (2001), I include $A d v$ and $R \& D$ control variables. $A d v(R \& D)$ is advertising expense (research and development expense) divided by operating expense. I also measure firm-specific stock return for business or operation volatility. Std_Ret is the standard deviation of the monthly stock returns in the prior year. $\mathrm{H} 2$ predicts the relation between analyst forecast dispersion and the use of uncertain and weak modal words in 10-K filings. I estimate the following regression for $\mathrm{H} 2$.

$$
\begin{aligned}
\text { Dispersion }_{i, t} & =\beta_{0}+\beta_{1} \text { Uncertain }_{i, t}+\beta_{2} \text { Weak_Modal }_{i, t}+\beta_{3} \text { File_Size }_{i, t} \\
& +\beta_{4} \text { Pos_Tone }_{i, t}+\beta_{5} \text { Neg_Tone }_{i, t}+\beta_{6} \text { Firm_Size }_{i, t}+\beta_{7} \text { Growth }_{i, t} \\
& +\beta_{8} \text { Segments }_{i, t}+\beta_{9} \text { F_Inst }_{i, t}+\beta_{10} 10 K_{-} \text {News }_{i, t}+\beta_{11} \text { Adv }_{i, t} \\
& +\beta_{12} \text { R\&D }_{i, t}+\beta_{13} \text { Std_Ret }_{i, t}+\beta_{14} \# \text { Analysts }_{i, t} \\
& +\varepsilon_{i, t}
\end{aligned}
$$

Dispersion is the standard deviation of the individual analyst forecasts in the first analyst consensus earnings forecast after the $10-\mathrm{K}$ report, scaled by share price 90 days before the consensus earnings forecast. In model (3), the variables of interest and control variables, except \#Analysts, are the same as those used in regression model (2). I include \#Analysts to examine whether the number of analysts influences the results.

$\mathrm{H} 3$ predicts the relation between analyst forecast accuracy and the use of uncertain and weak modal words in 10-K filings. I estimate the following regression for $\mathrm{H} 3$. 


$$
\begin{aligned}
& \text { Accuracy }_{i, t}=\beta_{0}+\beta_{1} \text { Uncertain }_{i, t}+\beta_{2} \text { Weak_Modal } \text { Met }_{-}+\beta_{3} \text { File_Size }_{i, t} \\
& +\beta_{4} \text { Pos_Tone }_{i, t}+\beta_{5} \text { Neg_Tone }_{i, t}+\beta_{6} \text { Firm_Size }_{i, t}+\beta_{7} \text { Growth }_{i, t} \\
& +\beta_{8} \text { Segments }_{i, t}+\beta_{9} \%_{-} \text {Inst }_{i, t}+\beta_{10} 10 K_{-} N e w s_{i, t}+\beta_{11} A d v_{i, t} \\
& +\beta_{12} R \& D_{i, t}+\beta_{13} \text { Std_Ret }_{i, t}+\beta_{14} \# \text { Analyst }_{i, t} \\
& +\varepsilon_{i, t}
\end{aligned}
$$

Accuracy is the squared value of the difference between the reported earnings in $\mathrm{I} / \mathrm{B} / \mathrm{E} / \mathrm{S}$ and the most recent analyst consensus forecast, scaled by stock price 90 days before the consensus earnings forecast. In model (4), all the variables of interest and control variables are the same as those in the regression model (3).

For H4 and H5, I follow Barron et al. (1998) to measure uncertainty in analyst private and common (public) information environment using the following equations.

Uncertainty_Overall

$$
=\left(1-\frac{1}{\# \text { Analysts }}\right) * \text { Dispersion }+ \text { Accuracy }
$$

\section{Uncertainty_Common}

$$
=\frac{\text { Accuracy }-\frac{\text { Dispersion }}{\text { \#Analysts }}}{\text { Uncertainty_Overall }}
$$

These measures combine the accuracy, the dispersion, and the number of analyst forecasts and enable me to directly measure how uncertain and weak modal words in 10-Ks are related to analysts' private and common information environment. Uncertainty_Overall is the sum of uncertainty related to analysts' private information and uncertainty related to common (public) information to all analysts. Uncertainty_Common is the ratio of uncertainty in analysts' common information environment to uncertainty in analysts' 
overall information environment, and it measures whether or not the public information (e.g., 10-Ks) becomes more important to analysts in comparison with private information. It measures how much average analysts' beliefs reflect common versus private information. For example, if Dispersion in the above equations nears zero (i.e., no disagreement among analysts), then total uncertainty is only associated with analysts' common information (i.e., Uncertainty_Common approaches 1).

$\mathrm{H} 4$ predicts the relation between uncertainty in analyst's overall information environment and the use of uncertain and weak modal words in 10-K filings. I estimate the following regression for $\mathrm{H} 4$.

$$
\begin{aligned}
& \text { Uncertainty_Overall }_{i, t} \\
& =\beta_{0}+\beta_{1} \text { Uncertain }_{i, t}+\beta_{2} \text { Weak_Modal }_{i, t}+\beta_{3} \text { File_Size }_{i, t} \\
& +\beta_{4} \text { Pos_Tone }_{i, t}+\beta_{5} \text { Neg_Tone }_{i, t}+\beta_{6} \text { Firm_Size }_{i, t}+\beta_{7} \text { Growth }_{i, t} \\
& +\beta_{8} \text { Segments }_{i, t}+\beta_{9} \%_{-} \text {Inst }_{i, t}+\beta_{10} 10 K_{-} \text {News }_{i, t}+\beta_{11} A d v_{i, t} \\
& +\beta_{12} R \& D_{i, t}+\beta_{13} S t d \_R e t_{i, t}+\beta_{14} \# \text { Analysts } s_{i, t} \\
& +\varepsilon_{i, t}
\end{aligned}
$$

In model (7), all the variables of interest and control variables are the same as those in the regression model (3).

$\mathrm{H} 5$ predicts the relation between uncertainty in analysts' common information environment and the use of uncertain and weak modal words in 10-K filings. I estimate the following regression for $\mathrm{H} 5$. 


$$
\begin{aligned}
& \text { Uncertainty_Common }_{i, t} \\
& =\beta_{0}+\beta_{1} \text { Uncertain }_{i, t}+\beta_{2} \text { Weak_Modal }_{i, t}+\beta_{3} \text { File_Size }_{i, t} \\
& +\beta_{4} \text { Pos_Tone }_{i, t}+\beta_{5} \text { Neg_Tone }_{i, t}+\beta_{6} \text { Firm_Size }_{i, t}+\beta_{7} \text { Growth }_{i, t} \\
& +\beta_{8} \text { Segments }_{i, t}+\beta_{9} \%_{-} \text {Inst }_{i, t}+\beta_{10} 10 K_{-} N e w s_{i, t}+\beta_{11} A d v_{i, t} \\
& +\beta_{12} R \& D_{i, t}+\beta_{13} \text { Std_Ret }_{i, t}+\beta_{14} \# \text { Analysts }_{i, t} \\
& +\varepsilon_{i, t}
\end{aligned}
$$

In model (8), all the variables of interest and control variables are the same as those in the regression model (3). All multivariate regression analyses are controlled for year and industry fixed effect (two-digit SIC code).

For the additional tests in a later chapter in this study, I follow Li (2008) to measure the readability of 10-K filings. The Fog Index, developed by the computational linguistics literature, indicates the number of years of formal education required for a reader of average intelligence would need to read the document once and understand it. Specifically, the Fog Index is measured as follows:

$F O G_{i, t}=($ average words per sentence + percent of complex words $) \times 0.4$

Where a complex word is defined as a word with three or more syllables. For example, the Fog Index greater than or equal to 18 means unreadable; the Fog Index between 14 and 18 means difficult; the Fog Index between 12 and 14 means ideal; the Fog Index between 10 and 12 means acceptable; and the Fog Index between 8 and 10 indicates childish language. 


\section{CHAPTER 5}

\section{DATA COLLECTION AND SAMPLE SELECTION}

The sample in this study consists of U.S. firms. The sample period is 2000-2016 because this study employs the uncertain and weak modal word lists from Loughran and McDonald (2011), and they have updated the word lists up to 2016.

Panel A in Table 1 presents the sample selection procedure for the analysis of the determinants of the use of uncertain and weak modal words in 10-Ks. I obtain uncertain and weak modal words from the sentimental word lists in Loughran and McDonald (2011), and this yields a sample of 133,745 observations. I exclude regulated utilities (SIC code 4900-4999) and financial (SIC code 6000-6999) firms because they have a different operating and regulatory environment. This yields a sample of 84,861 observations. I obtain financial data from Compustat, business segment data from Compustat Segments data, stock return data from CRSP, M\&A data from SDC Platinum M\&A database, and SEO data from SDC Global New Issue database. I merge Loughran and McDonald's sentiment word lists with these datasets by CIK, ticker, and fiscal year. This yields a sample of 37,442 observations.

Panel B of Table 1 presents the sample selection procedure to examine the relation between the use of uncertain and weak modal words in 10-Ks and analysts' behavior and forecast outcomes. I obtain 10-K file size and the sentiment word lists such as positive, negative, uncertain, and weak modal, from Loughran and McDonald's database. This yields a sample of 133,745 observations. I exclude regulated utilities (SIC code 4900-4999) and financial (SIC code 6000-6999) firms because they have a different operating and 
regulatory environment. This yields a sample of 84,861 observations. I retrieve financial data from Compustat, analyst data from I/B/E/S, stock return data from CRSP, and institutional holdings data from Thomson-Reuters $13 \mathrm{f}$ Holdings. I merge these financial and analysts' forecast related data with Loughran and McDonald sentiment word lists by CIK and fiscal year. This procedure yields a sample of 42,627 observations. The final sample size for multivariate regressions depends on the number of observation of dependent variables. These five dependent variables are the number of analysts (\#Analysts), analysts' forecast dispersion (Dispersion), analysts' forecast accuracy (Accuracy), the uncertainty in analysts' overall information environment (Uncertainty_Overall), and the uncertainty in analysts' common (public) information environment (Uncertainty_Common). This yields a sample of 25,673. In detail, I have 25,673 observations for the number of analysts, 19,003 $(15,213)$ observations for analysts' forecast dispersion (accuracy), and 14,308 (14,306) observations for uncertainty in analysts' overall (common) information environment. 


\section{CHAPTER 6}

\section{RESULTS}

\subsection{Determinants of the Use of Uncertain and Weak Modal Words in 10-K Filings Descriptive Statistics}

Following Li (2008), Table 2 presents descriptive statistics for variables used in this study. I have two dependent variables - uncertain (Uncertain) and weak modal (Weak_Modal) words in 10-K filings. The mean (median) of Uncertain is 0.0131 (0.0131), and the standard deviation is 0.0031 , indicating that on average $1.3 \%$ of words used in 10 Ks are uncertain words. The mean (median) of Weak_Modal is $0.0056(0.0054)$, and the standard deviation is 0.0020 , indicating on average about $0.6 \%$ of words used in 10 -Ks are weak modal words. My study also includes independent variables that explain the determinants of the use of uncertain and weak modal words in 10-K filings. These variables are firm size (Firm_Size), market-to-book ratio (MTB), firm age (Age), special items (Special_Items), return and earnings volatility (Std_Ret and Std_Earn), number of business segments (Segments), merger-and-acquisition $(M \& A)$, seasoned equity offering $(S E O)$, and firms incorporated in the state of Delaware (Delaware). The mean (median) of Firm_Size is 5.9224 (5.9018). The mean (median) of $M T B$ is 2.0583 (1.5466). The mean (median) of Age is $17.5012(13.1710)$. The mean (median) of Special_Items is $-0.0224(-0.0009)^{11}$. The mean (median) of Std_Ret is 0.1483 (0.1228). The mean (median) of Std_Earn is 0.1504 (0.0608). The mean (median) of Segments is 1.0460 (0.6931). The mean (median) of $M \& A$

${ }^{11}$ Special items are scaled by book value of assets. 
is $0.2846(0.0000)$. The mean (median) of $S E O$ is $0.1393(0.0000)$. The mean (median) of Delaware is 0.0028 (0.0000). Overall, these results are compatible with those of $\operatorname{Li}(2008)$.

\section{Univariate Analysis}

Table 3 reports the correlation analysis. The correlation coefficients below (above) the diagonal line are Pearson (Spearman) correlation coefficients. Panel A discusses the determinants of the use of uncertain words in 10-K filings. Panel A reports that the use of uncertain words in 10-K filings is positively correlated with Firm_Size $($ coefficient $=$ 0.0544, $\mathrm{p}<0.05), M T B($ coefficient $=0.1101, \mathrm{p}<0.05)$, Std_Earn $($ coefficient $=0.0969$, $\mathrm{p}<0.05), M \& A($ coefficient $=0.0347, \mathrm{p}<0.05)$, and $S E O($ coefficient $=0.0772, \mathrm{p}<0.05)$. It reports a negative relation between the use of uncertain words in 10-K filings and Age $($ coefficient $=-0.1181, \mathrm{p}<0.05)$, Std_Ret $($ coefficient $=-0.0154, \mathrm{p}<0.05)$, Segments (coefficient $=-0.1387, \mathrm{p}<0.05)$, and Delaware $($ coefficient $=-0.0264, \mathrm{p}<0.05)$. Overall, the results in Panel B are consistent with those of Panel A except for the relation between the use of weak modal words and Std_Ret and $M \& A$ which have the opposite sign on coefficients.

\section{Multivariate Analysis}

The first column in Table 4 reports uncertain words (Uncertain) as the dependent variable and the second column presents weak modal words (Weak_Modal) as the dependent variable. In the first column, I find a positive relation between uncertain words in $10-$ Ks and these variables - Firm_Size (coefficient $=0.0001, t=13.34$ ), Std $\_$Ret (coefficient $=0.0008, t=4.71)$, Std_Earn $($ coefficient $=0.0005, t=10.03)$, and $M \& A$ (coefficient $=0.0001, t=2.78$ ). I find a negative relation between uncertain words in 10Ks and these variables - Age $($ coefficient $=-0.0000, t=-28.35)$, Segments $($ coefficient $=-$ 
$0.0007, t=-19.68$ ), and Delaware (coefficient $=-0.0006, t=-2.30$ ). The results are overall consistent with my predictions except for $M \& A$. Unlike my prediction, the firms engaged in $M \& A$ are more likely to report uncertain words in their $10-\mathrm{Ks}$. The second column reports overall consistent results with the first column, however, I find a positive relation between weak modal words in $10-\mathrm{Ks}$ and $M T B$ (coefficient $=0.0001, t=10.87$ ) and Special_Items (coefficient $=0.0002, t=1.87)$; I find a negative relation between weak modal words in $10-\mathrm{Ks}$ and $M \& A$ (coefficient $=0.0000, \mathrm{t}=-1.73$ ). These findings are different from the first column.

Overall, this analysis finds that firm size, firm age, volatility of price returns and earnings, and number of business segments are consistently associated with the use of both uncertain and weak modal words in firms' financial reports. However, MTB, special items, and M\&A differently impact the use of either uncertain or weak modal words in firms' 10K filings.

\subsection{The Association between the Use of Uncertain and Weak Modal Words in 10-K Filings and Analyst Forecast Attributes}

\section{Descriptive Statistics}

Table 5 presents descriptive statistics for 25,673 firm-year observations. For multivariate analysis, I have five dependent variables - \#Analysts, Dispersion, Accuracy, Uncertainty_Overall $^{12}$, and Uncertainty_Common ${ }^{13}$. The mean (median) number of

\footnotetext{
${ }^{12}$ The sum of uncertainty related to analysts' private information and uncertainty related to common (public) information to all analysts following Barron et al. (1998).

${ }^{13}$ The ratio of common uncertainty to total uncertainty among analysts following Barron et al. (1998).
} 
analysts (\#Analysts) per firm-year observation is 7.5121 (5.0000). The standard deviation of \#Analysts is 6.5571. The mean (median) of forecast dispersion (Dispersion) is 0.0143 (0.0041). The mean (median) of squared forecast error (Accuracy) is $0.0402(0.0024)$. The standard deviation for Dispersion and Accuracy is 0.0308 and 0.1567 , respectively. The mean (median) of Uncertainty_Overall and Uncertainty_Common are $0.0445(0.0076)$ and 0.3259 (0.3056), respectively. This indicates that about 4 (33) percent of analyst uncertainty about future earnings following the $10-\mathrm{K}$ filing is based on overall information among analysts (publicly available information). The standard deviation for Uncertainty_Overall and Uncertainty_Common are 0.1413 and 0.4299 , respectively.

I have five independent variables - Uncertain, Weak_Modal, File_Size, Pos_Tone, and Neg_Tone. The mean (median) of Uncertain is 0.0134 (0.0135), indicating on average about $1.3 \%$ of words used in $10-\mathrm{Ks}$ are uncertain words. The mean (median) of Weak_Modal is $0.0058(0.0056)$, indicating on average about $0.6 \%$ of words used in 10Ks are weak modal words. The mean of 10-K file size (File_Size) is $12.7344(383,427$ in megabytes); the median of File_Size is 12.6999 (327,702 in megabytes). The mean (median) of positive tone (Pos_Tone) is 0.0074 (0.0073), indicating on average about $0.7 \%$ of words used in 10-Ks have positive tone. The mean (median) of negative tone (Neg_Tone) is $0.0170(0.0169)$, indicating on average about $1.7 \%$ of words used in 10-Ks have negative tone. Table 5 also provides descriptive statistics on control variables. The mean (median) size of sample firm (Firm_Size) is 6.4350 (6.3575). The mean (median) of sales growth rate (Growth) is 0.1565 (0.0801). The mean (median) number of the business segment (Segments) is $1.0578(0.6931)$, and the mean (median) of the percent of institutional ownership (\%_Inst) is 0.6263 (0.6825). The mean (median) of 10K_News is 
0.0355 (0.0211). The mean (median) ratio of advertisement expense to operating expense $(A d v)$ is $0.0128(0.0000)$. The mean (median) ratio of research and development expense $(R \& D)$ to operating expense is $0.1114(0.0171)$. The mean (median) of price return volatility (Std_Ret) is 0.1407 (0.1184).

\subsubsection{Analyst following}

\section{Univariate Analysis}

Table 6 reports the correlation analysis. The correlation coefficients below (above) the diagonal line are Pearson (Spearman) correlation coefficients. I find a positive correlation between analyst following (\#Analysts) and these variables - File_Size $($ coefficient $=0.2613, \mathrm{p}<0.05)$, Neg_Tone $($ coefficient $=0.0298, \mathrm{p}<0.05)$, Firm_Size (coefficient $=0.7225, \mathrm{p}<0.05)$, Segments $($ coefficient $=0.1148, \mathrm{p}<0.05)$, \%_Inst (coefficient $=0.3904, \mathrm{p}<0.05)$, and $A d v$ (coefficient $=0.0792, \mathrm{p}<0.05)$. Also, I report a negative correlation between \#Analysts and these variables - Weak_Modal $($ coefficient $=-$ $0.0157, \mathrm{p}<0.05)$, Pos_Tone $($ coefficient $=-0.0206, \mathrm{p}<0.05)$, Growth $($ coefficient $=-0.0165$, $\mathrm{p}<0.05), 10 K \_$News $($coefficient $=-0.1591, \mathrm{p}<0.05), R \& D($ coefficient $=-0.0312, \mathrm{p}<0.05)$, and Std_Ret (coefficient $=-0.2516, \mathrm{p}<0.05)$. I find that uncertain words $($ Uncertain $)$ and weak modal words (Weak_Modal) are highly and positively correlated with each other (coefficient $=0.7414, \mathrm{p}<0.05)$. I find that the correlation coefficients among the independent variables are generally moderate.

\section{Multivariate Analysis}

In Table 7, I predict that analyst following is affected by the level of uncertain and weak modal words in 10-K filings. To investigate an incremental effect of uncertain and weak modal words in 10-K filings over readability and tone management on analyst 
following, I include variables for the 10-K file size (File_Size), positive (Pos_Tone) and negative (Neg_Tone) tone. In this multivariate analysis, the variables of interest are Uncertain and Weak_Modal. Due to a high correlation between these two variables, I separate the two variables and run two different regressions thereby capturing any incremental effect of each variable. I follow Lehavy et al. (2011) to control for other factors that can affect analyst following.

\section{Main test variable: Uncertain}

Models $1-4$ in Table 7 include uncertain words as the main test variable and model $5-8$ have weak modal words as the main test variable. From models $2-4$, I find a positive and significant relation between analyst following and the use of uncertain words in 10-K filings. Model 1 tests the regression without including uncertain words and indicates analyst following is positively associated with File_Size, Pos_Tone, and Neg_Tone. Model 2 is the most comprehensive model. This model includes all test and control variables. It examines the incremental effect of uncertain words in a 10-K filing in addition to readability (File_Size) and tone management (Pos_Tone and Neg_Tone) on analyst following, indicating that more analysts follow firms with more uncertain words, less readable contexts, and more tone management in 10-K filings. Model 3 excludes positive and negative tone variables, and Model 4 excludes File_Size from Model 2 accordingly, but the results are consistent with Model 2. Interestingly, Model 3 shows the largest economic magnitude (coefficient $=28.5131, t=17.61$ ) for the Uncertain variable, suggesting the relation between analyst following and the use of uncertain words becomes even stronger when the model is controlled by File_Size and other control variables. 


\section{Main test variable: Weak_Modal}

Models 5 - 8 in Table 7 examine the relation between analyst following and the effect of weak modal words in 10-K filings. Overall, the results are similar to those found in Models $1-4$. I find a significantly positive relation between analyst following and the use of weak modal words in 10-K filings. Model 6 contains all test and control variables. Model 7 reports the largest economic magnitude (coefficient $=47.2850, t=18.59$ ) for Weak_Modal variable, suggesting the relation between analyst following and the use of weak modal words becomes stronger when the model is controlled by File_Size (readability) and other control variables.

The regression results on control variables overall are consistent with the prior literature. For example, analyst following is positively associated with firm size, advertisement and R\&D expenses (e.g., Barth et al. 2001), and stock return volatility (e.g., Bhushan, 1989). Consistent with Lehavy et al. (2011), I find a negative relation between analyst following and number of business segments. Overall, I find that more analysts follow firms with more use of uncertain and weak modal words in firms' $10-\mathrm{K}$ filings.

\subsubsection{Forecast Dispersion}

\section{Univariate Analysis}

Table 8 reports the correlation analysis. The correlation coefficients below (above) the diagonal line are Pearson (Spearman) correlation coefficients. The univariate analysis finds that analyst forecast dispersion (Dispersion) is positively correlated with these variables - Uncertain $($ coefficient $=0.0207, \mathrm{p}<0.05)$, Weak_Modal $($ coefficient $=0.1175$, $\mathrm{p}<0.05)$, File_Size $($ coefficient $=0.0805, \mathrm{p}<0.05)$, Pos_Tone $($ coefficient $=0.0395$, $\mathrm{p}<0.05)$, Neg_Tone $($ coefficient $=0.1362, \mathrm{p}<0.05)$, Growth $($ coefficient $=0.0254, \mathrm{p}<0.05)$, 
$10 K \_N e w s$ (coefficient $\left.=0.2194, \mathrm{p}<0.05\right), R \& D($ coefficient $=0.1913, \mathrm{p}<0.05)$, and Std_Ret $($ coefficient $=0.4039, \mathrm{p}<0.05)$. Also, I find a negative correlation between Dispersion and these variables - Firm_Size $($ coefficient $=-0.3924, \mathrm{p}<0.05)$, Segments $($ coefficient $=-0.1239, \mathrm{p}<0.05), \%$ Inst $($ coefficient $=-0.3409, \mathrm{p}<0.05)$, and \#Analysts (coefficient $=-0.1493, \mathrm{p}<0.05)$. I find that uncertain words and weak modal words are highly and positively correlated with each other (coefficient $=0.7405, p<0.05$ ). I find that the correlation coefficients between the independent variables are generally moderate.

\section{Multivariate Analysis}

In Table 9, I predict that forecast dispersion is affected by the level of uncertain and weak modal words in $10-\mathrm{K}$ filings. To investigate the incremental effect of uncertain and weak modal words in 10 -K filings over readability and tone management on forecast dispersion, I include variables such as File_Size, Pos_Tone, and Neg_Tone. The variables of interest are Uncertain and Weak_modal. Due to a high correlation between these two variables, I also separate the two variables and run two different regressions. I follow Lehavy et al. (2011) to control other factors that can affect forecast dispersion.

\section{Main test variable: Uncertain}

Models $1-4$ in Table 9 include uncertain words as the main test variable and models $5-8$ include weak modal words as the main test variable. From models $2-4$, I find a negative and statistically significant relation between analyst forecast dispersion (Dispersion) and the use of uncertain words (Uncertain) in 10-K filings. Model 1 tests the regression without Uncertain and indicates forecast dispersion is positively associated with File_Size and Pos_Tone. Model 2 includes all test and control variables. It examines the incremental effect of uncertain words in 10-K filings over File_Size, Pos_Tone, and 
Neg_Tone on forecast dispersion, indicating that Dispersion is associated with the use of less uncertain words, less readable contexts (i.e., greater 10-K file size), and more positive tone in firms'10-K filings. Model 3 excludes tone management, and Model 4 excludes File_Size accordingly, but the results are overall consistent with Model 2. Model 4 reports the largest economic magnitude (coefficient $=-0.6781, t=-9.20$ ) for Uncertain, suggesting the relation between forecast dispersion and the use of uncertain words becomes stronger when the model is controlled by tone management and other control variables.

\section{Main test variable: Weak_Modal}

Models 5 - 8 in Table 9 examine the relation between forecast dispersion and the effect of weak modal words in firms' $10-\mathrm{K}$ filings. Overall, the results report a negative and significant relation between forecast dispersion and the use of weak modal words in 10-K filings. Model 6 is the most comprehensive model and reports positive (negative) relation between Dispersion and 10-K file size and tone variables (weak modal words). Model 8 reports the largest economic magnitude (coefficient $=-1.7907, t=-13.18$ ) for Weak_Modal, suggesting the relation between analyst forecast dispersion and the use of uncertain words becomes stronger when the model includes tone management and other control variables.

The regression results on control variables are consistent with prior literature except for Growth. Consistent with Lehavy et al. (2011), analyst forecast dispersion is positively associated with number of business segments, 10-K news, advertisement and R\&D expenses, and stock return volatility. There is a positive relation between forecast dispersion and analyst following (\#Analyst) and a negative relation between forecast dispersion and firm size, sales growth, and \% of institutional ownership. 
Overall the results show that analyst forecast dispersion is negatively related to uncertain and weak modal words in 10-K filings, supporting the management-relations, analyst extra effort, and signaling theories. The management-relations hypothesis predicts that financial analysts collectively bias their forecasts upward with more uncertain information environment, which in turn reduces forecast dispersion. The analyst extra effort hypothesis predicts that analysts make extra efforts to produce earnings forecasts when facing more uncertain information environment. Finally, the signaling theory predicts that uncertain and weak modal words in 10-K filings signal analysts about the uncertainty of future earnings. Both theories also predict to reduce forecast dispersion.

\subsubsection{Forecast Accuracy}

\section{Univariate Analysis}

The correlation analysis is reported in Table 10. The correlation coefficients below (above) the diagonal line are Pearson (Spearman) correlation coefficients. The univariate analysis finds negative and statistically significant correlations between forecast accuracy (forecast error) and Uncertain (coefficient $=-0.0475, \mathrm{p}<0.05$ ) and Weak_Modal (coefficient $=-0.0259, \mathrm{p}<0.05)$, indicating that forecast error may decrease when firm's management uses more ambiguous language in their 10-Ks. Accuracy is positively correlated with File_Size (i.e., less readable 10-Ks) $($ coefficient $=0.0804$, p $<0.05)$, Neg_Tone $($ coefficient $=0.0515, \mathrm{p}<0.05), 10 K \_$News $($coefficient $=0.0882, \mathrm{p}<0.05)$, and Std_Ret $($ coefficient $=0.1989, \mathrm{p}<0.05)$. I also find a negative correlation between forecast error $($ Accuracy) and these variables - Pos_Tone $($ coefficient $=-0.0575, \mathrm{p}<0.05)$, Firm_Size $($ coefficient $=-0.1589, \mathrm{p}<0.05), \% \_$Inst $($coefficient $=-0.1285, \mathrm{p}<0.05)$, and \#Analysts (coefficient $=-0.0686, \mathrm{p}<0.05$ ). I find that uncertain and weak modal words are positively 
correlated with each other (coefficient $=0.7343, \mathrm{p}<0.05$ ) and that the correlation coefficients between the independent variables are generally moderate.

\section{Multivariate Analysis}

I predict that forecast accuracy (forecast error) is affected by the level of uncertain and weak modal words in 10-K filings. To investigate an incremental effect of uncertain and weak modal words in $10-\mathrm{K}$ filings over readability and tone management on forecast accuracy, I include variables such as File_Size, Pos_Tone, and Neg_Tone. The variables of interest in this analysis are Uncertain and Weak_Modal. Due to a high correlation between Uncertain and Weak_Modal, I separate the two variables and run two different regressions so that I can capture any incremental effect of each variable. I follow Lehavy et al. (2011) to control other factors that can affect forecast accuracy (forecast error).

\section{Main test variable: Uncertain}

Models $1-4$ in Table 11 include uncertain words as the main test variable and models $5-8$ have weak modal words as the main test variable. From models $2-4$, I find a negative and significant relation between forecast accuracy (forecast error) and the use of uncertain words (Uncertain) in 10-K filings. Model 1 tests the regression without Uncertain and reports forecast error are positively (negatively) associated with File_Size (Pos_Tone). Model 2 includes all test and control variables. It examines the incremental effect of uncertain words in a 10-K filing in addition to readability (File_Size) and tone management (Pos_Tone and Neg_Tone) on forecast accuracy (forecast error). The results show that analysts have fewer forecast error for firms that use more uncertain words in 10K filings. Model 3 excludes tone management and Model 4 excludes File_Size accordingly, but the results are overall consistent with Model 2. Model 4 reports the largest economic 
magnitude (coefficient $=-3.6533, t=-7.49)$ for Uncertain, suggesting the relation between forecast error and the use of uncertain words becomes stronger when the model includes tone management and other control variables.

\section{Main test variable: Weak_Modal}

Models 5 - 8 in Table 11 examine the relation between forecast accuracy (forecast error) and the effect of weak modal words in firms' 10 -K filings. Overall, the results are similar to Models $1-4$ and report a negative and statistically significant relation between forecast error and the use of weak modal words in 10-K filings. Model 6 contains all test and control variables, and it reports that forecast error may decrease when firms use more weak modal words in $10-\mathrm{Ks}$. Also, it reports that forecast error may increase when firm's10-K becomes (contains) more complex (more negative tone). Model 8 reports a negative relation between Accuracy and Weak_Modal and has the largest economic magnitude (coefficient $=-9.4055, t=-10.37$ ) for Weak_Modal, suggesting the relation between analyst forecast error and the use of weak modal words becomes stronger when the model includes tone management and other control variables.

The regression results on control variables are partially consistent with prior literature. Consistent with Lehavy et al. (2011), analyst forecast accuracy (forecast error) is positively associated with number of business segments, and stock return volatility. I also find that analyst following (\#Analyst) is associated with increased forecast error. However, forecast accuracy (forecast error) is negatively associated with firm size, sales growth, \% of institutional ownership and R\&D expense.

Overall the results provide evidence that forecast accuracy (forecast error) is negatively related to uncertain and weak modal words in $10-\mathrm{K}$ filings, supporting the 
analyst extra effort and signaling theories. The analyst extra effort hypothesis predicts that analysts make extra efforts to produce more accurate earnings forecasts when facing more uncertain information environment. Finally, the signaling theory predicts that uncertain and weak modal words in 10-K filings signal analysts about the uncertainty of future earnings, which in turn improves forecast accuracy (i.e., decreased forecast error).

\subsubsection{Uncertainty in Analysts' Overall Information Environment Univariate Analysis}

Table 12 reports the correlation analysis. The correlation coefficients below (above) the diagonal line are Pearson (Spearman) correlation coefficients. The univariate analysis shows uncertainty in analysts' overall information environment (Uncertainty_Overall) is positively correlated with File_Size $($ coefficient $=0.1048, \mathrm{p}<0.05)$, Neg_Tone $($ coefficient $=0.0655, \mathrm{p}<0.05), 10 K \_N e w s($ coefficient $=0.1078, \mathrm{p}<0.05)$, and Std_Ret $($ coefficient $=$ $0.2364, \mathrm{p}<0.05)$. I find a negative relation between Uncertainty_Overall and these variables - Uncertain $($ coefficient $=-0.0430, \mathrm{p}<0.05)$, Pos_Tone $($ coefficient $=-0.0566$, $\mathrm{p}<0.05)$, Firm_Size $($ coefficient $=-0.1827, \mathrm{p}<0.05), \%$ Inst $($ coefficient $=-0.1378$, $\mathrm{p}<0.05$ ), and \#Analysts (coefficient $=-0.0620, \mathrm{p}<0.05$ ). Also, I find that uncertain and weak modal words are highly and positively correlated with each other $($ coefficient $=0.7331, p$ $<0.05)$. I find that the correlation coefficients between the independent variables are generally moderate.

\section{Multivariate Analysis}

I predict that uncertainty in analysts' overall information environment is affected by the level of uncertain and weak modal words in 10-Ks. To investigate an incremental effect of uncertain and weak modal words in 10-K filings over readability and tone 
management on analysts' overall information environment, I include variables for File_Size, Pos_Tone, and Neg_Tone. The variables of interest are Uncertain and Weak_Modal. Due to a high correlation between these two variables, I separate them and run two different regressions so that I can capture any incremental effect of each variable. I follow Lehavy et al. (2011) to control for other factors that can affect uncertainty in overall information among analysts.

\section{Main test variable: Uncertain}

Models $1-4$ in Table 13 include uncertain words as the main test variable and models $5-8$ have weak modal words as the main test variable. From models $2-4$, I find a negative and significant relation between uncertainty in analysts' overall information environment (Uncertainty_Overall) and the use of uncertain words (Uncertain) in 10-K filings. Model 1 tests the regression without uncertain words and reports that uncertainty in analysts' overall information environment (Uncertainty_Overall) is positively associated with File_Size (i.e., less readable 10-K). This result is consistent with Lehavy et al. (2011). I find a negative relation between Uncertainty_Overall and Pos_Tone. Model 2 includes all test and control variables. It examines the incremental effect of uncertain words in a 10-K filing in addition to readability (File_Size) and tone management (Pos_Tone and Neg_Tone) on uncertainty in overall information among analysts, indicating that less uncertainty in analysts' overall information environment is associated with firms having more uncertain words in their 10-Ks. Model 3 excludes Pos_Tone and Neg_Tone, and Model 4 excludes File_Size accordingly, but the results are overall consistent with Model 2. Model 4 shows the largest economic effect (coefficient $=-3.5870$, $t=-8.04)$ on Uncertain, suggesting the relation between uncertainty in analysts' overall 
information environment and the use of uncertain words becomes stronger when the model includes tone management and other control variables.

\section{Main test variable: Weak_Modal}

Models 5 - 8 in Table 13 examine the relation between uncertainty in analysts' overall information environment (Uncertainty_Overall) and the effect of weak modal words (Weak_Modal) in firms' 10 -K filings. Overall, the results present negative and statistically significant relation between Uncertainty_Overall and Weak_Modal in 10-K filings. Model 6 contains all test and control variables. It shows a positive (negative) relation between Uncertainty_Overall and Neg_Tone (Weak_Modal). Among models 6 8, model 8 indicates the largest coefficient $(-8.7673, \mathrm{t}=-10.55)$ on Weak_Modal, suggesting the relation between uncertainty in analysts' overall information environment and the use of weak modal words becomes stronger when the model includes tone management and other control variables.

For control variables in this analysis, uncertainty in overall information among analysts is positively associated with number of business segments, stock return volatility, and number of analysts. I report a negative relation between uncertainty in overall information among analysts and variables such as firm size, sales growth, \% of institutional ownership and R\&D expense.

Overall, Table 13 reports that uncertainty in analysts' overall information environment is decreasing in Uncertain and Weak_Modal, suggesting that uncertainty in the analysts' overall information environment decreases with firms' use of more ambiguous language in $10-\mathrm{K}$ filings. This finding is different from my prediction which suggests that managers may use ambiguous words to signal analysts and investors about 
the uncertainty of future earnings. Future research should investigate the extent to which uncertain and weak model words used in 10-Ks affect analysts' overall information environment using behavioral research methods including interviews with analysts.

\subsubsection{Uncertainty in Analysts' Common Information Environment Univariate Analysis}

Table 14 reports the correlation analysis. The correlation coefficients below (above) the diagonal line are Pearson (Spearman) correlation coefficients. The univariate analysis finds that uncertainty in analysts common information environment (Uncertainty_Common) is positively correlated with File_Size (coefficient $=0.0600$, $\mathrm{p}<0.05)$, Firm_Size $($ coefficient $=0.0942, \mathrm{p}<0.05)$, Segments $($ coefficient $=0.0810$, $\mathrm{p}<0.05), \% \_$Inst $($coefficient $=0.1093, \mathrm{p}<0.05)$, Std_Ret $($ coefficient $=0.0192, \mathrm{p}<0.05)$, and \#Analysts (coefficient $=0.1070, \mathrm{p}<0.05$ ). I find a negative relation between Uncertainty_Common and these variables - Uncertain $($ coefficient $=-0.0704, \mathrm{p}<0.05)$, Weak_Modal $($ coefficient $=-0.0947, \mathrm{p}<0.05)$, Pos_Tone $($ coefficient $=-0.0710, \mathrm{p}<0.05)$, Neg_Tone $($ Coefficient $=-0.0181, \mathrm{p}<0.05), 10 K \_N e w s($ coefficient $=-0.0184, \mathrm{p}<0.05)$, and $R \& D$ (coefficient $=-0.1151, \mathrm{p}<0.05)$. Also, I find that Uncertain and Weak_Modal are highly correlated with each other (coefficient $=0.7330, \mathrm{p}<0.05)$. I find that the correlation coefficients between the independent variables are generally moderate.

\section{Multivariate Analysis}

I predict that uncertainty in analysts' common information environment is affected by the level of uncertain and weak modal words in 10-K filings. To investigate an incremental effect of uncertain and weak modal words in 10-K filings over readability and tone management on uncertainty in public information among analysts, I include File_Size, 
Pos_Tone, and Neg_Tone. The variables of interest are Uncertain and Weak_Modal. Due to a high correlation between these variables, I separate them and run two different regressions so that I can capture any incremental effect of each variable. I follow Lehavy et al. (2011) to control other factors that can affect uncertainty in analysts' common information environment.

\section{Main test variable: Uncertain}

Models $1-4$ in Table 15 include uncertain words as the main test variable and models $5-8$ have weak modal words as the main test variable. From models $2-4$, I find overall a negative relation between Uncertainty_Common and Uncertain. Model 1 tests the regression without uncertain words. I find Uncertainty_Common is positively associated with File_Size (i.e., less readable 10-K) and negatively associated with Pos_Tone. Model 2 contains all test and control variables. It examines the incremental effect of uncertain words in 10-K filings in addition to readability (File_Size) and tone management (Pos_Tone and Neg_Tone) on uncertainty in analysts' common information environment. I find a negative but insignificant effect on Uncertain. Model 3 excludes tone variables, and Model 4 excludes the File_Size variable accordingly. Among models 2 - 4, model 4 reports the largest economic effect $($ coefficient $=-5.4532, \mathrm{t}=-3.87)$ on Uncertain, indicating that a negative and significant relation between uncertainty in analysts' common information environment and the use of uncertain words becomes stronger when the model includes tone management and other control variables.

\section{Main test variable: Weak_Modal}

Models $5-8$ in Table 15 examine the relation between uncertainty in analysts' common information environment (Uncertainty_Common) and the effect of weak modal 
words (Weak_Modal) in firms'10-K filings. Overall, the results report a negative and statistically significant relation between Uncertainty_Common and Weak_Modal. Model 6 includes all test and control variables. It reports a positive (negative) relation between Uncertainty_Common and File_Size (Weak_Modal). Among models 6 - 8, model 8 reports the largest economic magnitude (coefficient $=-9.0535, \mathrm{t}=-3.44$ ) for Weak_Modal, suggesting the relation between uncertainty in analysts' common information environment and the use of weak modal words becomes stronger when the model includes tone management and other control variables. Consistent with Lehavy et al. (2011), Uncertainty_Common is positively (negatively) associated with these control variables \%_Inst and Std_Ret $(R \& D)$. I also find a positive relation between Uncertainty_Common and Segments and \#Analysts.

Overall, this analysis finds that uncertainty in analysts' common information environment decreases for firms with increased use of uncertain and weak modal words in firms' annual financial disclosures. Again, this finding is different from my prediction, which indicates that managers may use ambiguous words in $10-\mathrm{K}$ filings to signal analysts and investors about the uncertainty of future earnings. Future research should investigate the extent to which the use of uncertain and weak modal words in 10-Ks affects the uncertainty in analysts' common information environment using behavioral research methods including interviews with analysts.

\subsection{Additional Tests}

For a robustness test, I replace File_Size with the Fog Index $(F o g)$ to examine if the effect of uncertain and weak modal words in 10-Ks hold for analyst forecast attributes with 
a different measure of readability (Fog). I employ the Fog Index data from Feng Li's website $^{14}$ for the sample period of $2000-2011$. Results are reported in Appendix 3.

\subsubsection{Analyst following: Fog Replacement}

Table 16 reports the correlation analysis. The univariate analysis reports overall consistent results with Table 6, but the correlation between analyst following and the Fog index $(F o g)($ coefficient $=0.0442, \mathrm{p}<0.05)$ in Table 16 is weaker than the correlation between analyst following and File_Size (coefficient $=0.2613, \mathrm{p}<0.05)$ in Table 6. I find that the correlation coefficients between the independent variables are generally moderate.

Table 17 reports multivariate analysis with Fog as the readability measure. Overall, it provides consistent results with Table 7 . In Table 17, the coefficients of uncertain and weak modal words in Model $2($ coefficient $=8.2556, t=4.35)$ and Model $5($ coefficient $=$ 28.8694, $t=7.99$ ) become weaker than those of Model 2 and 6 in Table 7 when File_Size is replaced with Fog. The results for control variables are consistent with those of Table 7.

\subsubsection{Analyst Forecast Dispersion: Fog Replacement}

Table 18 reports the correlation analysis. The univariate analysis reports overall consistent results with Table 8, but the correlation between forecast dispersion (Dispersion) and the Fog index $(F o g)$ (coefficient $=0.0085, \mathrm{p}<0.05)$ in Table 18 is weaker than the correlation between forecast dispersion and File_Size (coefficient $=0.0805, \mathrm{p}<0.05)$ in Table 8 . I find that the correlation coefficients between the independent variables are generally moderate.

Table 19 reports multivariate analysis with Fog as the readability measure. Overall it reports consistent results with Table 9. In Table 19, the coefficients of uncertain and

14 Please check the data from http://webuser.bus.umich.edu/feng/. 
weak modal words in Model 2 (coefficient $=-0.5170, t=-5.91)$ and Model 5 (coefficient $=-1.5384, t=-9.23$ ) become stronger than those of Model 2 and 6 in Table 9 when File_Size is replaced with Fog. This indicates the incremental effect of the use of uncertain and weak modal words in $10-\mathrm{K}$ filings on forecast dispersion is increasing when the Fog index used for the readability measure. The results for control variables are consistent with those of Table 9.

\subsubsection{Analyst Forecast Accuracy: Fog Replacement}

Table 20 reports the correlation analysis. The univariate analysis reports overall consistent results with Table 10, but the correlation between forecast accuracy (forecast error) and the Fog index $(F o g)($ coefficient $=0.0108, \mathrm{p}<0.05)$ in Table 20 is weaker than the correlation between analyst accuracy and File_Size (coefficient $=0.0804, \mathrm{p}<0.05$ ) in Table 10. I find that the correlation coefficients between the independent variables are generally moderate.

Table 21 reports multivariate analysis with Fog as the readability measure. Overall, results are consistent results with Table 11 . In Table 21, the coefficients of uncertain and weak modal words in Model 2 (coefficient $=-3.3171, t=-5.59)$ and Model 5 (coefficient $=-9.9156, t=-8.74)$ are stronger than those of Model 2 and 6 in Table 11 when File_Size is replaced with Fog. This indicates the incremental effect of the use of uncertain and weak modal words in 10-K filings on forecast accuracy is increased when the Fog index is used for the readability measure. The results of control variables are consistent with those of Table 11. 


\subsubsection{Uncertainty in Analysts' Overall Information Environment: Fog Replacement}

Table 22 reports the correlation analysis. The univariate analysis reports overall consistent results with Table 12, but the correlation between Common_Overall and the Fog index $(F o g)($ coefficient $=0.0104, \mathrm{p}<0.05)$ in Table 22 is weaker than the correlation between analyst following and File_Size (coefficient $=0.1048, \mathrm{p}<0.05)$ in Table 12. I find that the correlation coefficients between the independent variables are generally moderate.

Table 23 replaces File_Size with Fog for a readability proxy. Overall results are consistent with Table 13. In Table 23, the coefficients of uncertain and weak modal words in Model $2($ coefficient $=-3.0118, t=-5.61)$ and Model $5($ coefficient $=-8.9429, t=-8.69)$ are stronger than those of Model 2 and 6 in Table 13 when File_Size is replaced with Fog. This indicates the incremental effect of the use of uncertain and weak modal words in 10$\mathrm{K}$ filings on uncertainty in analysts' overall information is increasing when the Fog index is used for the readability proxy. The results of control variables are consistent with those of Table 13.

\subsubsection{Uncertainty in Analysts' Common Information Environment: Fog Replacement}

Table 24 reports the correlation analysis. The univariate analysis reports overall consistent results with Table 14. In Table 24, the correlation between Uncertainty_Common and Fog is negative and significant (coefficient $=-0.0305, \mathrm{p}<0.05)$, but in Table 14 the coefficient of File_Size (coefficient $=0.0600, \mathrm{p}<0.05)$ reports positive and significant correlation. I find that the correlation coefficients between the independent variables are generally moderate.

Table 25 reports multivariate analysis with Fog as a readability measure. Overall,

it reports consistent results with Table 15. In Table 25, the coefficients of uncertain and 
weak modal words in Model 2 (coefficient $=-8.5482, t=-4.61)$ and Model 5 (coefficient $=-16.4710, t=-4.63)$ are stronger than those of Model 2 and 6 in Table 15 when File_Size is replaced with Fog. This indicates the incremental effect of the use of uncertain and weak modal words in 10-K filings on uncertainty in analysts' common information environment is increasing when the Fog index is used for the readability measure. The results of control variables are consistent with those of Table 15.

This additional analysis reports that the Fog replacement does not change overall results. Interestingly, it also reports that the effect of the use of ambiguous language in 10Ks on analysts' forecast attributes becomes stronger when Fog replaces File_Size (except Analyst Following). One limitation of this additional analysis is inconsistent sample period $^{15}$. Future studies will match the sample period.

${ }^{15}$ Main test sample period is $2000-2016$. 


\section{CHAPTER 7}

\section{SUMMARY AND CONCLUSION}

There is a growing body of literature demonstrating that language sentiment and tone embedded in financial disclosures and earnings press releases are informative for users of financial information. This study aims to contribute to this literature by investigating the determinants of the use of uncertain and weak modal words in 10-K filings and the extent to which the use of these words affects analyst forecast attributes. These are important issues because the use of ambiguous language such as uncertain and weak modal words in 10-K filings can increase informational risk and decrease investors' ability to comprehend financial reports. Recent studies find evidence supporting that ambiguous language of corporate disclosures affects valuation uncertainty and cost of debt. This is the first study to examine the characteristics of firms that use uncertain and weak modal words in their 10-K filings. This is also the first study to examine how financial analysts perceive information contained in uncertain and weak modal words in $10-\mathrm{K}$ filings and reflect this information into their decision making.

This study first examines the determinants of the use of uncertain and weak modal words in 10-K filings, and I find that the use of uncertain and weak modal words in 10-K filings is positively associated with firm size and volatility of stock return and earnings. I further find that the use of these words is negatively associated with firm age and number of business segments. More importantly, this study investigates the extent to which the use of uncertain and weak modal words in 10-K filings affects analysts' behavior and forecast outcomes. First, I examine the relation between analyst following and the use of uncertain and weak modal words in $10-\mathrm{K}$ filings. I find a positive and significant relation between 
number of analysts and the use of ambiguous language in 10-Ks. Second, I examine whether forecast dispersion is associated with the use of uncertain and weak modal words in 10-Ks. I find that analyst forecast dispersion is negatively related to uncertain and weak modal words in 10-K filings. The result indicates that uncertain and weak modal words in 10-K filings contain valuable information about firms' future earnings so that analysts produce less dispersed forecasts among them. This finding is consistent with the notion that financial analysts collectively bias their forecasts upward with more uncertain information environment (i.e. the management-relations hypothesis). This finding is also consistent with the notion that analysts make extra efforts to produce forecasts when facing more uncertain information environment (i.e. the analyst extra effort hypothesis). Finally, this finding is also consistent with the notion that uncertain and weak modal words signal analysts and other market participations about firms' future earnings (i.e. the signaling theory). Analysts are able to use this information to produce more accurate forecasts, which in turn reduces forecast dispersion among analysts. Third, I examine the relation between forecast accuracy and the use of uncertain and weak modal words in 10-Ks. The finding provides evidence that use of uncertain and weak modal words in $10-\mathrm{K}$ filings relates to more accurate analyst forecasts. The result suggests that analysts effectively process information contains uncertain and weak modal words in 10-K filings, which in turn produce more accurate forecasts. This finding is also consistent with the analyst extra effort and the signaling theories as described in this dissertation. Fourth, I predict that higher uncertainty in the analysts' overall information environment increases the use of uncertain and weak modal words in firms' $10-\mathrm{K}$ filings. Inconsistent with my prediction, I find that uncertainty in the analysts' overall information environment decreases with firms' use of 
more ambiguous language in 10-Ks. Finally, I predict that use of ambiguous words in 10$\mathrm{K}$ filings increases the degree to which analysts share a common belief such as analysts' perception about the information contained in 10-K filings. Inconsistent with prediction, I find that increased use of uncertain and weak modal words in 10-K filings is associated with less uncertainty in analysts' common information environment. Both findings suggest that managers may use uncertain and weak modal words in 10-Ks to signal the market participants about their future earnings, which in turn reduces uncertainty in analysts' overall and common information environment. Future research should use behavioral research methods such as interviews with analysts to enhance our understanding of the effect of uncertain information environment on analysts' behavior.

The above results and findings are robust even after controlling for readability, measured by the FOG Index and file size, and management tone. Overall, I find that uncertain and weak modal words in $10-\mathrm{K}$ filings provide significant incremental information content regarding analyst forecast attributes beyond readability and management tone. Also, I provide evidence that analysts can effectively process the information contained in uncertain and weak modal words in 10 -Ks to produce their forecasts.

As a limitation, some of my findings are not consistent with my predictions due to potential measurement errors in variables. Therefore, future research is to survey analysts to further understand how they interpret and process financial disclosures with ambiguous language such as uncertain and weak modal words. 


\section{REFERENCES}

Ackert, Lucy F., and George Athanassakos, 1997, Prior uncertainty, analyst bias and subsequent abnormal returns, Journal of Financial Research 20, 253-273.

Ball, R. 1992. The earnings price anomaly. Journal of Accounting and Economics 15_23_: 319-345.

Barron, O. E., D. Byard, O. Kim, and D. E. Stevens. 1998. Using analysts' forecasts to measure properties of analysts' information environment. The Accounting Review 73 _4_: $421-433$.

Barth, M. E., R. Kasznik, and M. F. McNichols. 2001. Analyst coverage and intangible assets. Journal of Accounting Research 39 ___: 1-34.

Bhushan, R. 1989. Firm characteristics and analyst following. Journal of Accounting and Economics 11_2-3_: 255-274.

Biddle, G.; G. Hilary; and R. Verdi. "How Does Financial Reporting Quality Relate to Investment Efficiency?” Journal of Accounting and Economics 48 (2009): 112-31.

Bloomfield, Robert J., 2002, The "incomplete revelation hypothesis" and financial reporting, Accounting Horizons 16, 233-243.

Bonsall, S. B., and B. P. Miller. "The Impact of Narrative Disclosure Readability on Bond Ratings and Rating Agency Disagreement." Working paper, Ohio State University, 2014.

Botosan, C. A., and M. S. Harris. 2000. Motivations for a change in disclosure frequency and its consequences: An examination of voluntary quarterly segment disclosures. Journal of Accounting Research 38 _2_: 329-353.

Bradley, D. J., Gokkaya, S., \& Liu, X. (2017). Before an analyst becomes an analyst: Does industry experience matter? Journal of Finance 72-2 (2017): 751-792.

Bradshaw, M. T., G. S. Miller, and G. Serafeim. 2008. Accounting method heterogeneity and analysts' forecasts. Working paper, Harvard University and University of Michigan.

Bratten, B.; C. A. Gleason; S. Larocque; and L. F. Mills. "Forecasting Tax Expense: New Evidence from Analysts.” Working paper, University of Notre Dame, 2014.

Brennan, and A. Subrahmanyam. 1995. Investment analysis and price formation in securities markets. Journal of Financial Economics 38 _3_: 361-381. 
Callen, J. L., M. Khan, and H. Lu. 2009. Accounting quality, stock price delay and future stock returns. Working paper, University of Toronto and Massachusetts Institute of Technology.

Chen, S., Matsumoto, D. 2006. Favorable versus unfavorable recommendations: The impact on analyst access to management-provided information. Journal of Accounting Research 44, 657-689.

Cox, C. 2007. Closing remarks to the Second Annual Corporate Governance Summit. Delivered at the USC Marshall School of Business, Los Angeles, CA, March 23. Available at http://www.sec.gov/news/speech/2007/spch032307cc.htm.

Daines, R., 2001. Does Delaware law improve firm value? Journal of Financial Economics $62,525-558$.

Das, S., Levine, C., Sivaramakrishnan, K., 1998. Earnings predictability and bias in analysts' earnings forecasts. The Accounting Review 73, 277-294.

Davis, A. K., W. Ge, D. Matsumoto, and J. L. Zhang. "The Effect of Manager-specific Optimism on the Tone of Earnings Conference Calls." Review of Accounting Studies, 20, (2015), pp. 639-673.

Davis, A. K., J. M. Piger and L. M. Sedor. "Beyond the Numbers: managers' use of optimistic and pessimistic tone in earnings press release." Contemporary Accounting Research 29 (2012): 845-868.

Davis, A., and I. Tama-Sweet. 2012. Managers' use of language across alternative disclosure outlets:Earnings press releases versus MD\&A. Contemporary Accounting Research 29: 804-837.

De Franco,G.; O.Hope; D.Vyas; and Y.Zhou. "Analyst Report Readability." Contemporary Accounting Research 32 (2015): 76-104.

Demers, E., \& Vega, C. (2014). Understanding the role of managerial optimism and uncertainty in the price formation process: evidence from the textual content of earnings announcements. Working paper, Univeristy of Virginia.

Druz, Marina and Wagner, Alexander F. and Zeckhauser, Richard J., Reading Managerial Tone: How Analysts and the Market Respond to Conference Calls (January 22, 2016). HKS Working Paper No. 16-004. Available at SSRN: https://ssrn.com/abstract=2782672.

Duru, A., and D. M. Reeb. 2002. International diversification and analysts' forecast accuracy and bias. The Accounting Review 77 _2_: 415-433. 
Ertugrul, M., J. Lei, J. Qiu, and C. Wan. “Annual Report Readability, Tone Ambiguity, and the Cost of Borrowing." Journal of Financial and Quantitative Analysis 52 (2017): No.2: 811-836.

Feldman, R., S. Govindaraj, J. Livnat, and B. Segal. 2009. Management's tone change, post earnings announcement drift and accruals. Review of Accounting Studies 15: 915-953.

Francis, T. 2014, September 14. To be clear, SEC reviewers want filings in plain English, period. Wall Street Journal. Available at: http://www.wsj.com/articles/to-be-clearsecreviewers-want-filings-in-plain-english-period-1410555347.

Frankel, R., S. P. Kothari, and J. Weber. 2006. Determinants of the informativeness of analyst research. Journal of Accounting and Economics 41_1-2_: 29-54.

Frankel, R., W. Mayew, and Y. Sun. 2010. Do pennies matter? Investor relations consequences of small negative earnings surprises. Review of Accounting Studies 15: 220242.

Guay, W.; D. Samuels; and D. Taylor. "Guiding Through the Fog: Financial Statement Complexity and Voluntary Disclosure." Working paper, University of Pennsylvania, 2015.

Healy, P. M., A. P. Hutton, and K. G. Palepu. 1999. Stock performance and intermediation changes surrounding sustained increases in disclosure. Contemporary Accounting Research 16_3_: 485-520.

Hirst, D. E., and P. E. Hopkins. 1998. Comprehensive income reporting and analysts' valuation judgments. Journal of Accounting Research 36: 47-75.

Hirst, D. E., P. E. Hopkins, and J. M. Wahlen. 2004. Fair values, income measurement, and bank analysts' risk and valuation judgments. The Accounting Review 79 _2_: 453-472.

Hong H., and J. Kubik. "Analyzing the Analysts: Career Concerns and Biased Earnings Forecasts Authors." The Journal of Finance 58 (2003): Issue 1: 313-351.

Hopkins, P. E., R. W. Houston, and M. F. Peters. 2000. Purchase, pooling, and equity analysts' valuation judgments. The Accounting Review 75 _3_: 257-281.

Huang, X.; S. H. Teoh; and Y. Zhang. "Tone Management." The Accounting Review 89 (2014):1083-113.

Huberts, L., Fuller, R., 1995. Predictability bias in the U.S. equity market. Financial Analysts Journal 51, 12-28.

Indjejikian, R., 1991, The impact of costly information interpretation on firm disclosure decisions, Journal of Accounting Research 29, 277-301. 
Jones, Michael J., and Paul A. Shoemaker, 1994, Accounting narratives: A review of empirical studies of content and readability, Journal of Accounting Literature 13, 142-184.

Lang, M.H., K. V. Lins, and D. P. Miller. 2004. Concentrated control, analyst following, and valuation: Do analysts matter most when investors are protected least? Journal of Accounting Research $42 \_3 \_: 589-623 .$

Lang, M. H., and R. J. Lundholm. 1996. Corporate disclosure policy and analyst behavior. The Accounting Review 71 _4_: 467-492.

Lawrence, A. "Individual Investors and Financial Disclosure." Journal of Accounting \& Economics 56 (2013): 130-47.

Lehavy, R.; F. Li; and K. Merkley. "The Effect of Annual Report Readability on Analyst Following and the Properties of Their Earnings Forecasts." The Accounting Review 86 (2011): 1087-115.

Li, F. “Annual Report Readability, Current Earnings, and Earnings Persistence.” Journal of Accounting and Economics 45 (2008): 221-47.

Li, J., and X. Zhao. "Complexity and Information Content of Financial Disclosures: Evidence from Evolution of Uncertainty Following 10-K Filings." Working paper, University of Texas at Dallas, 2014.

Lim, T. (2001). Rationality and Analysts' Forecast Bias. Journal of Finance, LVI (1), 369385.

Loughran, T., and B. McDonald. "When Is a Liability Not a Liability? Textual Analysis, Dictionaries, and 10-Ks." Journal of Finance 66 (2011): 35-65.

Loughran, T., and B. McDonald. "IPO First-Day Returns, Offer Price Revisions, Volatility, and Form S-1 Language." Journal of Financial Economics 109 (2013): 307-26.

Loughran, T., and B. McDonald. "Measuring Readability in Financial Disclosures." Journal of Finance 69 (2014): 1643-71.

Loughran, T., and B. McDonald. "Textual Analysis in Accounting and Finance: A Survey." Journal of Accounting Research (2016) 54(4): 1187-1230.

Mikhail, M. B., B. R. Walther, and R. H. Willis. 1999. Does forecast accuracy matter to security analysts? The Accounting Review 74_2_: 185-200.

Milian, J. and A. Smith. 2017. "An Investigation of Analysts' Praise of Management During Earnings Conference Calls. Journal of Behavioral Finance Volume 18, 2017 - Issue 1. 
Miller, B. P. "The Effects of Reporting Complexity on Small and Large Investor Trading." The Accounting Review 85 (2010): 2107-43.

O'Brien and R. Bhushan. 1990. Analyst following and institutional ownership. Journal of Accounting Research 28: 55-76.

Plumlee, M (2003) The Effect of Information Complexity on Analysts' Use of That Information. The Accounting Review: January 2003, Vol. 78, No. 1, pp. 275-296.

Price, S., Doran, J., Peterson, D., \& Bliss, B. (2012). Earnings conference calls and stock returns: the incremental informativeness of textual tone. Journal of Banking \& Finance, 36(4), 992-1011.

Rennekamp, Kristina, 2012, "Processing fluency and investors' reactions to disclosure readability." Journal of Accounting Research 50, 1319-1354.

Schipper, K. 1991. Analysts' forecasts. Accounting Horizons 5 (4): 105-121.

Schroeder, M. 2002. SEC proposes rules to improve disclosure by public companies. Wall Street Journal_May 1_: C5.

SEC, 1998. A Plain English Handbook: How to Create Clear SEC Disclosure Documents. U.S. Securities and Exchange Commission, Washington, DC.

You, Haifeng, and Xiao-jun Zhang. "Financial reporting complexity and investor underreaction to 10-K information." Review of Accounting Studies 14.4 (2009): 559-586. 
TABLE 1

\section{Sample Selection}

Panel A: Sample Selection for the Determinants of the Use of Uncertain and Weak Modal Words in 10-K Filings

Observations

All firms in Loughran and McDonald Word Lists firm-years

2000-2016

Less: observations in regulated utilities (SIC 4900-4999) and

financial (SIC 6000-6999) firms

84,861

Less: firm-years with insufficient financial and special events data

Number of observations

37,442

Panel B: Sample Selection for the Association between the Use of Uncertain and Weak Modal Words in 10-K Filings and Analyst Forecast Attributes

Observations

All firms in Loughran and McDonald Word Lists firm-years 2000-2016

Less: observations in regulated utilities (SIC 4900-4999) and financial (SIC 6000-6999) firms

Less: firm-years with insufficient Financial data

42,627

Less: unmatched firm-years between $\mathrm{I} / \mathrm{B} / \mathrm{E} / \mathrm{S}$ data and financial data for five dependent variables

Number of observations 25,673 
TABLE 2

Descriptive Statistics for the Determinants of the Use of Uncertain and Weak Modal Words in 10-K Filings

\begin{tabular}{|c|c|c|c|c|}
\hline Variable & $\underline{\mathbf{N}}$ & $\underline{\text { Mean }}$ & $\underline{\text { Median }}$ & $\underline{\text { Std. Dev }}$ \\
\hline \multicolumn{5}{|l|}{$\overline{\text { Dependent }}$} \\
\hline Uncertain & 37,442 & 0.0131 & 0.0131 & 0.0031 \\
\hline Weak_Modal & 37,442 & 0.0056 & 0.0054 & 0.0020 \\
\hline \multicolumn{5}{|l|}{ Independent } \\
\hline Firm_Size & 37,442 & 5.9224 & 5.9018 & 2.0292 \\
\hline$M T B$ & 37,442 & 2.0583 & 1.5466 & 1.5606 \\
\hline Age & 37,442 & 17.5012 & 13.1710 & 15.2377 \\
\hline Special_Items & 37,442 & -0.0224 & -0.0009 & 0.0759 \\
\hline Std_Ret & 37,442 & 0.1483 & 0.1228 & 0.0946 \\
\hline Std_Earn & 37,442 & 0.1504 & 0.0608 & 0.2844 \\
\hline Segments & 37,442 & 1.0460 & 0.6931 & 0.4277 \\
\hline$M \& A$ & 37,442 & 0.2846 & 0.0000 & 0.4512 \\
\hline$S E O$ & 37,442 & 0.1393 & 0.0000 & 0.3463 \\
\hline Delaware & 37,442 & 0.0028 & 0.0000 & 0.0529 \\
\hline
\end{tabular}

$\overline{\text { Variables are defined in Appendix } 1 .}$ 


\section{TABLE 3}

\section{Correlation Matrix for the Determinants of the Use of Uncertain and Weak Modal Words in 10-K Filings}

\section{Panel A: Uncertain Words}

\begin{tabular}{|c|c|c|c|c|c|c|c|c|c|c|c|c|}
\hline & & 1 & 2 & 3 & 4 & 5 & 6 & 7 & 8 & 9 & 10 & 11 \\
\hline 1 & Uncertain & & $0.0556^{*}$ & $0.1323^{*}$ & $-0.1230 *$ & $-0.0271 *$ & $0.0117^{*}$ & $0.1447 *$ & $-0.1386^{*}$ & $0.0332 *$ & $0.0757 *$ & $-0.0282 *$ \\
\hline 2 & Firm_Size & $0.0544^{*}$ & & $0.3743^{*}$ & $0.2016^{*}$ & $-0.0147^{*}$ & $-0.4539 *$ & $-0.3723^{*}$ & $0.2295^{*}$ & $0.3027^{*}$ & $0.1292 *$ & -0.0085 \\
\hline 3 & $M T B$ & $0.1101^{*}$ & $0.2193^{*}$ & & $-0.0913^{*}$ & $0.1015^{*}$ & $-0.0619 *$ & $0.1608^{*}$ & $-0.1420 *$ & $0.0533^{*}$ & $0.0720 *$ & 0.0018 \\
\hline 4 & Age & $-0.1181 *$ & $0.2822 *$ & $-0.1217 *$ & & $0.0318^{*}$ & $-0.3428 *$ & $-0.3654^{*}$ & $0.2824^{*}$ & $0.0787^{*}$ & -0.0093 & 0.0055 \\
\hline 5 & Special_Items & -0.0036 & $0.1480 *$ & $0.0411 *$ & $0.0758 *$ & & $-0.0850 *$ & $-0.1048^{*}$ & $-0.0657 *$ & $-0.0472 *$ & 0.0071 & 0.0048 \\
\hline 6 & Std_Ret & $-0.0154 *$ & $-0.4055^{*}$ & $0.0842 *$ & $-0.2757 *$ & $-0.2101 *$ & & $0.5339 *$ & $-0.2077 *$ & $-0.2176^{*}$ & $-0.0154 *$ & -0.0078 \\
\hline 7 & Std_Earn & $0.0969 *$ & $-0.1990^{*}$ & $0.2615^{*}$ & $-0.2289 *$ & $-0.1767^{*}$ & $0.3410^{*}$ & & $-0.2723 *$ & $-0.1976^{*}$ & 0.0022 & -0.0031 \\
\hline 8 & Segments & $-0.1387 *$ & $0.2438^{*}$ & $-0.1818 *$ & $0.3165^{*}$ & $0.0165^{*}$ & $-0.1781 *$ & $-0.1901^{*}$ & & $0.1172 *$ & $0.0107 *$ & 0.0014 \\
\hline 9 & $M \& A$ & $0.0347^{*}$ & $0.3084 *$ & $-0.0275^{*}$ & $0.0953^{*}$ & $0.0319 *$ & $-0.1858^{*}$ & $-0.1103 *$ & $0.1199 *$ & & $0.0521 *$ & -0.0066 \\
\hline 10 & $S E O$ & $0.0772 *$ & $0.1215^{*}$ & $0.0596 *$ & $0.0231 *$ & $0.0394 *$ & $-0.0159 *$ & $0.0265^{*}$ & $0.0136^{*}$ & $0.0521 *$ & & -0.0038 \\
\hline 11 & Delaware & $-0.0264 *$ & -0.0012 & 0.0015 & $0.0190 *$ & 0.0026 & -0.0079 & 0.0007 & 0.0064 & -0.0066 & -0.0038 & \\
\hline
\end{tabular}

Panels A and B report the Pearson (below the diagonal) and Spearman (above the diagonal) correlation coefficients for the variables used in the regression analysis. * stands for $\mathrm{p}<0.05$ two-tailed t-tests. All continuous variables are winsorized at $1 \%$ and $99 \%$. All variables are defined in Appendix 1. 
TABLE 3 (Continued)

\section{Panel B: Weak Modal Words}

\begin{tabular}{|c|c|c|c|c|c|c|c|c|c|c|c|}
\hline & 1 & 2 & 3 & 4 & 5 & 6 & 7 & 8 & 9 & 10 & 11 \\
\hline 1 Weak_Modal & & 0.0009 & $0.2060 *$ & $-0.2741 *$ & $-0.0292 *$ & $0.1432 *$ & $0.3076 *$ & $-0.2444 *$ & $-0.0132 *$ & $0.0794 *$ & $-0.0187 *$ \\
\hline 2 Firm_Size & 0.0005 & & $0.3743 *$ & $0.2016^{*}$ & $-0.0147 *$ & $-0.4539 *$ & $-0.3723 *$ & $0.2295 *$ & $0.3027^{*}$ & $0.1292 *$ & -0.0085 \\
\hline$M T B$ & $0.2240^{*}$ & $0.2193^{*}$ & & $-0.0913^{*}$ & $0.1015^{*}$ & $-0.0619 *$ & $0.1608 *$ & $-0.1420 *$ & $0.0533^{*}$ & $0.0720 *$ & 0.0018 \\
\hline Age & $-0.2574 *$ & $0.2822 *$ & $-0.1217 *$ & & $0.0318 *$ & $-0.3428 *$ & $-0.3654 *$ & $0.2824 *$ & $0.0787^{*}$ & -0.0093 & 0.0055 \\
\hline Special_Items & $-0.0208 *$ & $0.1480 *$ & $0.0411^{*}$ & $0.0758 *$ & & $-0.0850 *$ & $-0.1048 *$ & $-0.0657 *$ & $-0.0472 *$ & 0.0071 & 0.0048 \\
\hline 6 Std_Ret & $0.1022 *$ & $-0.4055^{*}$ & $0.0842 *$ & $-0.2757 *$ & $-0.2101 *$ & & $0.5339 *$ & $-0.2077 *$ & $-0.2176^{*}$ & $-0.0154 *$ & -0.0078 \\
\hline Std_Earn & $0.2326^{*}$ & $-0.1990 *$ & $0.2615^{*}$ & $-0.2289 *$ & $-0.1767 *$ & $0.3410^{*}$ & & $-0.2723^{*}$ & $-0.1976 *$ & 0.0022 & -0.0031 \\
\hline Segments & $-0.2489 *$ & $0.2438 *$ & $-0.1818 *$ & $0.3165^{*}$ & $0.0165^{*}$ & $-0.1781 *$ & $-0.1901 *$ & & $0.1172 *$ & $0.0107 *$ & 0.0014 \\
\hline$M \& A$ & $-0.0193^{*}$ & $0.3084^{*}$ & $-0.0275^{*}$ & $0.0953^{*}$ & $0.0319^{*}$ & $-0.1858^{*}$ & $-0.1103^{*}$ & 0.1199* & & $0.0521 *$ & -0.0066 \\
\hline SEO & $0.0899 *$ & $0.1215^{*}$ & $0.0596^{*}$ & $0.0231 *$ & $0.0394 *$ & $-0.0159 *$ & $0.0265^{*}$ & $0.0136^{*}$ & $0.0521 *$ & & -0.0038 \\
\hline Delaware & $-0.0153 *$ & -0.0012 & 0.0015 & $0.0190 *$ & 0.0026 & -0.0079 & 0.0007 & 0.0064 & -0.0066 & -0.0038 & \\
\hline
\end{tabular}

Panels A and B report the Pearson (below the diagonal) and Spearman (above the diagonal) correlation coefficients for the variables used in the regression analysis. * stands for $\mathrm{p}<0.05$ two-tailed t-tests. All continuous variables are winsorized at $1 \%$ and $99 \%$. All variables are defined in Appendix 1 . 


\section{TABLE 4}

\section{Multivariate Analysis for the Determinants of the Use of Uncertain and Weak}

Modal Words in the 10-K Filings

\begin{tabular}{|c|c|c|c|}
\hline \multirow[b]{2}{*}{ Independent variable } & \multirow[b]{2}{*}{ Prediction } & \multicolumn{2}{|c|}{ Dependent variable } \\
\hline & & Uncertain & Weak_Modal \\
\hline Firm_Size & + & $\begin{array}{c}0.0001 * * * \\
(13.34)\end{array}$ & $\begin{array}{c}0.0001 * * * \\
(15.53)\end{array}$ \\
\hline$M T B$ & + & $\begin{array}{c}0.0000 \\
(0.44)\end{array}$ & $\begin{array}{c}0.0001 * * * \\
(10.87)\end{array}$ \\
\hline Age & - & $\begin{array}{c}-0.0000 * * * \\
(-28.35)\end{array}$ & $\begin{array}{c}-0.0000 * * * \\
(-49.23)\end{array}$ \\
\hline Special_Items & - & $\begin{array}{c}-0.0001 \\
(-0.28)\end{array}$ & $\begin{array}{c}0.0002 * \\
(1.87)\end{array}$ \\
\hline Std_Ret & + & $\begin{array}{c}0.0008 * * * \\
(4.71)\end{array}$ & $\begin{array}{c}0.0017 * * * \\
(15.90)\end{array}$ \\
\hline Std_Earn & + & $\begin{array}{c}0.0005 * * * \\
(10.03)\end{array}$ & $\begin{array}{c}0.0007 * * * \\
(22.82)\end{array}$ \\
\hline Segments & - & $\begin{array}{c}-0.0007 * * * \\
(-19.68)\end{array}$ & $\begin{array}{c}-0.0006 * * * \\
(-30.27)\end{array}$ \\
\hline$M \& A$ & - & $\begin{array}{c}0.0001 * * * \\
(2.78)\end{array}$ & $\begin{array}{c}-0.0000^{*} \\
(-1.73)\end{array}$ \\
\hline SEO & - & $\begin{array}{c}0.0000 \\
(0.63)\end{array}$ & $\begin{array}{c}0.0000 \\
(1.29)\end{array}$ \\
\hline Delaware & $?$ & $\begin{array}{c}-0.0006 * * * \\
(-2.30)\end{array}$ & $\begin{array}{c}0.0001 \\
(0.33)\end{array}$ \\
\hline Intercept & & $\begin{array}{c}0.0096 * * * \\
(33.01)\end{array}$ & $\begin{array}{c}0.0031 * * * \\
(18.38)\end{array}$ \\
\hline Year/Ind Fixed Effects & & Yes & Yes \\
\hline $\begin{array}{l}\mathrm{n} \\
\text { Adj. } \mathrm{R}^{2}\end{array}$ & & $\begin{array}{l}37,442 \\
0.2869\end{array}$ & $\begin{array}{l}37,442 \\
0.4180\end{array}$ \\
\hline
\end{tabular}

The $t$-statistics in parentheses *, **, $* * *$ stands for $\mathrm{p}<0.1, \mathrm{p}<0.05, \mathrm{p}<0.01$, respectively, two-tailed t-tests. All continuous variables are winsorized at $1 \%$ and $99 \%$. Variables are defined in the Appendix 1. 
TABLE 5

Descriptive Statistics for the Association between the Use of Uncertain and Weak Modal Words in 10-K Filings and Analyst Forecast Attributes

Variable

Dependent

\#Analysts

Dispersion

Accuracy

Uncertainty_Overall

Uncertainty_Common

$\underline{\text { Independent }}$

Uncertain

Weak_Modal

File_Size

Pos_Tone

Neg_Tone

Control

Firm_Size

Growth

Segments

\%_Inst

10K_News

$A d v$

$R \& D$

Std_Ret

n $\quad \underline{\text { Mean }}$

25,673

19,003

15,213

14,308

14,306

25,673

25,673

25,673

25,673

25,673

25,673

25,673

25,673

25,673

25,673

25,673

25,673

25,673
7.5121

0.0143

0.0402

0.0445

0.3259

0.0134

0.0058

12.7344

0.0074

0.0170

6.4350

0.1565

1.0578

0.6263

0.0355

0.0128

0.1114

0.1407 $\underline{\text { Median }}$

5.0000

0.0041

0.0024

0.0076

0.3056

0.0135

0.0056

12.6999

0.0073

0.0169

6.3575

0.0801

0.6931

0.6825

0.0211

0.0000

0.0171

0.1184
Std. Dev.

6.5571

0.0308

0.1567

0.1413

0.4299

0.0030

0.0019

0.4589

0.0017

0.0037

1.8124

0.4815

0.4350

0.2642

0.0418

0.0334

0.1913

0.0848

Variables are defined in Appendix 2. 


\section{TABLE 6}

\section{Correlation Matrix for the Association between Analyst Following and the Use of Uncertain and Weak Modal Words in}

10-K Filings

\begin{tabular}{|c|c|c|c|c|c|c|c|c|c|c|c|c|c|c|}
\hline & 1 & 2 & 3 & 4 & 5 & 6 & 7 & 8 & 9 & 10 & 11 & 2 & 3 & 14 \\
\hline 1 \# & & 9 & 0023 & $9 *$ & 556 & 0368* & * & $7 *$ & $57 *$ & $4890 *$ & $.1812^{*}$ & $42 *$ & -0.0099 & \\
\hline $2 U n c$ & 0046 & & $7400 *$ & 50* & $0.2592 *$ & $9 *$ & & & -0 . & .0041 & & & & \\
\hline 3 Weal & $0.0157 *$ & 0.741 & & & 0.2 & & & $*$ & $*$ & $-0 .($ & $*$ & & $*$ & \\
\hline ne & 6* & $2445^{*}$ & $0.2798^{*}$ & -0.0 & & $0.0833^{*}$ & & & & & & & & \\
\hline & $*$ & 0.2 & 0.45 & $0.3288 *$ & $0.0624 *$ & & -0. & -0.0 & & $-0.0240 *$ & & & $*$ & \\
\hline & & $0 *$ & $07 *$ & $3 *$ & -0.0 & -0.0 & & $5^{*}$ & & & & & & -0 \\
\hline & $5 *$ & $.0421 *$ & $39 *$ & $63 *$ & $0.0662 *$ & -0.0098 & $0.0202 *$ & & $23 *$ & $0.0804 *$ & -0 . & 03 & & 067 \\
\hline & & $-0.1689 *$ & -0.3021 & & $-0.1080 *$ & -0 . & $0.2898 *$ & $-0 .($ & & $0.1362 *$ & -0 . & & -0 . & \\
\hline 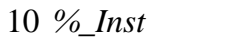 & & & -0.0 & $5^{*}$ & -0.0 & $2 *$ & $0.5461 *$ & $48 *$ & & & $22 *$ & 84 & & \\
\hline K_Ne & $1 *$ & $0.0234^{*}$ & $0.0898 *$ & $11 *$ & 7 & $0 *$ & $-0.2668 *$ & $0.0268 *$ & $-0.1021 *$ & $-0.2200 *$ & & -0.0111 & $0.0649 *$ & $778 *$ \\
\hline & & & & & & & & & & -0.0104 & $0.0146 *$ & & $-0.0290 *$ & -0.0357 \\
\hline & $0.0312 *$ & $0.1790 *$ & $4060 *$ & $0.0909 *$ & & $0.2096^{*}$ & $-0.1124^{*}$ & $0.1909 *$ & $-0.2867^{*}$ & $-0.1510 *$ & $0.0929 *$ & $-0.0872 *$ & & $0.2098 *$ \\
\hline Std_Ret & $-0.2516^{*}$ & 0.0014 & $0.1373 *$ & $-0.0174 *$ & $0.0627 *$ & $0.1578^{*}$ & $-0.4468 *$ & $0.0909 *$ & $-0.2033^{*}$ & $-0.3657 *$ & $0.3904 *$ & -0.0054 & $12 *$ & \\
\hline
\end{tabular}
This table reports the Pearson (below the diagonal) and Spearman (above the diagonal) correlation coefficients for the variables used in the regression analysis.
$*$ stands for $\mathrm{p}<0.05$ two-tailed t-tests. All continuous variables are winsorized at $1 \%$ and $99 \%$. All variables are defined in Appendix 2 . 


\section{TABLE 7}

Multivariate Analysis for the Association between Analyst Following and the Use of Uncertain and Weak Modal Words in 10-K Filings

DV: \#Analysts
$\frac{\text { UV }}{\text { Uncertain }}$
Weak_Modal
File_Size
Pos_Tone
Neg_Tone
Firm_Size
Growth
Segments
Odo-K_News

\begin{tabular}{|c|c|c|c|c|}
\hline \multirow[b]{2}{*}{ Prediction } & \multicolumn{4}{|c|}{ Uncertain } \\
\hline & Model 1 & Model 2 & $\underline{\text { Model } 3}$ & Model 4 \\
\hline+ & & $\begin{array}{c}24.5022 * * * \\
(14.23)\end{array}$ & $\begin{array}{c}28.5131 * * * \\
(17.61)\end{array}$ & $\begin{array}{c}6.7185 * * * \\
(4.56)\end{array}$ \\
\hline+ & & & & \\
\hline+ & $\begin{array}{c}0.1377 * * * \\
(14.21)\end{array}$ & $\begin{array}{c}0.2228 * * * \\
(19.62)\end{array}$ & $\begin{array}{c}0.2538 * * * \\
(24.83)\end{array}$ & \\
\hline+ & $\begin{array}{c}10.6225^{* * *} \\
(4.09)\end{array}$ & $\begin{array}{c}5.3943 * * \\
(2.06)\end{array}$ & & $\begin{array}{c}2.8300 \\
(1.08)\end{array}$ \\
\hline+ & $\begin{array}{c}13.9095 * * * \\
(11.76)\end{array}$ & $\begin{array}{c}8.2424 * * * \\
(6.63)\end{array}$ & & $\begin{array}{c}18.7498 * * * \\
(16.58)\end{array}$ \\
\hline+ & $\begin{array}{c}0.3494 * * * \\
(120.42)\end{array}$ & $\begin{array}{c}0.3465^{* * * *} \\
(119.61)\end{array}$ & $\begin{array}{c}0.3446 * * * \\
(120.1)\end{array}$ & $\begin{array}{c}0.3607 * * * \\
(127.56)\end{array}$ \\
\hline+ & $\begin{array}{c}-0.0646 * * * \\
(-8.05)\end{array}$ & $\begin{array}{c}-0.0721 * * * \\
(-9.00)\end{array}$ & $\begin{array}{c}-0.0756^{* * * *} \\
(-9.44)\end{array}$ & $\begin{array}{c}-0.0646 * * * \\
(-8.01)\end{array}$ \\
\hline- & $\begin{array}{c}-0.1541 * * * \\
(-15.87)\end{array}$ & $\begin{array}{c}-0.1477 * * * \\
(-15.25)\end{array}$ & $\begin{array}{c}-0.1504 * * * \\
(-15.54)\end{array}$ & $\begin{array}{c}-0.1326 * * * \\
(-13.64)\end{array}$ \\
\hline+ & $\begin{array}{c}0.6341 * * * \\
(35.21)\end{array}$ & $\begin{array}{c}0.6185^{* * * *} \\
(34.42)\end{array}$ & $\begin{array}{c}0.6222 * * * \\
(34.63)\end{array}$ & $\begin{array}{c}0.6323 * * * \\
(34.95)\end{array}$ \\
\hline+ & $\begin{array}{c}0.0031 \\
(0.03)\end{array}$ & $\begin{array}{c}-0.0233 \\
(-0.24)\end{array}$ & $\begin{array}{l}-0.0154 \\
(-0.16)\end{array}$ & $\begin{array}{c}0.0081 \\
(0.08)\end{array}$ \\
\hline+ & $\begin{array}{c}0.8001 * * * \\
(6.69)\end{array}$ & $\begin{array}{c}0.7236^{* * * *} \\
\quad(6.06)\end{array}$ & $\begin{array}{c}0.7595 * * * \\
(6.36)\end{array}$ & $\begin{array}{c}0.8269 * * * \\
(6.88)\end{array}$ \\
\hline+ & $\begin{array}{c}0.4146^{* * *} \\
(14.52)\end{array}$ & $\begin{array}{c}0.3767 * * * \\
(13.19)\end{array}$ & $\begin{array}{c}0.3977 * * * \\
(14.46)\end{array}$ & $\begin{array}{c}0.4398 * * * \\
(15.38)\end{array}$ \\
\hline
\end{tabular}

\begin{tabular}{cccc}
\multicolumn{4}{c}{ Weak_Modal } \\
\hline Model 5 & $\underline{\text { Model 6 }}$ & $\underline{\text { Model 7 }}$ & $\underline{\text { Model 8 }}$ \\
& & & \\
& $41.2014 * * *$ & $47.2850 * * *$ & $33.6183 * * *$ \\
$0.1377 * * *$ & $0.16222^{* * *}$ & $0.1795 * * *$ & $(12.35)$ \\
$(14.21)$ & $(16.58)$ & $(19.87)$ & \\
$10.6225 * * *$ & $5.4277 * *$ & & 0.1571 \\
$(4.09)$ & $(2.08)$ & & $(0.06)$ \\
$13.9095 * * *$ & $7.0756 * * *$ & & $14.5946 * * *$ \\
$(11.76)$ & $(5.60)$ & & $(12.32)$ \\
$0.3494 * * *$ & $0.3526 * * *$ & $0.3519 * * *$ & $0.3638 * * *$ \\
$(120.42)$ & $(121.72)$ & $(122.29)$ & $(128.47)$ \\
$-0.0646 * * *$ & $-0.0763 * * *$ & $-0.0799 * * *$ & $-0.0721 * * *$ \\
$(-8.05)$ & $(-9.5)$ & $(-9.98)$ & $(-8.93)$ \\
$-0.1541 * * *$ & $-0.1313 * * *$ & $-0.1311 * * *$ & $-0.1162 * * *$ \\
$(-15.87)$ & $(-13.42)$ & $(-13.4)$ & $(-11.87)$ \\
$0.6341 * * *$ & $0.6229 * * *$ & $0.6264 * * *$ & $0.6274 * * *$ \\
$(35.21)$ & $(34.71)$ & $(34.92)$ & $(34.78)$ \\
0.0031 & -0.0256 & -0.0199 & -0.0083 \\
$(0.03)$ & $(-0.26)$ & $(-0.2)$ & $(-0.08)$ \\
$0.8001 * * *$ & $0.6981 * * *$ & $0.7237 * * *$ & $0.7636 * * *$ \\
$(6.69)$ & $(5.85)$ & $(6.06)$ & $(6.37)$ \\
$0.4146 * * *$ & $0.3127 * * *$ & $0.3231 * * *$ & $0.3663 * * *$ \\
$(14.52)$ & $(10.7)$ & $(11.41)$ & $(12.54)$ \\
& & &
\end{tabular}




\section{TABLE 7 (Continued)}

DV: \#Analysts

IV

Std_Ret

Intercept

Year/Ind. Fixed Effects

$n$

Adjusted R-Squared

\section{Uncertain}

$\frac{\text { Prediction }}{+}$

\begin{tabular}{cccc}
\hline$\underline{\text { Model 1 }}$ & $\underline{\text { Model 2 }}$ & $\underline{\text { Model 3 }}$ & $\underline{\text { Model 4 }}$ \\
$0.5631 * * *$ & $0.5176 * * *$ & $0.5562 * * *$ & $0.6350 * * *$ \\
$(9.50)$ & $(8.75)$ & $(9.44)$ & $(10.71)$ \\
$-3.3613 * * *$ & $-4.5274 * * *$ & $-4.8040 * * *$ & $-1.8063 * * *$ \\
$(-20.62)$ & $(-24.89)$ & $(-27.67)$ & $(-15.23)$ \\
Yes & Yes & Yes & Yes \\
25,673 & 25,673 & 25,673 & 25,673 \\
0.6043 & 0.6074 & 0.6067 & 0.6015
\end{tabular}

\begin{tabular}{cccc}
\hline \multicolumn{4}{c}{ Weak_Modal } \\
$\underline{\text { Model 5 }}$ & $\underline{\text { Model 6 }}$ & $\underline{\text { Model 7 }}$ & $\underline{\text { Model 8 }}$ \\
$0.5631 * * *$ & $0.5261 * * *$ & $0.5593 * * *$ & $0.6155^{* * *}$ \\
$(9.50)$ & $(8.91)$ & $(9.51)$ & $(10.41)$ \\
$-3.3613 * * *$ & $-3.6967 * * *$ & $-3.8052 * * *$ & $-1.7992^{* * *}$ \\
$(-20.62)$ & $(-22.56)$ & $(-24.12)$ & $(-15.26)$ \\
Yes & Yes & Yes & Yes \\
25,673 & 25,673 & 25,673 & 25,673 \\
0.6043 & 0.6078 & 0.6073 & 0.6036
\end{tabular}

The $t$-statistics in parentheses. *,**,*** stands for $\mathrm{p}<0.1, \mathrm{p}<0.05, \mathrm{p}<0.01$, respectively, two-tailed t-tests. All continuous variables are winsorized at $1 \%$ and 99\%. Variables are defined in the Appendix 2. 


\section{TABLE 8}

\section{Correlation Matrix for the Association between Analyst Forecast Dispersion and the Use of Uncertain and Weak Modal} Words in 10-K Filings

\begin{tabular}{|c|c|c|c|c|c|c|c|c|c|c|c|c|c|c|c|}
\hline & 1 & 2 & 3 & 4 & 5 & 6 & 7 & 8 & 9 & 10 & 11 & 12 & 13 & 14 & 15 \\
\hline 1 Dispersion & & $0.0666^{*}$ & $0.1778^{*}$ & $0.1003^{*}$ & $0221 *$ & $0.1804 *$ & $-0.4635^{*}$ & $-0.1842 *$ & $-0.1361^{*}$ & $-0.2993^{*}$ & $2421 *$ & $-0.1101 *$ & $0.0935^{*}$ & $0.4705^{*}$ & $-0.2203 *$ \\
\hline 2 Uncertain & $0.0207 *$ & & $0.7384 *$ & $-0.3136^{*}$ & $0.2586^{*}$ & $0.2538^{*}$ & $-0.1133 *$ & $0.0367 *$ & $-0.1867 *$ & $-0.0263 *$ & $0.0387 *$ & $0.0247 *$ & $0.2273 *$ & $0.0679 *$ & $-0.0255^{*}$ \\
\hline 3 Weak_Modal & $0.1175^{*}$ & $0.7405^{*}$ & & -0.0086 & $0.2528^{*}$ & $0.4312 *$ & $-0.2360 *$ & $0.0829^{*}$ & $-0.3268^{*}$ & $-0.1098 *$ & $0.1214^{*}$ & $0.0427 *$ & $0.3825^{*}$ & $0.2251^{*}$ & $-0.0570 *$ \\
\hline 4 File_Size & $0.0805^{*}$ & $-0.3527^{*}$ & -0.0142 & & $-0.1063^{*}$ & $0.2857 *$ & $0.2500 *$ & 0.0008 & $0.1248 *$ & $0.1004 *$ & -0.012 & $0.0249 *$ & $0.0707 *$ & -0.0122 & $0.2489 *$ \\
\hline 5 Pos_Tone & $0.0395^{*}$ & $0.2410 *$ & $0.2784^{*}$ & $-0.0985^{*}$ & & $0.0958^{*}$ & $-0.0406^{*}$ & 0.0048 & $-0.1083^{*}$ & $-0.0756^{*}$ & -0.0118 & $0.0170^{*}$ & $0.4199 *$ & $0.0493^{*}$ & $-0.0386 *$ \\
\hline 6 Neg_Tone & $0.1362 *$ & $0.2578 *$ & $0.4430 *$ & $0.2908^{*}$ & $0.0685^{*}$ & & $-0.1493 *$ & $-0.0785^{*}$ & $-0.1261 *$ & $-0.0614 *$ & $0.1010^{*}$ & $0.0671^{*}$ & $0.3088^{*}$ & $0.2134 *$ & -0.0132 \\
\hline 7 Firm_Size & $-0.3924 *$ & $-0.1058^{*}$ & $-0.2217 *$ & $0.2464 *$ & $-0.0333^{*}$ & $-0.1235^{*}$ & & $0.0925^{*}$ & $0.2780 *$ & $0.4524 *$ & $-0.2634^{*}$ & $0.0179^{*}$ & $-0.1057^{*}$ & $-0.5209 *$ & $0.6867 *$ \\
\hline 8 Growth & $0.0254^{*}$ & $0.0423 *$ & $0.1260^{*}$ & $0.0271 *$ & $0.0782 *$ & -0.0053 & $-0.0159 *$ & & $-0.0932 *$ & $0.0565 *$ & 0.0018 & 0.0106 & $0.0598 *$ & 0.0079 & $0.0339 *$ \\
\hline 9 Segment. & $-0.1239 *$ & $-0.1869^{*}$ & $-0.3257 *$ & $0.1299 *$ & $-0.1158^{*}$ & $-0.1198 *$ & $0.2881 *$ & $-0.1081^{*}$ & & $0.1167 *$ & $-0.1196^{*}$ & $-0.0598 *$ & $-0.2160^{*}$ & $-0.2339 *$ & $0.0996^{*}$ \\
\hline $10 \% \_$Inst & $-0.3409 *$ & $-0.0231 *$ & $-0.1208 *$ & $0.0998 *$ & $-0.0773 *$ & $-0.0625 *$ & $0.4551 *$ & $-0.0476^{*}$ & $0.1309^{*}$ & & $-0.1582 *$ & 0.0032 & $-0.1380 *$ & $-0.2972 *$ & $0.3769 *$ \\
\hline $1110 K \_$News & $0.2194 *$ & $0.0407 *$ & $0.1129^{*}$ & $-0.0150 *$ & 0.0126 & $0.0981^{*}$ & $-0.2562 *$ & $0.0407 *$ & $-0.1047 *$ & $-0.1947 *$ & & $-0.0180^{*}$ & $0.0581 *$ & $0.3691 *$ & $-0.1586 *$ \\
\hline $12 A d v$ & 0.0008 & $0.0153 *$ & $0.0507^{*}$ & $0.0417 *$ & -0.0062 & $0.0617 *$ & $0.0372 *$ & 0.0132 & $-0.0386^{*}$ & $-0.0292 *$ & 0.0106 & & $-0.0147 *$ & $-0.0332 *$ & $0.0487 *$ \\
\hline $13 R \& D$ & $0.1913^{*}$ & $0.1820^{*}$ & $0.4193^{*}$ & $0.0924 *$ & $0.4649^{*}$ & $0.2207^{*}$ & $-0.1421^{*}$ & $0.2025^{*}$ & $-0.2950 *$ & $-0.1718 *$ & $0.0982 *$ & $-0.0835^{*}$ & & $0.2135^{*}$ & $-0.0365 *$ \\
\hline 14 Std_Ret & $0.4039 *$ & $0.0277 *$ & $0.1728 *$ & -0.010 & $0.0721 *$ & $0.1795^{*}$ & $-0.4669 *$ & $0.1120^{*}$ & $-0.2069^{*}$ & $-0.3517 *$ & $0.3884^{*}$ & 0.0021 & $0.2621 *$ & & $-0.2901 *$ \\
\hline 15 \#Analysts & $-0.1493 *$ & $-0.0329 *$ & $-0.0580 *$ & $0.2334 *$ & $-0.0544 *$ & -0.0014 & $0.6949 *$ & $-0.0381 *$ & $0.1037^{*}$ & $0.3048 *$ & $-0.1441 *$ & $0.0631^{*}$ & $-0.0527 *$ & $-0.2457 *$ & \\
\hline
\end{tabular}

\footnotetext{
This table reports the Pearson (below the diagonal) and Spearman (above the diagonal) correlation coefficients for the variables used in the regression analysis.

* stands for $\mathrm{p}<0.05$ two-tailed t-tests. All continuous variables are winsorized at $1 \%$ and $99 \%$. All variables are defined in Appendix 2 .
} 


\section{TABLE 9}

Multivariate Analysis for the Association between Analyst Forecast Dispersion and the Use of Uncertain and Weak Modal Words in 10-K Filings

DV:Dispersion
UV
Weak_Modain
File_Size
Pos_Tone
Neg_Tone
Firm_Size
Growth
Segments
ToK_Nowst

\section{Uncertain}

\begin{tabular}{c} 
Prediction \\
\hline$?$
\end{tabular}

?

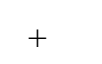

$0.0067 * * *$

(13.94)

0.2586 ***

(2.00)

0.0506

(0.85)

$-0.0076 * * *$

$(-39.58)$

$-0.0008 * *$

(-2.02)

$0.0025 * * *$

$$
\text { (5.22) }
$$

$-0.0193 * * *$

(-20.98)

$0.0303 * * *$

(5.91)

$0.0197 * * *$

(3.34)

$0.0076 * * *$

(5.36)

Model 2
$-0.1629 *$
$(-1.85)$

$(-1.85)$

Model 3
-0.1050
$(-1.26)$

Model 4

$-0.6781 * * *$

(-9.20)

$0.0061 * * * \quad 0.0063 * * *$

(10.62) (12.00)

$0.2903 * *$

$$
\text { (2.22) }
$$

0.0859

(1.37)

$-0.0076^{* * * *}$

$(-39.53)$

$-0.0007^{*}$

$(-1.89)$

$0.0025 * * *$

$$
\text { (5.13) }
$$

$-0.0192 * * *$

$(-20.89)$

$0.0306^{* * *}$

(5.96)

$0.0202 * * *$

$0.0078 * * *$

(5.51)

$-0.0076 * * *$

$(-39.94)$

$-0.0008 * *$

$(-2.00)$

$0.0025 * * *$

(5.09)

$-0.0193 * * *$

$(-20.96)$

$0.0306 * * *$

(5.96)

$0.0206 * * *$

(3.51)

$0.0087 * * *$

(6.43)

\begin{tabular}{|c|c|c|c|}
\hline Model 5 & Model 6 & Model 7 & Model 8 \\
\hline & $\begin{array}{c}-1.4781 * * * \\
(-10.71)\end{array}$ & $\begin{array}{c}-1.2375^{* * *} \\
(-9.56)\end{array}$ & $\begin{array}{c}-1.7907 * * * \\
(-13.18)\end{array}$ \\
\hline $\begin{array}{c}0.0067 * * * \\
(13.94)\end{array}$ & $\begin{array}{c}0.0057 * * * \\
(11.63)\end{array}$ & $\begin{array}{c}0.0062 * * * \\
(13.53)\end{array}$ & \\
\hline $\begin{array}{c}0.2586 * * * \\
(2.00)\end{array}$ & $\begin{array}{c}0.4201 * * * \\
(3.23)\end{array}$ & & $\begin{array}{c}0.2287^{*} \\
(1.77)\end{array}$ \\
\hline $\begin{array}{c}0.0506 \\
(0.85)\end{array}$ & $\begin{array}{c}0.2760 * * * \\
(4.37)\end{array}$ & & $\begin{array}{c}0.5171 * * * \\
(8.64)\end{array}$ \\
\hline $\begin{array}{c}-0.0076^{* * * *} \\
(-39.58)\end{array}$ & $\begin{array}{c}-0.0078 * * * \\
(-40.63)\end{array}$ & $\begin{array}{c}-0.0078 * * * \\
(-40.95)\end{array}$ & $\begin{array}{c}-0.0075^{* * * *} \\
(-39.32)\end{array}$ \\
\hline $\begin{array}{c}-0.0008 * * \\
(-2.02)\end{array}$ & $\begin{array}{c}-0.0004 \\
(-0.99)\end{array}$ & $\begin{array}{c}-0.0005 \\
(-1.34)\end{array}$ & $\begin{array}{c}-0.0002 \\
(-0.55)\end{array}$ \\
\hline $\begin{array}{c}0.0025 * * * \\
(5.22)\end{array}$ & $\begin{array}{c}0.0018 * * * \\
(3.61)\end{array}$ & $\begin{array}{c}0.0018 * * * \\
(3.64)\end{array}$ & $\begin{array}{c}0.0023 * * * \\
(4.81)\end{array}$ \\
\hline $\begin{array}{c}-0.0193 * * * \\
(-20.98)\end{array}$ & $\begin{array}{c}-0.0190 * * * \\
(-20.7)\end{array}$ & $\begin{array}{c}-0.0190 * * * \\
(-20.72)\end{array}$ & $\begin{array}{c}-0.0189 * * * \\
(-20.58)\end{array}$ \\
\hline $\begin{array}{c}0.0303 * * * \\
(5.91)\end{array}$ & $\begin{array}{c}0.0319 * * * \\
(6.23)\end{array}$ & $\begin{array}{c}0.0321 * * * \\
(6.27)\end{array}$ & $\begin{array}{c}0.0323 * * * \\
(6.28)\end{array}$ \\
\hline $\begin{array}{c}0.0197 * * * \\
(3.34)\end{array}$ & $\begin{array}{c}0.0237 * * * \\
(4.03)\end{array}$ & $\begin{array}{c}0.0250 * * * \\
(4.24)\end{array}$ & $\begin{array}{c}0.0263 * * * \\
(4.46)\end{array}$ \\
\hline $\begin{array}{c}0.0076^{* * *} \\
(5.36)\end{array}$ & $\begin{array}{c}0.0113 * * * \\
(7.78)\end{array}$ & $\begin{array}{c}0.0123 * * * \\
(8.78)\end{array}$ & $\begin{array}{c}0.0133 * * * \\
(9.23)\end{array}$ \\
\hline
\end{tabular}

Weak_Modal 


\section{TABLE 9 (Continued)}

\begin{tabular}{|c|c|c|c|c|c|c|c|c|c|}
\hline \multirow{2}{*}{$\begin{array}{l}\text { DV: Dispersion } \\
\text { IV }\end{array}$} & \multirow[b]{2}{*}{ Prediction } & \multicolumn{4}{|c|}{ Uncertain } & \multicolumn{4}{|c|}{ Weak_Modal } \\
\hline & & Model 1 & $\underline{\text { Model } 2}$ & Model 3 & Model 4 & Model 5 & $\underline{\text { Model } 6}$ & Model 7 & Model 8 \\
\hline Std_Ret & + & $\begin{array}{c}0.0829 * * * \\
(25.80)\end{array}$ & $\begin{array}{c}0.0832 * * * \\
(25.87)\end{array}$ & $\begin{array}{c}0.0837 * * * \\
(26.15)\end{array}$ & $\begin{array}{c}0.0865 * * * \\
(26.92)\end{array}$ & $\begin{array}{c}0.0829 * * * \\
(25.80)\end{array}$ & $\begin{array}{c}0.0844 * * * \\
(26.34)\end{array}$ & $\begin{array}{c}0.0860 * * * \\
(26.92)\end{array}$ & $\begin{array}{c}0.0876 * * * \\
(27.33)\end{array}$ \\
\hline \#Analysts & + & $\begin{array}{c}0.0010 * * * \\
(22.47)\end{array}$ & $\begin{array}{c}0.0010^{* * *} \\
(22.5)\end{array}$ & $\begin{array}{c}0.0010^{* * *} \\
(22.55)\end{array}$ & $\begin{array}{c}0.0010 * * * \\
(23.06)\end{array}$ & $\begin{array}{c}0.0010 * * * \\
(22.47)\end{array}$ & $\begin{array}{c}0.0010^{* * * *} \\
(22.98)\end{array}$ & $\begin{array}{c}0.0010 * * * \\
(23.10)\end{array}$ & $\begin{array}{c}0.0010 * * * \\
(23.62)\end{array}$ \\
\hline Intercept & & $\begin{array}{c}-0.0429 * * * \\
(-4.39)\end{array}$ & $\begin{array}{c}-0.0346 * * * \\
(-3.21)\end{array}$ & $\begin{array}{c}-0.0346 * * * \\
(-3.30)\end{array}$ & $\begin{array}{c}0.0428 * * * \\
(5.37)\end{array}$ & $\begin{array}{c}-0.0429 * * * \\
(-4.39)\end{array}$ & $\begin{array}{c}-0.0280 * * * \\
(-2.85)\end{array}$ & $\begin{array}{c}-0.0282^{* * * *} \\
(-2.93)\end{array}$ & $\begin{array}{c}0.0404 * * * \\
(5.09)\end{array}$ \\
\hline Year/Ind Fixed Effects & & Yes & Yes & Yes & Yes & Yes & Yes & Yes & Yes \\
\hline $\mathrm{n}$ & & 19,003 & 19,003 & 19,003 & 19,003 & 19,003 & 19,003 & 19,003 & 19,003 \\
\hline Adjusted R-Squared & & 0.3302 & 0.3303 & 0.3302 & 0.3264 & 0.3302 & 0.3342 & 0.3333 & 0.3295 \\
\hline
\end{tabular}

The $t$-statistics in parentheses. $*, * *, * * *$ stands for $\mathrm{p}<0.1, \mathrm{p}<0.05, \mathrm{p}<0.01$, respectively, two-tailed t-tests. All continuous variables are winsorized at $1 \%$ and 99\%. Variables are defined in the Appendix 2. 


\section{TABLE 10}

\section{Correlation Matrix for the Association between Analyst Forecast Accuracy and the Use of Uncertain and Weak Modal}

Words in 10-K Filings

\begin{tabular}{|c|c|c|c|c|c|c|c|c|c|c|c|c|c|c|c|}
\hline & 1 & 2 & 3 & 4 & 5 & 6 & 7 & 8 & 9 & 10 & 11 & 12 & 13 & 14 & 15 \\
\hline 1 Accuracy & & $-0.0232 *$ & 0.0133 & $.0738 *$ & $-0.0701 *$ & $0.0585^{*}$ & $-0.2256 *$ & $-0.1020^{*}$ & 0.0084 & $-0.0982 *$ & $0.1238^{*}$ & $-0.0843^{*}$ & $-0.0417^{*}$ & $0.2844 *$ & $-0.1495^{*}$ \\
\hline 2 Uncertain & $-0.0475 *$ & & $0.7313^{*}$ & $-0.3120 *$ & $0.2365^{*}$ & $0.2469 *$ & $-0.1099 *$ & $0.0404 *$ & $-0.1858^{*}$ & -0.0135 & $0.0406^{*}$ & $0.0316^{*}$ & $0.2156^{*}$ & $0.0814 *$ & -0.0158 \\
\hline 3 Weak_Modal & $-0.0259 *$ & $0.7343^{*}$ & & -0.0033 & $0.2171 *$ & $0.4227 *$ & $-0.2296^{*}$ & $0.1006^{*}$ & $-0.3275^{*}$ & $-0.0827 *$ & $0.1214^{*}$ & $0.0436^{*}$ & $0.3645^{*}$ & $0.2348^{*}$ & $-0.0512 *$ \\
\hline 4 File_Size & $0.0804 *$ & $-0.3496^{*}$ & -0.0091 & & $-0.1056^{*}$ & $0.2898 *$ & $0.2623^{*}$ & -0.0132 & $0.1238^{*}$ & $0.1022^{*}$ & -0.0117 & $0.0186^{*}$ & $0.0761 *$ & $-0.0320 *$ & $0.2493 *$ \\
\hline 5 Pos_Tone & $-0.0575^{*}$ & $0.2221 *$ & $0.2488 *$ & $-0.0974 *$ & & $0.0992 *$ & $-0.0268 *$ & -0.0003 & $-0.0874 *$ & $-0.0643 *$ & $-0.0224 *$ & $0.0324 *$ & $0.4192 *$ & $0.0426^{*}$ & $-0.0360 *$ \\
\hline 6 Neg_Tone & $0.0515 *$ & $0.2496^{*}$ & $0.4330 *$ & $0.2950 *$ & $0.0694 *$ & & $-0.1137 *$ & $-0.0687 *$ & $-0.1177 *$ & $-0.0342 *$ & $0.0914^{*}$ & $0.0736^{*}$ & $0.3215^{*}$ & $0.1939 *$ & 0.0112 \\
\hline 7 Firm_Size & $-0.1589 *$ & $-0.1032 *$ & $-0.2157 *$ & $0.2588 *$ & $-0.0185^{*}$ & $-0.0873 *$ & & $0.0332 *$ & $0.2721 *$ & $0.3869^{*}$ & $-0.2556^{*}$ & $0.0350 *$ & $-0.0784 *$ & $-0.5166^{*}$ & $0.7044^{*}$ \\
\hline 8 Growth & -0.0056 & $0.0407 *$ & $0.1337 *$ & $0.0187 *$ & $0.0727 *$ & 0.0043 & $-0.0452 *$ & & $-0.1222 *$ & $0.0227 *$ & $0.0278^{*}$ & 0.0124 & $0.0708^{*}$ & $0.0608 *$ & -0.0131 \\
\hline 9 Segments & 0.0001 & $-0.1853^{*}$ & $-0.3272 *$ & $0.1274 *$ & $-0.0960 *$ & $-0.1109 *$ & $0.2818^{*}$ & $-0.1252 *$ & & $0.0914^{*}$ & $-0.1172 *$ & $-0.0537 *$ & $-0.1952 *$ & $-0.2381 *$ & $0.0968 *$ \\
\hline $10 \%$ Inst & $-0.1285^{*}$ & -0.0134 & $-0.0978 *$ & $0.1058 *$ & $-0.0657 *$ & $-0.0371 *$ & $0.3963^{*}$ & $-0.0712 *$ & $0.1103^{*}$ & & $-0.1310^{*}$ & 0.0065 & $-0.1140^{*}$ & $-0.2573^{*}$ & $0.3539 *$ \\
\hline 11 10K_News & $0.0882 *$ & $0.0380 *$ & $0.1119 *$ & -0.0149 & 0.0039 & $0.0854 *$ & $-0.2396^{*}$ & $0.0588 *$ & $-0.0999 *$ & $-0.1606^{*}$ & & $-0.0218 *$ & $0.0494 *$ & $0.3724 *$ & $-0.1642 *$ \\
\hline $12 A d v$ & -0.0129 & $0.0239 *$ & $0.0548 *$ & $0.0387 *$ & 0.0045 & $0.0626^{*}$ & $0.0630^{*}$ & $0.0208 *$ & $-0.0330 *$ & $-0.0205^{*}$ & 0.0069 & & -0.0005 & $-0.0395^{*}$ & $0.0640 *$ \\
\hline $13 R \& D$ & -0.0076 & $0.1748 *$ & $0.4135^{*}$ & $0.0946^{*}$ & $0.4515^{*}$ & $0.2317^{*}$ & $-0.1270 *$ & $0.2068 *$ & $-0.2900 *$ & $-0.1522 *$ & $0.0947 *$ & $-0.0753^{*}$ & & $0.2063^{*}$ & $-0.0197 *$ \\
\hline 14 Std_Ret & $0.1989 *$ & $0.0445^{*}$ & $0.1866^{*}$ & $-0.0311 *$ & $0.0709 *$ & $0.1626^{*}$ & $-0.4507 *$ & $0.1489 *$ & $-0.2136^{*}$ & $-0.3212 *$ & $0.3846^{*}$ & -0.0014 & $0.2662 *$ & & $-0.3106^{*}$ \\
\hline 15 \#Analysts & $-0.0686^{*}$ & $-0.0193^{*}$ & $-0.0459^{*}$ & $0.2291 *$ & $-0.0492 *$ & $0.0215^{*}$ & $0.7081^{*}$ & $-0.0612 *$ & $0.0967^{*}$ & $0.2961^{*}$ & $-0.1487^{*}$ & $0.0712 *$ & $-0.0477 *$ & $-0.2607 *$ & \\
\hline
\end{tabular}

This table reports the Pearson (below the diagonal) and Spearman (above the diagonal) correlation coefficients for the variables used in the regression analysis.
$*$ stands for $\mathrm{p}<0.05$ two-tailed t-tests. All continuous variables are winsorized at $1 \%$ and $99 \%$. All variables are defined in Appendix 2 . 


\section{TABLE 11}

Multivariate Analysis for the Association between Analyst Forecast Accuracy and the Use of Uncertain and Weak Modal Words in 10-K Filings

DV:Accuracy
$\frac{\text { IV }}{\text { Uncertain }}$
Weak_Modal
File_Size
Pos_Tone
Neg_Tone
Firm_Size
Growth
Segments
IOK_Nowst

\begin{tabular}{|c|c|c|c|c|}
\hline \multirow[b]{2}{*}{ Prediction } & \multicolumn{4}{|c|}{ Uncertain } \\
\hline & Model 1 & Model 2 & Model 3 & Model 4 \\
\hline$?$ & & $\begin{array}{c}-1.2960 * * \\
(-2.22)\end{array}$ & $\begin{array}{c}-1.0987 * * \\
(-1.98)\end{array}$ & $\begin{array}{c}-3.6533 * * * \\
(-7.49)\end{array}$ \\
\hline$?$ & & & & \\
\hline+ & $\begin{array}{c}0.0324 * * * \\
(10.27)\end{array}$ & $\begin{array}{c}0.0278^{* * * *} \\
(7.36)\end{array}$ & $\begin{array}{c}0.0312 * * * \\
(8.98)\end{array}$ & \\
\hline+ & $\begin{array}{c}-1.9465 * * \\
(-2.28)\end{array}$ & $\begin{array}{c}-1.7223^{* *} \\
(-2.00)\end{array}$ & & $\begin{array}{c}-2.1091 * * \\
(-2.45)\end{array}$ \\
\hline+ & $\begin{array}{c}0.5120 \\
(1.29)\end{array}$ & $\begin{array}{c}0.7807 * \\
(1.89)\end{array}$ & & $\begin{array}{c}1.9494 * * * \\
(5.09)\end{array}$ \\
\hline- & $\begin{array}{c}-0.0170 * * * \\
(-13.26)\end{array}$ & $\begin{array}{c}-0.0169 * * * \\
(-13.20)\end{array}$ & $\begin{array}{c}-0.0174 * * * \\
(-13.71)\end{array}$ & $\begin{array}{c}-0.0155 * * * \\
(-12.24)\end{array}$ \\
\hline- & $\begin{array}{c}-0.0056^{* *} \\
(-2.19)\end{array}$ & $\begin{array}{c}-0.0052^{* *} \\
(-2.05)\end{array}$ & $\begin{array}{c}-0.0054 * * \\
(-2.12)\end{array}$ & $\begin{array}{c}-0.0043^{*} \\
(-1.69)\end{array}$ \\
\hline+ & $\begin{array}{c}0.0126 * * * \\
(3.98)\end{array}$ & $\begin{array}{c}0.0122 * * * \\
(3.86)\end{array}$ & $\begin{array}{c}0.0120 * * * \\
(3.78)\end{array}$ & $\begin{array}{c}0.0141 * * * \\
(4.46)\end{array}$ \\
\hline- & $\begin{array}{c}-0.0440 * * * \\
(-7.26)\end{array}$ & $\begin{array}{c}-0.0432 * * * \\
(-7.12)\end{array}$ & $\begin{array}{c}-0.0426 * * * \\
(-7.02)\end{array}$ & $\begin{array}{c}-0.0414 * * * \\
(-6.80)\end{array}$ \\
\hline+ & $\begin{array}{c}0.0186 \\
(0.52)\end{array}$ & $\begin{array}{c}0.0205 \\
(0.57)\end{array}$ & $\begin{array}{c}0.0231 \\
(0.65)\end{array}$ & $\begin{array}{c}0.0261 \\
(0.73)\end{array}$ \\
\hline+ & $\begin{array}{l}-0.0305 \\
(-0.77)\end{array}$ & $\begin{array}{c}-0.0258 \\
(-0.65)\end{array}$ & $\begin{array}{l}-0.0217 \\
(-0.55)\end{array}$ & $\begin{array}{c}-0.0123 \\
(-0.31)\end{array}$ \\
\hline- & $\begin{array}{c}-0.0459 * * * \\
(-4.88)\end{array}$ & $\begin{array}{c}-0.0438 * * * \\
(-4.64)\end{array}$ & $\begin{array}{c}-0.0486 * * * \\
(-5.35)\end{array}$ & $\begin{array}{c}-0.0354 * * * \\
(-3.77)\end{array}$ \\
\hline
\end{tabular}

\begin{tabular}{cccc}
\multicolumn{4}{c}{ Weak_Modal } \\
\cline { 1 - 3 } & $\underline{\text { Model 6 }}$ & $\underline{\text { Model 7 }}$ & Model 8 \\
& & & \\
& & & \\
$0.0324 * * *$ & $0.0272 * * *$ & $0.0321 * * *$ & \\
$(10.27)$ & $(8.51)$ & $(10.7)$ & \\
$-1.9465 * *$ & -1.2415 & & $-2.1892 * *$ \\
$(-2.28)$ & $(-1.45)$ & & $(-2.57)$ \\
0.5120 & $1.6509 * * *$ & & $2.7824 * * *$ \\
$(1.29)$ & $(3.96)$ & & $(7.03)$ \\
$-0.0170 * * *$ & $-0.0183 * * *$ & $-0.0188 * * *$ & $-0.0168 * * *$ \\
$(-13.26)$ & $(-14.22)$ & $(-14.72)$ & $(-13.18)$ \\
$-0.0056 * *$ & -0.0035 & -0.0041 & -0.0027 \\
$(-2.19)$ & $(-1.38)$ & $(-1.60)$ & $(-1.06)$ \\
$0.0126 * * *$ & $0.0084 * * *$ & $0.0084 * * *$ & $0.0111 * * *$ \\
$(3.98)$ & $(2.63)$ & $(2.61)$ & $(3.47)$ \\
$-0.0440 * * *$ & $-0.0417 * * *$ & $-0.0411 * * *$ & $-0.0407 * * *$ \\
$(-7.26)$ & $(-6.89)$ & $(-6.78)$ & $(-6.70)$ \\
0.0186 & 0.0280 & 0.0313 & 0.0326 \\
$(0.52)$ & $(0.78)$ & $(0.87)$ & $(0.91)$ \\
-0.0305 & -0.0056 & 0.0020 & 0.0057 \\
$(-0.77)$ & $(-0.14)$ & $(0.05)$ & $(0.14)$ \\
$-0.0459 * * *$ & $-0.0258 * * *$ & $-0.0303 * * *$ & -0.0158 \\
$(-4.88)$ & $(-2.67)$ & $(-3.24)$ & $(-1.64)$ \\
& & &
\end{tabular}


TABLE 11 (Continued)

\begin{tabular}{|c|c|c|c|c|c|c|c|c|c|}
\hline \multirow{2}{*}{$\begin{array}{l}\text { DV: Accuracy } \\
\underline{\text { IV }}\end{array}$} & \multirow[b]{2}{*}{ Prediction } & \multicolumn{4}{|c|}{ Uncertain } & \multicolumn{4}{|c|}{ Weak_Modal } \\
\hline & & Model 1 & Model 2 & Model 3 & $\underline{\text { Model } 4}$ & Model 5 & Model 6 & Model 7 & Model 8 \\
\hline Std_Ret & + & $\begin{array}{c}0.3427 * * * \\
(15.79)\end{array}$ & $\begin{array}{c}0.3459 * * * \\
(15.91)\end{array}$ & $\begin{array}{c}0.3493 * * * \\
(16.13)\end{array}$ & $\begin{array}{c}0.3602 * * * \\
(16.6)\end{array}$ & $\begin{array}{c}0.3427 * * * \\
(15.79)\end{array}$ & $\begin{array}{c}0.3539 * * * \\
(16.32)\end{array}$ & $\begin{array}{c}0.3615 * * * \\
(16.73)\end{array}$ & $\begin{array}{c}0.36756 * * * \\
(16.95)\end{array}$ \\
\hline \#Analysts & + & $\begin{array}{c}0.0021 * * * \\
(7.71)\end{array}$ & $\begin{array}{c}0.0021 * * * \\
(7.76)\end{array}$ & $\begin{array}{c}0.0021 * * * \\
(7.98)\end{array}$ & $\begin{array}{c}0.0022 * * * \\
(8.06)\end{array}$ & $\begin{array}{c}0.0021 * * * \\
(7.71)\end{array}$ & $\begin{array}{c}0.0022^{* * *} \\
(8.13)\end{array}$ & $\begin{array}{c}0.0023 * * * \\
(8.41)\end{array}$ & $\begin{array}{c}0.0023 * * * \\
(8.49)\end{array}$ \\
\hline Intercept & & $\begin{array}{c}-0.2776 * * * \\
(-4.34)\end{array}$ & $\begin{array}{c}-0.2125 * * * \\
(-3.02)\end{array}$ & $\begin{array}{c}-0.2571 * * * \\
(-3.76)\end{array}$ & $\begin{array}{c}0.1362 * * * \\
\quad(2.62)\end{array}$ & $\begin{array}{c}-0.2776 * * * \\
(-4.34)\end{array}$ & $\begin{array}{c}-0.2003 * * * \\
(-3.11)\end{array}$ & $\begin{array}{c}-0.2500 * * * \\
(-3.97)\end{array}$ & $\begin{array}{l}0.1261 * * \\
(2.43)\end{array}$ \\
\hline Year/Ind Fixed Effects & & Yes & Yes & Yes & Yes & Yes & Yes & Yes & Yes \\
\hline $\mathrm{n}$ & & 15,213 & 15,213 & 15,213 & 15,213 & 15,213 & 15,213 & 15,213 & 15,213 \\
\hline Adjusted R-Squared & & 0.0958 & 0.0961 & 0.0957 & 0.0929 & 0.0958 & 0.1002 & 0.0992 & 0.0959 \\
\hline
\end{tabular}

The $t$-statistics in parentheses. $* * *, * * *$ stands for $\mathrm{p}<0.1, \mathrm{p}<0.05, \mathrm{p}<0.01$, respectively, two-tailed t-tests. All continuous variables are winsorized at $1 \%$ and 99\%. Variables are defined in the Appendix 2. 


\section{TABLE 12}

\section{Correlation Matrix for the Association between Uncertainty in Analysts' Overall Information Environment and the Use of} Uncertain and Weak Modal Words in 10-K Filings

\begin{tabular}{|c|c|c|c|c|c|c|c|c|c|c|c|c|c|c|c|}
\hline \multirow{2}{*}{\multicolumn{2}{|c|}{1 Uncertainty_Overall }} & 2 & 3 & 4 & 5 & 6 & 7 & 8 & 9 & 10 & 11 & 12 & 13 & 14 & 15 \\
\hline & & .0153 & $0.0950 *$ & $0.1251 *$ & $-0.0686^{*}$ & $1224 *$ & $-0.3314^{*}$ & $-0.1472 *$ & $-0.0583 *$ & $-0.1538^{*}$ & $0.1940^{*}$ & $-0.1216^{*}$ & .0075 & $0.4098 *$ & $.1563^{*}$ \\
\hline 2 Uncertain & $-0.0430 *$ & & $0.7303^{*}$ & $-0.3266^{*}$ & $0.2354 *$ & $0.2462 *$ & $-0.1294 *$ & $0.0416^{*}$ & $-0.1905^{*}$ & $-0.0184^{*}$ & $0.0436^{*}$ & $0.0301^{*}$ & $0.2134 *$ & $0.0872 *$ & $-0.0363^{*}$ \\
\hline 3 Weak_Modal & -0.0072 & $0.7331 *$ & & $-0.0171 *$ & $0.2141 *$ & $0.4200 *$ & $-0.2570 *$ & $0.1042 *$ & $-0.3328 *$ & $-0.0862 *$ & $0.1248 *$ & $0.0436 *$ & $0.3616^{*}$ & $0.2431 *$ & $-0.0746^{*}$ \\
\hline 4 File_Size & $0.1048^{*}$ & $-0.3648 *$ & $-0.0223 *$ & & $-0.1102 *$ & $0.2801 *$ & $0.2426^{*}$ & -0.0136 & $0.1219^{*}$ & $0.0730 *$ & -0.0047 & $0.0169 *$ & $0.0786^{*}$ & $-0.0217 *$ & $0.2243^{*}$ \\
\hline 5 Pos_Tone & $-0.0566^{*}$ & $0.2201 *$ & $0.2464 *$ & $-0.1020 *$ & & $0.0987^{*}$ & $-0.0275^{*}$ & 0.0002 & $-0.0825 *$ & $-0.0664^{*}$ & $-0.0265^{*}$ & $0.0333^{*}$ & $0.4176^{*}$ & $0.0360 *$ & $-0.0455^{*}$ \\
\hline 6 Neg_Tone & $0.0655^{*}$ & $0.2494 *$ & $0.4303 *$ & $0.2850 *$ & $0.0686 *$ & & $-0.1333 *$ & $-0.0673 *$ & $-0.1233 *$ & $-0.0440 *$ & $0.0965^{*}$ & $0.0754 *$ & $0.3241 *$ & $0.2023 *$ & -0.0066 \\
\hline 7 Firm_Size & $-0.1827 *$ & $-0.1212 *$ & $-0.2411 *$ & $0.2384 *$ & $-0.0199 *$ & $-0.1042 *$ & & $0.0257 *$ & $0.2774 *$ & $0.3286^{*}$ & $-0.2486^{*}$ & $0.0301 *$ & $-0.0806^{*}$ & $-0.5209 *$ & $0.6855^{*}$ \\
\hline 8 Growth & -0.0008 & $0.0439 *$ & $0.1397 *$ & $0.0179 *$ & $0.0784 *$ & 0.0044 & $-0.0517 *$ & & $-0.1258 *$ & $0.0237 *$ & $0.0295^{*}$ & 0.0151 & $0.0715 *$ & $0.0592 *$ & $-0.0218 *$ \\
\hline 9 Segments & -0.0105 & $-0.1895^{*}$ & $-0.3326 *$ & $0.1244^{*}$ & $-0.0928 *$ & $-0.1171 *$ & $0.2860 *$ & $-0.1269 *$ & & $0.0777^{*}$ & $-0.1154 *$ & $-0.0585^{*}$ & $-0.1910 *$ & $-0.2363^{*}$ & $0.0968 *$ \\
\hline $0 \%$ Inst & $-0.1378 *$ & $-0.0182 *$ & $-0.1045^{*}$ & $0.0739^{*}$ & $-0.0682 *$ & $-0.0472 *$ & $0.3390 *$ & $-0.0745^{*}$ & $0.0974 *$ & & $-0.1113^{*}$ & 0.0032 & $-0.1144 *$ & $-0.2331 *$ & $0.2941^{*}$ \\
\hline 11 10K_News & $0.1078 *$ & $0.0421 *$ & $0.1149 *$ & -0.0118 & 0.0015 & $0.0907^{*}$ & $-0.2349 *$ & $0.0618 *$ & $-0.0975^{*}$ & $-0.1462 *$ & & $-0.0216^{*}$ & $0.0464 *$ & $0.3706^{*}$ & $-0.1489^{*}$ \\
\hline $12 A d v$ & -0.0114 & $0.0231 *$ & $0.0538^{*}$ & $0.0378^{*}$ & 0.0048 & $0.0636^{*}$ & $0.0612 *$ & $0.0239 *$ & $-0.0339 *$ & $-0.0240^{*}$ & 0.0024 & & 0.0042 & $-0.0371 *$ & $0.0553^{*}$ \\
\hline $13 R \& D$ & 0.0125 & $0.1726 *$ & $0.4133 *$ & $0.0982 *$ & $0.4509 *$ & $0.2342 *$ & $-0.1321 *$ & $0.2083 *$ & $-0.2895 *$ & $-0.1504 *$ & $0.0943 *$ & $-0.0726^{*}$ & & $0.2028 *$ & $-0.0272 *$ \\
\hline 14 Std_Ret & $0.2364 *$ & $0.0479 *$ & $0.1938^{*}$ & $-0.0190 *$ & $0.0651 *$ & $0.1717^{*}$ & $-0.4564 *$ & $0.1509^{*}$ & $-0.2120 *$ & $-0.3046^{*}$ & $0.3863^{*}$ & -0.003 & $0.2634^{*}$ & & $-0.3037 *$ \\
\hline 15 \#Analysts & $-0.0620 *$ & $-0.0335 *$ & $-0.0613 *$ & $0.2087 *$ & $-0.0569 *$ & 0.0109 & $0.6940 *$ & $-0.0664 *$ & $0.0945^{*}$ & $0.2442 *$ & $-0.1380 *$ & $0.0690 *$ & $-0.0503 *$ & $-0.2519 *$ & \\
\hline
\end{tabular}

\footnotetext{
This table reports the Pearson (below the diagonal) and Spearman (above the diagonal) correlation coefficients for the variables used in the regression analysis.

* stands for $\mathrm{p}<0.05$ two-tailed t-tests. All continuous variables are winsorized at $1 \%$ and $99 \%$. All variables are defined in Appendix 2 .
} 


\section{TABLE 13}

Multivariate Analysis for the Association between Uncertainty in Analysts' Overall Information Environment and the Use of Uncertain and Weak Modal Words in 10-K Filings

\begin{tabular}{|c|c|c|c|c|c|c|c|c|c|}
\hline \multicolumn{2}{|c|}{ DV: Uncertainty_Overall } & \multicolumn{4}{|c|}{ Uncertain } & \multicolumn{4}{|c|}{ Weak_Modal } \\
\hline$\underline{\text { IV }}$ & Prediction & Model 1 & Model 2 & $\underline{\text { Model } 3}$ & $\underline{\text { Model } 4}$ & Model 5 & Model 6 & Model 7 & $\underline{\text { Model } 8}$ \\
\hline Uncertain & + & & $\begin{array}{c}-0.9548 * \\
(-1.78)\end{array}$ & $\begin{array}{l}-0.8239 \\
(-1.61)\end{array}$ & $\begin{array}{c}-3.5870 * * * \\
(-8.04)\end{array}$ & & & & \\
\hline Weak_Modal & + & & & & & & $\begin{array}{c}-7.1363 * * * \\
(-8.46)\end{array}$ & $\begin{array}{c}-6.2906 * * * \\
(-7.86)\end{array}$ & $\begin{array}{c}-8.7673 * * * \\
(-10.55)\end{array}$ \\
\hline File_Size & + & $\begin{array}{c}0.0340 * * * \\
(11.82)\end{array}$ & $\begin{array}{c}0.0306^{* * * *} \\
(8.82)\end{array}$ & $\begin{array}{c}0.0332 * * * \\
(10.36)\end{array}$ & & $\begin{array}{c}0.0340 * * * \\
(11.82)\end{array}$ & $\begin{array}{c}0.0292 \\
(9.99)\end{array}$ & $\begin{array}{c}0.0332 * * * \\
(12.08)\end{array}$ & \\
\hline Pos_Tone & - & $\begin{array}{c}-1.6522 * * \\
(-2.12)\end{array}$ & $\begin{array}{c}-1.4938 * \\
(-1.90)\end{array}$ & & $\begin{array}{c}-1.9572 * * \\
(-2.49)\end{array}$ & $\begin{array}{c}-1.6522 * * \\
(-2.12)\end{array}$ & $\begin{array}{c}-1.0359 \\
(-1.32)\end{array}$ & & $\begin{array}{c}-2.0954 * * * \\
(-2.69)\end{array}$ \\
\hline Neg_Tone & + & $\begin{array}{c}0.3846 \\
(1.06)\end{array}$ & $\begin{array}{c}0.5780 \\
(1.52)\end{array}$ & & $\begin{array}{c}1.8250 * * * \\
(5.17)\end{array}$ & $\begin{array}{c}0.3846 \\
(1.06)\end{array}$ & $\begin{array}{c}1.3795 * * * \\
(3.62)\end{array}$ & & $\begin{array}{c}2.5590 * * * \\
(7.04)\end{array}$ \\
\hline Firm_Size & - & $\begin{array}{c}-0.0197 * * * \\
(-16.7)\end{array}$ & $\begin{array}{c}-0.0196 * * * \\
(-16.67)\end{array}$ & $\begin{array}{c}-0.0200 * * * \\
(-17.17)\end{array}$ & $\begin{array}{c}-0.0182 * * * \\
(-15.54)\end{array}$ & $\begin{array}{c}-0.0197 * * * \\
(-16.7)\end{array}$ & $\begin{array}{c}-0.0210 * * * \\
(-17.71)\end{array}$ & $\begin{array}{c}-0.0214 * * * \\
(-18.20)\end{array}$ & $\begin{array}{c}-0.0195 * * * \\
(-16.51)\end{array}$ \\
\hline Growth & - & $\begin{array}{c}-0.0052 * * \\
(-2.17)\end{array}$ & $\begin{array}{c}-0.0050 * * \\
(-2.05)\end{array}$ & $\begin{array}{c}-0.0051 * * \\
(-2.12)\end{array}$ & $\begin{array}{c}-0.0038 \\
(-1.58)\end{array}$ & $\begin{array}{c}-0.0052 * * \\
(-2.17)\end{array}$ & $\begin{array}{c}-0.0032 \\
(-1.31)\end{array}$ & $\begin{array}{l}-0.0037 \\
(-1.53)\end{array}$ & $\begin{array}{c}-0.0022 \\
(-0.91)\end{array}$ \\
\hline Segments & + & $\begin{array}{c}0.0113 * * * \\
(3.91)\end{array}$ & $\begin{array}{c}0.0110 * * * \\
(3.81)\end{array}$ & $\begin{array}{c}0.0108 * * * \\
(3.74)\end{array}$ & $\begin{array}{c}0.0130 * * * \\
(4.51)\end{array}$ & $\begin{array}{c}0.0113 * * * \\
(3.91)\end{array}$ & $\begin{array}{c}0.0076 * * * \\
(2.59)\end{array}$ & $\begin{array}{c}0.0075 * * \\
(2.56)\end{array}$ & $\begin{array}{c}0.0104 * * * \\
(3.59)\end{array}$ \\
\hline$\% \_I n s t$ & - & $\begin{array}{c}-0.0403 * * * \\
(-7.10)\end{array}$ & $\begin{array}{c}-0.0398 * * * \\
(-7.01)\end{array}$ & $\begin{array}{c}-0.0393 * * * \\
(-6.92)\end{array}$ & $\begin{array}{c}-0.0384 * * * \\
(-6.74)\end{array}$ & $\begin{array}{c}-0.0403 * * * \\
(-7.10)\end{array}$ & $\begin{array}{c}-0.0388 * * * \\
(-6.84)\end{array}$ & $\begin{array}{c}-0.0382 * * * \\
(-6.75)\end{array}$ & $\begin{array}{c}-0.0382 * * * \\
(-6.72)\end{array}$ \\
\hline $10 K \_N e w s$ & + & $\begin{array}{c}0.0335 \\
(1.00)\end{array}$ & $\begin{array}{c}0.0351 \\
(1.05)\end{array}$ & $\begin{array}{c}0.0375 \\
(1.12)\end{array}$ & $\begin{array}{c}0.0405 \\
(1.21)\end{array}$ & $\begin{array}{c}0.0335 \\
(1.00)\end{array}$ & $\begin{array}{c}0.0422 \\
(1.26)\end{array}$ & $\begin{array}{c}0.0455 \\
(1.36)\end{array}$ & $\begin{array}{c}0.0454 \\
(1.36)\end{array}$ \\
\hline$A d v$ & + & $\begin{array}{c}0.0050 \\
(0.14)\end{array}$ & $\begin{array}{c}0.0085 \\
(0.23)\end{array}$ & $\begin{array}{c}0.0118 \\
(0.33)\end{array}$ & $\begin{array}{c}0.0241 \\
(0.66)\end{array}$ & $\begin{array}{c}0.0050 \\
(0.14)\end{array}$ & $\begin{array}{c}0.0266 \\
(0.73)\end{array}$ & $\begin{array}{c}0.0336 \\
(0.93)\end{array}$ & $\begin{array}{c}0.0394 \\
(1.08)\end{array}$ \\
\hline$R \& D$ & - & $\begin{array}{c}-0.0394 * * * \\
(-4.56)\end{array}$ & $\begin{array}{c}-0.0379 * * * \\
(-4.38)\end{array}$ & $\begin{array}{c}-0.0421 * * * \\
(-5.05)\end{array}$ & $\begin{array}{c}-0.0286 * * * \\
(-3.32)\end{array}$ & $\begin{array}{c}-0.0394 * * * \\
(-4.56)\end{array}$ & $\begin{array}{c}-0.0213 * * \\
(-2.41)\end{array}$ & $\begin{array}{c}-0.0251 * * * \\
(-2.93)\end{array}$ & $\begin{array}{l}-0.0102 \\
(-1.15)\end{array}$ \\
\hline
\end{tabular}


TABLE 13 (Continued)

\begin{tabular}{|c|c|c|c|c|c|c|c|c|c|}
\hline \multicolumn{2}{|c|}{ DV: Uncertainty_Overall } & \multicolumn{4}{|c|}{ Uncertain } & \multicolumn{4}{|c|}{ Weak_Modal } \\
\hline IV & Prediction & Model 1 & Model 2 & Model 3 & Model 4 & Model 5 & Model 6 & Model 7 & Model 8 \\
\hline Std_Ret & + & $\begin{array}{c}0.3636 * * * \\
(17.58)\end{array}$ & $\begin{array}{c}0.3661 * * * \\
(17.66)\end{array}$ & $\begin{array}{c}0.3687 * * * \\
(17.87)\end{array}$ & $\begin{array}{c}0.3832 * * * \\
(18.52)\end{array}$ & $\begin{array}{c}0.3636 * * * \\
(17.58)\end{array}$ & $\begin{array}{c}0.3739 * * * \\
(18.09)\end{array}$ & $\begin{array}{c}0.3808 * * * \\
(18.50)\end{array}$ & $\begin{array}{c}0.3900 * * * \\
(18.86)\end{array}$ \\
\hline \#Analysts & + & $\begin{array}{c}0.0026 * * * \\
(10.59)\end{array}$ & $\begin{array}{c}0.0026 * * * \\
(10.62)\end{array}$ & $\begin{array}{c}0.0026 * * * \\
(10.84)\end{array}$ & $\begin{array}{c}0.0027 * * * \\
(10.90)\end{array}$ & $\begin{array}{c}0.0026 * * * \\
(10.59)\end{array}$ & $\begin{array}{c}0.0027 * * * \\
(11.02)\end{array}$ & $\begin{array}{c}0.0028 * * * \\
(11.3)\end{array}$ & $\begin{array}{c}0.0028 * * * \\
(11.37)\end{array}$ \\
\hline Intercept & & $\begin{array}{c}-0.2703 * * * \\
(-4.54)\end{array}$ & $\begin{array}{c}-0.2212 * * * \\
(-3.37)\end{array}$ & $\begin{array}{c}-0.2565 * * * \\
(-4.01)\end{array}$ & $\begin{array}{c}0.1666^{* * * *} \\
(3.41)\end{array}$ & $\begin{array}{c}-0.2703 * * * \\
(-4.54)\end{array}$ & $\begin{array}{c}-0.1972 * * * \\
(-3.28)\end{array}$ & $\begin{array}{c}-0.2375 * * * \\
(-4.04)\end{array}$ & $\begin{array}{c}0.1565 * * * \\
(3.22)\end{array}$ \\
\hline Year/Ind Fixed Effects & & Yes & Yes & Yes & Yes & Yes & Yes & Yes & Yes \\
\hline $\mathrm{n}$ & & 14,308 & 14,308 & 14,308 & 14,308 & 14,308 & 14,308 & 14,308 & 14,308 \\
\hline Adjusted R-Squared & & 0.1312 & 0.1313 & 0.1311 & 0.1266 & 0.1312 & 0.1355 & 0.1347 & 0.1295 \\
\hline
\end{tabular}

The $t$-statistics in parentheses. $* * *, * * *$ stands for $\mathrm{p}<0.1, \mathrm{p}<0.05, \mathrm{p}<0.01$, respectively, two-tailed t-tests. All continuous variables are winsorized at $1 \%$ and 99\%. Variables are defined in the Appendix 2. 


\section{TABLE 14}

\section{Correlation Matrix for the Association between Uncertainty in Analysts' Common Information Environment and the Use} of Uncertain and Weak Modal Words in 10-K Filings

\begin{tabular}{|c|c|c|c|c|c|c|c|c|c|c|c|c|c|c|c|}
\hline & 1 & 2 & 3 & 4 & 5 & 6 & 7 & 8 & 9 & 10 & 11 & 12 & 13 & 14 & 15 \\
\hline 1 Uncertainty_Common & & $-0.0726 *$ & $-0.0959 *$ & $0.0574 *$ & $-0.0675 *$ & $-0.0253 *$ & $0.0943 *$ & $-0.0287 *$ & $0.0818^{*}$ & $0.0950 *$ & $-0.0207 *$ & 0.004 & $-0.0991 *$ & $0.0239 *$ & $.1107 *$ \\
\hline 2 Uncertain & $-0.0704 *$ & & $0.7302 *$ & $-0.3267 *$ & $0.2354 *$ & $0.2459 *$ & $-0.1292 *$ & $0.0415 *$ & $-0.1904 *$ & $-0.0184 *$ & $0.0438 *$ & $0.0299 *$ & $0.2135^{*}$ & $0.0870 *$ & $-0.0360 *$ \\
\hline 3 Weak_Modal & $-0.0947 *$ & $0.7330^{*}$ & & $-0.0172 *$ & $0.2142 *$ & $0.4198 *$ & $-0.2568 *$ & $0.1041 *$ & $-0.3327 *$ & $-0.0862 *$ & $0.1250 *$ & $0.0435^{*}$ & $0.3617^{*}$ & $0.2429 *$ & $-0.0743 *$ \\
\hline 4 File_Size & $0.0600 *$ & $-0.3649 *$ & $-0.0223 *$ & & $-0.1100 *$ & $0.2801 *$ & $0.2427 *$ & -0.0135 & $0.1219 *$ & $0.0728 *$ & -0.0048 & $0.0169 *$ & $0.0787 *$ & $-0.0217 *$ & $0.2244 *$ \\
\hline 5 Pos_Tone & $-0.0710^{*}$ & $0.2202 *$ & $0.2465^{*}$ & $-0.1019 *$ & & $0.0988^{*}$ & $-0.0275^{*}$ & 0.0002 & $-0.0826 *$ & $-0.0663 *$ & $-0.0264 *$ & $0.0334 *$ & $0.4176^{*}$ & $0.0361^{*}$ & $-0.0456 *$ \\
\hline $6 \mathrm{Neg}_{-}$ & $-0.0181 *$ & $0.2491 *$ & $0.4301 *$ & $0.2850 *$ & $0.0687 *$ & & $-0.1330 *$ & $-0.0674 *$ & $-0.1232 *$ & $-0.0440 *$ & $0.0967 *$ & $0.0753^{*}$ & $0.3242 *$ & $0.2020 *$ & -0.0062 \\
\hline 7 Firm_Size & $0.0942 *$ & $-0.1210 *$ & $-0.2409 *$ & $0.2385^{*}$ & $-0.0200 *$ & $-0.1039 *$ & & $0.0258 *$ & $0.2773^{*}$ & $0.3287^{*}$ & $-0.2488^{*}$ & $0.0303 *$ & $-0.0806^{*}$ & $-0.5208 *$ & $0.6854 *$ \\
\hline 8 Growth & -0.0081 & $0.0439 *$ & $0.1396^{*}$ & $0.0179 *$ & $0.0784 *$ & 0.0043 & $-0.0517 *$ & & $-0.1257 *$ & $0.0238 *$ & $0.0297 *$ & 0.0151 & $0.0715^{*}$ & $0.0591^{*}$ & $-0.0217 *$ \\
\hline $9 \mathrm{Seg}$ & $0.0810^{*}$ & $-0.1894 *$ & $-0.3325^{*}$ & $0.1244^{*}$ & $-0.0928 *$ & $-0.1169 *$ & $0.2859 *$ & $-0.1269 *$ & & $0.0776 *$ & $-0.1155^{*}$ & $-0.0584 *$ & $-0.1910 *$ & $-0.2362 *$ & $0.0967 *$ \\
\hline $10 \%$ _Inst & 0.1093* & $-0.0182 *$ & $-0.1045^{*}$ & $0.0738 *$ & $-0.0681 *$ & $-0.0472 *$ & $0.3391 *$ & $-0.0745^{*}$ & $0.0974 *$ & & $-0.1114 *$ & 0.0032 & $-0.1144 *$ & $-0.2331^{*}$ & $0.2942 *$ \\
\hline $10 K \_N e w s$ & $-0.0184 *$ & $0.0422 *$ & $0.1150 *$ & -0.0119 & 0.0015 & $0.0908 *$ & $-0.2349 *$ & $0.0618^{*}$ & $-0.0975 *$ & $-0.1463 *$ & & $-0.0216^{*}$ & $0.0464 *$ & $0.3708^{*}$ & $-0.1491 *$ \\
\hline $12 A d v$ & 0.0068 & $0.0231 *$ & $0.0538^{*}$ & $0.0378^{*}$ & 0.0049 & $0.0636^{*}$ & $0.0612 *$ & $0.0239 *$ & $-0.0339 *$ & $-0.0241^{*}$ & 0.0023 & & 0.0042 & $-0.0372 *$ & $0.0555^{*}$ \\
\hline $13 R \& D$ & $-0.1151 *$ & $0.1726^{*}$ & $0.4134 *$ & $0.0982 *$ & $0.4509 *$ & $0.2342 *$ & $-0.1321 *$ & $0.2083^{*}$ & $-0.2895^{*}$ & $-0.1504 *$ & $0.0942 *$ & $-0.0726 *$ & & $0.2029 *$ & $-0.0273 *$ \\
\hline 4 & $0.0192 *$ & $0.0478 *$ & $0.1936^{*}$ & $-0.0190 *$ & $0.0652 *$ & $0.1715^{*}$ & $-0.4563^{*}$ & $0.1509^{*}$ & $-0.2119 *$ & $-0.3046^{*}$ & $0.3863^{*}$ & -0.003 & $0.2634^{*}$ & & $-0.3035 *$ \\
\hline 5 \#Analysts & $0.1070 *$ & $-0.0332 *$ & $-0.0610 *$ & $0.2089 *$ & $-0.0570 *$ & 0.0113 & $0.6939 *$ & $-0.0664 *$ & $0.0944 *$ & $0.2444 *$ & $-0.1381 *$ & $0.0690 *$ & $-0.0503 *$ & $-0.2518 *$ & \\
\hline
\end{tabular}

\footnotetext{
This table reports the Pearson (below the diagonal) and Spearman (above the diagonal) correlation coefficients for the variables used in the regression analysis.

* stands for $\mathrm{p}<0.05$ two-tailed t-tests. All continuous variables are winsorized at $1 \%$ and $99 \%$. All variables are defined in Appendix 2 .
} 


\section{TABLE 15}

Multivariate Analysis for the Association between Uncertainty in Analysts' Common Information Environment and the Use of Uncertain and Weak Modal Words in 10-K Filings

\begin{tabular}{|c|c|c|c|c|c|c|c|c|c|}
\hline \multicolumn{2}{|c|}{ DV: Uncertainty_Common } & \multicolumn{4}{|c|}{ Uncertain } & \multicolumn{4}{|c|}{ Weak_Modal } \\
\hline$\underline{\text { IV }}$ & Prediction & Model 1 & Model 2 & $\underline{\text { Model } 3}$ & Model 4 & Model 5 & Model 6 & Model 7 & Model 8 \\
\hline Uncertain & + & & $\begin{array}{c}-1.3166 \\
(-0.78)\end{array}$ & $\begin{array}{c}-1.1622 \\
(-0.72)\end{array}$ & $\begin{array}{c}-5.4532 * * * \\
(-3.87)\end{array}$ & & & & \\
\hline Weak_Modal & + & & & & & & $\begin{array}{c}-6.3455^{* *} \\
(-2.37)\end{array}$ & $\begin{array}{c}-5.5240 * * \\
(-2.18)\end{array}$ & $\begin{array}{c}-9.0535 * * * \\
(-3.44)\end{array}$ \\
\hline File_Size & + & $\begin{array}{c}0.0528 * * * \\
(5.79)\end{array}$ & $\begin{array}{c}0.0480 * * * \\
(4.38)\end{array}$ & $\begin{array}{c}0.0531 * * * \\
(5.24)\end{array}$ & & $\begin{array}{c}0.0528 * * * \\
(5.79)\end{array}$ & $\begin{array}{c}0.0485 * * * \\
(5.23)\end{array}$ & $\begin{array}{c}0.0546 * * * \\
(6.27)\end{array}$ & \\
\hline Pos_Tone & - & $\begin{array}{c}-4.0846^{*} \\
(-1.65)\end{array}$ & $\begin{array}{c}-3.8662 \\
(-1.55)\end{array}$ & & $\begin{array}{c}-4.5927 * \\
(-1.85)\end{array}$ & $\begin{array}{c}-4.0846^{*} \\
(-1.65)\end{array}$ & $\begin{array}{l}-3.5367 \\
(-1.43)\end{array}$ & & $\begin{array}{c}-5.2947 * * \\
(-2.15)\end{array}$ \\
\hline Neg_Tone & + & $\begin{array}{c}0.7664 \\
(0.67)\end{array}$ & $\begin{array}{c}1.0327 \\
(0.86)\end{array}$ & & $\begin{array}{c}2.9909 * * * \\
(2.68)\end{array}$ & $\begin{array}{c}0.7664 \\
(0.67)\end{array}$ & $\begin{array}{c}1.6502 \\
(1.37)\end{array}$ & & $\begin{array}{c}3.6080 * * * \\
(3.14)\end{array}$ \\
\hline Firm_Size & - & $\begin{array}{c}0.0040 \\
(1.07)\end{array}$ & $\begin{array}{c}0.0040 \\
(1.08)\end{array}$ & $\begin{array}{c}0.0032 \\
(0.86)\end{array}$ & $\begin{array}{c}0.0063 * \\
(1.71)\end{array}$ & $\begin{array}{c}0.0040 \\
(1.07)\end{array}$ & $\begin{array}{c}0.0028 \\
(0.75)\end{array}$ & $\begin{array}{c}0.0019 \\
(0.52)\end{array}$ & $\begin{array}{c}0.0053 \\
(1.43)\end{array}$ \\
\hline Growth & - & $\begin{array}{c}0.0120 \\
(1.57)\end{array}$ & $\begin{array}{c}0.0124 \\
(1.62)\end{array}$ & $\begin{array}{c}0.0122 \\
(1.59)\end{array}$ & $\begin{array}{c}0.0142 * \\
(1.85)\end{array}$ & $\begin{array}{c}0.0120 \\
(1.57)\end{array}$ & $\begin{array}{c}0.0139 * \\
(1.8)\end{array}$ & $\begin{array}{c}0.0133^{*} \\
(1.73)\end{array}$ & $\begin{array}{c}0.0154 * * \\
(2.01)\end{array}$ \\
\hline Segments & + & $\begin{array}{c}0.0217 * * \\
(2.38)\end{array}$ & $\begin{array}{c}0.0213 * * \\
(2.33)\end{array}$ & $\begin{array}{c}0.0209 * * \\
(2.29)\end{array}$ & $\begin{array}{c}0.0245^{* * *} \\
(2.69)\end{array}$ & $\begin{array}{c}0.0217 * * \\
(2.38)\end{array}$ & $\begin{array}{c}0.0184 * * \\
(1.99)\end{array}$ & $\begin{array}{c}0.0182 * * \\
(1.97)\end{array}$ & $\begin{array}{c}0.0232 * * \\
(2.52)\end{array}$ \\
\hline$\% \_I n s t$ & + & $\begin{array}{c}0.1767 * * * \\
(9.83)\end{array}$ & $\begin{array}{c}0.1774 * * * \\
(9.86)\end{array}$ & $\begin{array}{c}0.1786 * * * \\
(9.93)\end{array}$ & $\begin{array}{c}0.1796 * * * \\
(9.98)\end{array}$ & $\begin{array}{c}0.1767 * * * \\
(9.83)\end{array}$ & $\begin{array}{c}0.1781 * * * \\
(9.90)\end{array}$ & $\begin{array}{c}0.1794 * * * \\
(9.98)\end{array}$ & $\begin{array}{c}0.1790 * * * \\
(9.94)\end{array}$ \\
\hline 10K_News & + & $\begin{array}{c}-0.2754 * * * \\
(-2.60)\end{array}$ & $\begin{array}{c}-0.2732 * * * \\
(-2.58)\end{array}$ & $\begin{array}{c}-0.2678 * * \\
(-2.53)\end{array}$ & $\begin{array}{c}-0.2647 * * \\
(-2.5)\end{array}$ & $\begin{array}{c}-0.2754 * * * \\
(-2.60)\end{array}$ & $\begin{array}{c}-0.2677 * * \\
(-2.53)\end{array}$ & $\begin{array}{c}-0.2617 * * \\
(-2.47)\end{array}$ & $\begin{array}{c}-0.2622 * * \\
(-2.47)\end{array}$ \\
\hline$A d v$ & + & $\begin{array}{c}0.0253 \\
(0.22)\end{array}$ & $\begin{array}{c}0.0301 \\
(0.26)\end{array}$ & $\begin{array}{c}0.0360 \\
(0.31)\end{array}$ & $\begin{array}{c}0.0545 \\
(0.47)\end{array}$ & $\begin{array}{c}0.0253 \\
(0.22)\end{array}$ & $\begin{array}{c}0.0445 \\
(0.39)\end{array}$ & $\begin{array}{c}0.0528 \\
(0.46)\end{array}$ & $\begin{array}{c}0.0657 \\
(0.57)\end{array}$ \\
\hline$R \& D$ & - & $\begin{array}{c}-0.2476 * * * \\
(-9.07)\end{array}$ & $\begin{array}{c}-0.2456 * * * \\
(-8.95)\end{array}$ & $\begin{array}{c}-0.2566 * * * \\
(-9.73)\end{array}$ & $\begin{array}{c}-0.2310 * * * \\
(-8.48)\end{array}$ & $\begin{array}{c}-0.2476 * * * \\
(-9.07)\end{array}$ & $\begin{array}{c}-0.2316 * * * \\
(-8.23)\end{array}$ & $\begin{array}{c}-0.2427 * * * \\
(-8.93)\end{array}$ & $\begin{array}{c}-0.2131 * * * \\
(-7.63)\end{array}$ \\
\hline
\end{tabular}




\section{TABLE 15 (Continued)}

DV: Uncertainty_Common

IV

Std_Ret

\#Analysts

Intercept

Year/Ind Fixed Effects

Adjusted R-Squared

\section{Uncertain}

$\frac{\text { Prediction }}{+}$

\begin{tabular}{cccc}
\multicolumn{4}{c}{ Uncertain } \\
\hline$\underline{\text { Model 1 }}$ & $\underline{\text { Model 2 }}$ & $\underline{\text { Model 3 }}$ & $\underline{\text { Model 4 }}$ \\
$0.5739 * * *$ & $0.5773 * * *$ & $0.5817 * * *$ & $0.6042^{* * *}$ \\
$(8.77)$ & $(8.80)$ & $(8.91)$ & $(9.24)$ \\
$0.0054 * * *$ & $0.0054 * * *$ & $0.0055^{* * *}$ & $0.0055^{* * *}$ \\
$(6.99)$ & $(7.00)$ & $(7.15)$ & $(7.15)$ \\
-0.0658 & 0.0018 & -0.0743 & $0.6113 * * *$ \\
$(-0.35)$ & $(0.01)$ & $(-0.37)$ & $(3.96)$ \\
Yes & Yes & Yes & Yes \\
14,306 & 14,306 & 14,306 & 14,306 \\
0.0604 & 0.0603 & 0.0603 & 0.0591
\end{tabular}

\begin{tabular}{cccc}
\multicolumn{4}{c}{ Weak_Modal } \\
\hline$\underline{\text { Model 5 }}$ & $\underline{\text { Model 6 }}$ & $\underline{\text { Model 7 }}$ & $\underline{\text { Model 8 }}$ \\
$0.5739 * * *$ & $0.5831^{* * *}$ & $0.5905^{* * *}$ & $0.6098 * * *$ \\
$(8.77)$ & $(8.89)$ & $(9.05)$ & $(9.32)$ \\
$0.0054 * * *$ & $0.0055^{* * *}$ & $0.0056^{* * *}$ & $0.0056 * * *$ \\
$(6.99)$ & $(7.10)$ & $(7.25)$ & $(7.29)$ \\
-0.0658 & -0.0008 & -0.0800 & $0.5864 * * *$ \\
$(-0.35)$ & $(0.00)$ & $(-0.43)$ & $(3.81)$ \\
Yes & Yes & Yes & Yes \\
14,306 & 14,306 & 14,306 & 14,306 \\
0.0604 & 0.0607 & 0.0605 & 0.0589
\end{tabular}

The $t$-statistics in parentheses. *,**,*** stands for $\mathrm{p}<0.1, \mathrm{p}<0.05, \mathrm{p}<0.01$, respectively, two-tailed t-tests. All continuous variables are winsorized at $1 \%$ and 99\%. Variables are defined in the Appendix 2. 


\section{APPENDIX 1}

\section{Variable Definitions for Determinants of the Use of Uncertain and Weak Modal}

Words in 10-K Filings

\begin{tabular}{|c|c|}
\hline Variable & Definition \\
\hline Uncertain & $\begin{array}{l}\text { The proportion of uncertain words to the total words in 10-K filings as defined } \\
\text { in Loughran and McDonald (2011). }\end{array}$ \\
\hline Weak_Modal & $\begin{array}{l}\text { The proportion of weak modal words to the total words in } 10-\mathrm{K} \text { filings as } \\
\text { defined in Loughran and McDonald (2011). }\end{array}$ \\
\hline Firm_Size & The logarithm of the market value of equity at the fiscal year-end. \\
\hline$M T B$ & $\begin{array}{l}\text { The ratio of the market value of equity plus book value of liability to the book } \\
\text { value of total assets at the fiscal year-end. }\end{array}$ \\
\hline Age & $\begin{array}{l}\text { The number of years of firms that appear in the CRSP monthly stock return } \\
\text { database. }\end{array}$ \\
\hline Special_Items & The amount of special items divided by the book value of assets. \\
\hline Std_Ret & The standard deviation of the monthly stock returns in the prior year. \\
\hline Std_Earn & $\begin{array}{l}\text { The standard deviation of the operating earnings during the past five fiscal } \\
\text { years. }\end{array}$ \\
\hline Segments & The logarithm of the number of business segments. \\
\hline$M \& A$ & $\begin{array}{l}1 \text { for firms that engage in M\&A as an acquirer in a specific firm-year and } 0 \\
\text { otherwise. }\end{array}$ \\
\hline$S E O$ & $\begin{array}{l}1 \text { for firms that have the seasoned equity offering in a specific firm-year and } 0 \\
\text { otherwise. }\end{array}$ \\
\hline Delaware & 1 for firms that are incorporated in Delaware state and 0 otherwise. \\
\hline
\end{tabular}




\section{APPENDIX 2}

\section{Variable Definitions for the Association between the Use of Uncertain and Weak Modal Words in 10-K Filings and Analyst Forecast Attributes}

\begin{tabular}{|c|c|}
\hline Variable & Definition \\
\hline \#Analysts & $\begin{array}{l}\text { The number of analysts included in the first } \mathrm{I} / \mathrm{B} / \mathrm{E} / \mathrm{S} \text { consensus earnings } \\
\text { forecast after } 10-\mathrm{K} \text { filings. }\end{array}$ \\
\hline Dispersion & $\begin{array}{l}\text { The standard deviation of the individual analyst forecasts in the first analys } \\
\text { consensus earnings forecast after the } 10-\mathrm{K} \text { reporting, scaled by share price } \\
90 \text { days before the consensus earnings forecast. }\end{array}$ \\
\hline Accuracy & $\begin{array}{l}\text { The squared value of the difference between the reported earnings in } \\
\text { I/B/E/S and the most recent analyst consensus forecast, scaled by stock } \\
\text { price } 90 \text { days before the consensus earnings forecast. }\end{array}$ \\
\hline Uncertainty_Overall & $\begin{array}{l}\text { The sum of uncertainty related to analysts' private information and } \\
\text { uncertainty related to common (public) information to all analysts. }\end{array}$ \\
\hline Uncertainty_Common & $\begin{array}{l}\text { The ratio of common uncertainty to overall uncertainty, and it measures the } \\
\text { average analyst's belief reflects between common and private information }\end{array}$ \\
\hline Uncertain & $\begin{array}{l}\text { The proportion of uncertain words to the total words in } 10-\mathrm{K} \text { filings as } \\
\text { defined in Loughran and McDonald (2011). }\end{array}$ \\
\hline Weak_Modal & $\begin{array}{l}\text { The proportion of weak modal words to the total words in } 10-\mathrm{K} \text { filings as } \\
\text { defined in Loughran and McDonald (2011). }\end{array}$ \\
\hline File_Size & The natural logarithm of the net file size of $10-\mathrm{K}$ filings. \\
\hline Fog & $\begin{array}{l}\text { The Fog Index of the } 10-\mathrm{K} \text { filing calculated as (average words per sentence } \\
+ \text { percent of complex words) } \times 0.4 \text {. }\end{array}$ \\
\hline Pos_Tone & $\begin{array}{l}\text { The proportion of positive words to the total number of words in } 10-\mathrm{K} \\
\text { filings as defined in Loughran and McDonald (2011). }\end{array}$ \\
\hline Neg_Tone & $\begin{array}{l}\text { The proportion of negative words to the total number of words in } 10-\mathrm{K} \\
\text { filings as defined in Loughran and McDonald (2011). }\end{array}$ \\
\hline Std_Ret & The standard deviation of the monthly stock returns in the prior year. \\
\hline Firm_Size & The logarithm of the market value of equity at the fiscal year-end. \\
\hline Growth & $\begin{array}{l}\text { The difference of sales volume between the current year and prior year } \\
\text { divided by prior year sales volume. }\end{array}$ \\
\hline
\end{tabular}


Segments

$A d v$

$R \& D$

\%_Inst

10K_News
The logarithm of the number of business segments.

Advertising expense divided by operating expense.

Research and development expense divided by operating expense.

The percentage of a firm's shares that are held by institutional investors.

Two-day event window for market-adjusted return to control the informativeness of the $10-\mathrm{K}$ filing. 


\section{APPENDIX 3}

\section{Additional Tests}

\section{TABLE 16}

Correlation Matrix for the Association between Analyst Following and the Use of Uncertain and Weak Modal Words in 10K Filings: Fog Replacement

\begin{tabular}{|c|c|c|c|c|c|c|c|c|c|c|c|c|c|c|}
\hline & 1 & 2 & 3 & 4 & 5 & 6 & 7 & 8 & 9 & 10 & 11 & 12 & 13 & 14 \\
\hline 1 \#Analysts & & 0.0021 & $-0.0223 *$ & $0.0291 *$ & 0.0114 & $0.0239 *$ & $0.7247 *$ & $0.0827 *$ & $0.0978 *$ & $0.4899 *$ & $-0.1653 *$ & $0.0576^{*}$ & -0.0037 & $-0.2800 *$ \\
\hline 2 Uncertain & $-0.0182 *$ & & $0.6796^{*}$ & $-0.0349 *$ & $0.2530 *$ & $0.1874 *$ & $-0.0795^{*}$ & $0.0314^{*}$ & $-0.1592 *$ & $0.0347 *$ & $0.0442 *$ & $0.0417 *$ & $0.2493 *$ & $0.0998 *$ \\
\hline 3 Weak_Modal & $-0.0413 *$ & $0.6849 *$ & & $0.1251 *$ & $0.2267 *$ & $0.3975^{*}$ & $-0.1855^{*}$ & $0.0683 *$ & $-0.2843 *$ & $-0.0525^{*}$ & $0.1263 *$ & $0.0502 *$ & $0.4173 *$ & $0.2621 *$ \\
\hline 4 Fog & $0.0442 *$ & $-0.0805 *$ & $0.0863^{*}$ & & 0.0091 & $0.1489 *$ & -0.0026 & 0.0065 & -0.0131 & $0.0373^{*}$ & 0.0002 & -0.0049 & $0.0783 *$ & 0.008 \\
\hline 5 Pos_Tone & -0.0092 & $0.2359 *$ & $0.2506^{*}$ & -0.0091 & & $0.0584 *$ & -0.0051 & 0.0046 & $-0.0883 *$ & $-0.0349 *$ & 0.0039 & 0.0131 & $0.3777 *$ & $0.0553 *$ \\
\hline 6 Neg_Tone & $0.0290 *$ & $0.1942 *$ & $0.4039 *$ & $0.1349 *$ & $0.0346^{*}$ & & $-0.1133^{*}$ & $-0.0953^{*}$ & $-0.0808 *$ & -0.0069 & $0.1129 *$ & $0.0701 *$ & $0.2964 *$ & 0.25 \\
\hline 7 Firm_Size & $0.7217 *$ & $-0.0766 *$ & $-0.1759 *$ & $0.0230 *$ & 0.0069 & $-0.0962 *$ & & $0.1591 *$ & $0.2615^{*}$ & $0.5553 *$ & $-0.2604 *$ & $0.0163 *$ & -0.0 & -0.4 \\
\hline 8 Growth & 0.0017 & $0.0426^{*}$ & $0.1179 *$ & $0.0160 *$ & $0.0513^{*}$ & $-0.0312 *$ & $0.0523^{*}$ & & $-0.0599 *$ & $0.0819^{*}$ & $-0.0358^{*}$ & $-0.0256^{*}$ & $0.0533 *$ & $-0.0552 *$ \\
\hline 9 Segments & $0.0992 *$ & $-0.1612 *$ & $-0.2863^{*}$ & 0.0014 & $-0.0951 *$ & $-0.0799 *$ & $0.2753^{*}$ & $-0.0803 *$ & & $0.1266^{*}$ & $-0.1153^{*}$ & $-0.0501 *$ & $-0.1868^{*}$ & $-0.2166^{*}$ \\
\hline $10 \%$ Inst & $0.3896 *$ & $0.0296 *$ & $-0.0644 *$ & $0.0419 *$ & $-0.0352 *$ & -0.0089 & $0.5464 *$ & -0.0116 & $0.1405^{*}$ & & $-0.2010 *$ & 0.0129 & $-0.1359 *$ & $-0.3609 *$ \\
\hline 11 10K_News & $-0.1429 *$ & $0.0422 *$ & $0.1098^{*}$ & -0.0047 & $0.0164 *$ & $0.0947 *$ & $-0.2551 *$ & $0.0178 *$ & $-0.1000 *$ & $-0.2207 *$ & & -0.0054 & $0.1001 *$ & $0.3781 *$ \\
\hline $12 A d v$ & $0.0907 *$ & 0.0118 & $0.0315^{*}$ & $-0.0384 *$ & 0.0066 & $0.0307 *$ & $0.0627 *$ & $0.0199 *$ & $-0.0181 *$ & $-0.0285^{*}$ & 0.0038 & & -0.001 & -0.0144 \\
\hline $13 R \& D$ & -0.0138 & $0.1942 *$ & $0.4347 *$ & $0.0784 *$ & $0.4110^{*}$ & $0.2075^{*}$ & $-0.1073 *$ & $0.1826^{*}$ & $-0.2681 *$ & $-0.1538 *$ & $0.1055^{*}$ & $-0.0750 *$ & & $0.2399 *$ \\
\hline 14 Std_Ret & $-0.2337 *$ & $0.0621 *$ & $0.2111 *$ & $-0.0170 *$ & $0.0665^{*}$ & $0.2096^{*}$ & $-0.4322 *$ & $0.0624 *$ & $-0.1904 *$ & $-0.3873 *$ & $0.4090 *$ & 0.0024 & $0.2421 *$ & \\
\hline
\end{tabular}

\footnotetext{
This table reports the Pearson (below the diagonal) and Spearman (above the diagonal) correlation coefficients for the variables used in the regression analysis. * stands for $\mathrm{p}<0.05$ two-tailed t-tests. All continuous variables are winsorized at $1 \%$ and $99 \%$. All variables are defined in Appendix 2.
} 


\section{TABLE 17}

Multivariate Analysis for the Association between Analyst Following and the Use of Uncertain and Weak Modal Words in 10-K Filings: Fog replacement

DV: \#Analysts

$\underline{\text { IV }}$

Uncertain

Weak_Modal

Fog

Pos_Tone

Neg_Tone

Firm_Size

Growth

Segments

\%_Inst

10-K_News

$A d v$

$R \& D$

\begin{tabular}{cccc} 
& \multicolumn{3}{c}{ Uncertain } \\
\cline { 3 - 4 } \cline { 4 - 5 } & $\underline{\text { Model 1 }}$ & $\frac{\text { Model 2 }}{8.2556^{* * *} *}$ & $\underline{\text { Model 3 }}$ \\
& & (4.35) & (5.534)
\end{tabular}

$+$

$+$

$+$

$+$

$+$

$+$

$+$

$(-7.26)$

-0.1369 ***

(-11.19)

$+$

$+$

$0.6982 * * *$

$$
\text { (29.92) }
$$

0.1013

(0.79)

$+$

$+$

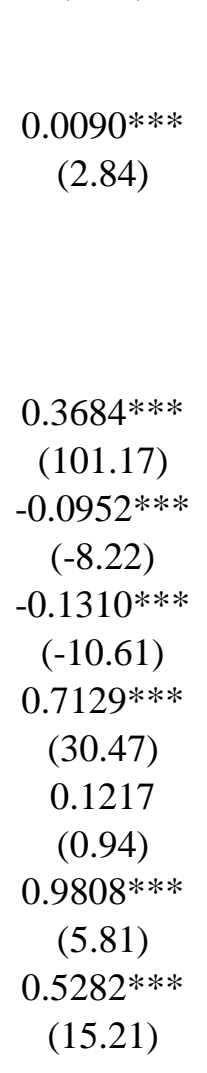

$0.8616^{* * * *}$

(5.12)

$0.5042 * * *$

(14.16)

\begin{tabular}{|c|c|c|}
\hline \multicolumn{3}{|c|}{ Weak_Modal } \\
\hline Model 4 & Model 5 & Model 6 \\
\hline & $\begin{array}{c}28.8694 * * * \\
(7.99)\end{array}$ & $\begin{array}{c}39.2189 * * * \\
(11.37)\end{array}$ \\
\hline 0.0024 & 0.0028 & $0.0059 *$ \\
\hline$(0.76)$ & $(0.91)$ & $(1.89)$ \\
\hline 4.4712 & 1.0572 & \\
\hline$(1.39)$ & $(0.33)$ & \\
\hline $\begin{array}{c}18.1086^{* * * *} \\
(13.04)\end{array}$ & $\begin{array}{c}14.7657 * * * \\
(10.20)\end{array}$ & \\
\hline $\begin{array}{c}0.3681 * * * \\
(101.45)\end{array}$ & $\begin{array}{c}0.3712 * * * \\
(101.93)\end{array}$ & $\begin{array}{c}0.3713 * * * \\
(101.96)\end{array}$ \\
\hline $\begin{array}{c}-0.0838 * * * \\
(-7.26)\end{array}$ & $\begin{array}{c}-0.0923 * * * \\
(-7.98)\end{array}$ & $\begin{array}{c}-0.1015 * * * \\
(-8.78)\end{array}$ \\
\hline $\begin{array}{c}-0.1369 * * * \\
(-11.19)\end{array}$ & $\begin{array}{c}-0.1214 * * * \\
(-9.82)\end{array}$ & $\begin{array}{c}-0.1161 * * * \\
(-9.36)\end{array}$ \\
\hline $0.6982 * * *$ & $0.6927 * * *$ & $0.7064 * * *$ \\
\hline$(29.92)$ & $(29.73)$ & $(30.28)$ \\
\hline 0.1013 & 0.0869 & 0.1087 \\
\hline$(0.79)$ & $(0.68)$ & $(0.85)$ \\
\hline $\begin{array}{c}0.8616^{* * * *} \\
(5.12)\end{array}$ & $\begin{array}{c}0.7809 * * * \\
(4.64)\end{array}$ & $\begin{array}{c}0.8663 * * * \\
(5.14)\end{array}$ \\
\hline $\begin{array}{c}0.5042 * * * \\
(14.16)\end{array}$ & $\begin{array}{c}0.4338^{* * * *} \\
(11.85)\end{array}$ & $\begin{array}{c}0.4357 * * * \\
(12.15)\end{array}$ \\
\hline
\end{tabular}


TABLE 17 (Continued)

DV: \#Analysts

$\underline{\text { IV }}$

$\overline{\text { Std_Ret }}$

Intercept

Year/Ind. Fixed Effects

n

Adjusted R-Squared

\begin{tabular}{cccc} 
& \multicolumn{3}{c}{ Uncertain } \\
\cline { 2 - 4 } Prediction & $\underline{\text { Model 1 }}$ & $\underline{\text { Model 2 }}$ & $\underline{\text { Model 3 }}$ \\
& $0.4887 * * *$ & $0.4820 * * *$ & $0.6396^{* * *}$ \\
$(6.87)$ & $(6.78)$ & $(9.10)$ \\
$-2.1011 * * *$ & $-2.2130 * * *$ & -2.1036 \\
$(-12.85)$ & $(-13.38)$ & $(-12.76)$ \\
Yes & Yes & Yes \\
& 15,898 & 15,898 & 15,898 \\
& 0.6010 & 0.6015 & 0.5975
\end{tabular}

\begin{tabular}{ccc}
\multicolumn{3}{c}{ Weak_Modal } \\
\hline$\underline{\text { Model 4 }}$ & $\underline{\text { Model 5 }}$ & $\underline{\text { Model 6 }}$ \\
$0.4887 * * *$ & $0.4621^{* * *}$ & $0.5766^{* * *}$ \\
$(6.87)$ & $(6.50)$ & $(8.19)$ \\
$-2.1011^{* * *}$ & $-2.1539 * * *$ & $-2.0736 * * *$ \\
$(-12.85)$ & $(-13.19)$ & $(-12.8)$ \\
Yes & Yes & Yes \\
15,898 & 15,898 & 15,898 \\
0.6010 & 0.6026 & 0.6000
\end{tabular}

The $t$-statistics in parentheses. *,**, $* * *$ stands for $\mathrm{p}<0.1, \mathrm{p}<0.05, \mathrm{p}<0.01$, respectively, two-tailed $\mathrm{t}$-tests. All continuous variables are winsorized at $1 \%$ and 99\%. Variables are defined in the Appendix 2. 


\section{TABLE 18}

\section{Correlation Matrix for the Association between Analyst Forecast Dispersion and the Use of Uncertain and Weak Modal} Words in 10-K Filings: Fog replacement

\begin{tabular}{|c|c|c|c|c|c|c|c|c|c|c|c|c|c|c|c|}
\hline & 1 & 2 & 3 & 4 & 5 & 6 & 7 & 8 & 9 & 10 & 11 & 12 & 13 & 14 & 15 \\
\hline 1 Dispersion & & $0.0795 *$ & $0.1851 *$ & $0.0272 *$ & $-0.0211 *$ & $0.2068^{*}$ & $-0.4284 *$ & $-0.1949 *$ & $-0.1236^{*}$ & $-0.2746^{*}$ & $0.2284 *$ & $-0.0740 *$ & $0.1067 *$ & $0.4645^{*}$ & $-0.1795 *$ \\
\hline 2 Uncertain & 0.0163 & & $0.6690 *$ & $-0.0514 *$ & $0.2416^{*}$ & $0.1722^{*}$ & $-0.1300 *$ & $0.0378^{*}$ & $-0.1780 *$ & 0.0135 & $0.0474 *$ & $0.0317 *$ & $0.2466^{*}$ & $0.1235^{*}$ & $-0.0443 *$ \\
\hline 3 Weak_Modal & $.1040 *$ & $0.6758 *$ & & $0.1113 *$ & $0.2172 *$ & $0.3808^{*}$ & $-0.2623 *$ & $0.0843^{*}$ & $-0.3094 *$ & $-0.0778 *$ & $0.1406^{*}$ & $0.0484 *$ & $0.4230 *$ & $0.2965^{*}$ & $-0.0870 *$ \\
\hline 4 Fog & 0.0085 & $-0.0955^{*}$ & $0.0747 *$ & & 0.0169 & $0.1449 *$ & 0.0009 & 0.0082 & -0.0026 & $0.0473 *$ & -0.0135 & -0.005 & $0.0763 *$ & 0.0026 & $0.0393 *$ \\
\hline 5 Pos_Tone & 0.0139 & $0.2221 *$ & $0.2399 *$ & -0.0036 & & $0.0674^{*}$ & $-0.0360 *$ & 0.0015 & $-0.0920 *$ & $-0.0673 *$ & -0.0027 & $0.0237^{*}$ & $0.3861 *$ & $0.0650 *$ & $-0.0316^{*}$ \\
\hline 6 Neg_Tone & $0.1434 *$ & $0.1812 *$ & $0.3863 *$ & $0.1289 *$ & $0.0396^{*}$ & & $-0.1618 *$ & $-0.0935^{*}$ & $-0.0929 *$ & $-0.0398 *$ & $0.1218 *$ & $0.0821 *$ & $0.3175^{*}$ & $0.2750 *$ & -0.0165 \\
\hline 7 Firm_Size & $-0.3675^{*}$ & $-0.1226^{*}$ & $-0.2469 *$ & $0.0244^{*}$ & $-0.0230 *$ & $-0.1357^{*}$ & & $0.1107 *$ & $0.2719^{*}$ & $0.4550 *$ & $-0.2584 *$ & 0.0151 & $-0.1250 *$ & $-0.5124 *$ & $0.6845^{*}$ \\
\hline 8 Growth & $-0.0186^{*}$ & $0.0489^{*}$ & $0.1321 *$ & 0.0124 & $0.0558^{*}$ & $-0.0291 *$ & 0.0089 & & $-0.0774 *$ & $0.0437 *$ & -0.0171 & -0.016 & $0.0617 *$ & $-0.0416^{*}$ & $0.0383^{*}$ \\
\hline 9 Segment. & $-0.1138^{*}$ & $-0.1796^{*}$ & $-0.3097 *$ & 0.0124 & $-0.1002 *$ & $-0.0919 *$ & $0.2793 *$ & $-0.0925^{*}$ & & $0.1060 *$ & $-0.1243^{*}$ & $-0.0538^{*}$ & $-0.1898 *$ & $-0.2168^{*}$ & $0.0921 *$ \\
\hline $10 \% \_I n s t$ & $-0.3239 *$ & 0.0079 & $-0.0962 *$ & $0.0516^{*}$ & $-0.0685^{*}$ & $-0.0448 *$ & $0.4582 *$ & $-0.0475^{*}$ & $0.1203^{*}$ & & $-0.1768^{*}$ & 0.0129 & $-0.1584 *$ & $-0.3432 *$ & $0.3776^{*}$ \\
\hline 11 10K_News & $0.2349 *$ & $0.0476^{*}$ & $0.1303 *$ & -0.0108 & 0.0175 & $0.1115^{*}$ & $-0.2549 *$ & $0.0373^{*}$ & $-0.1076^{*}$ & $-0.2093 *$ & & -0.0126 & $0.1011 *$ & $0.3759 *$ & $-0.1515^{*}$ \\
\hline $12 A d v$ & $0.0281 *$ & 0.0173 & $0.0449 *$ & $-0.0363^{*}$ & 0.0045 & $0.0497 *$ & $0.0452 *$ & $0.0305^{*}$ & $-0.0332 *$ & $-0.0518 *$ & 0.0068 & & 0.0114 & -0.0051 & $0.0480 *$ \\
\hline $13 R \& D$ & $0.1529 *$ & $0.1928^{*}$ & $0.4466^{*}$ & $0.0753^{*}$ & $0.4215^{*}$ & $0.2167^{*}$ & $-0.1388 *$ & $0.1865^{*}$ & $-0.2743^{*}$ & $-0.1728 *$ & $0.1120^{*}$ & $-0.0740^{*}$ & & $0.2479^{*}$ & $-0.0327 *$ \\
\hline 14 Std_Ret & $0.4207 *$ & $0.0827 *$ & $0.2428 *$ & $-0.0201 *$ & $0.0752 *$ & $0.2324^{*}$ & $-0.4560 *$ & $0.0819^{*}$ & $-0.1937^{*}$ & $-0.3947 *$ & $0.4201 *$ & 0.0148 & $0.2456^{*}$ & & $-0.2807 *$ \\
\hline 15 \#Analysts & $-0.1264 *$ & $-0.0554^{*}$ & $-0.0866^{*}$ & $0.0486^{*}$ & $-0.0424 *$ & 0.0073 & $0.6966^{*}$ & $-0.0247 *$ & $0.0892 *$ & $0.3028 *$ & $-0.1336^{*}$ & 0.0778* & $-0.0300 *$ & $-0.2270 *$ & \\
\hline
\end{tabular}

\footnotetext{
This table reports the Pearson (below the diagonal) and Spearman (above the diagonal) correlation coefficients for the variables used in the regression analysis

$*$ stands for $\mathrm{p}<0.05$ two-tailed t-tests. All continuous variables are winsorized at $1 \%$ and $99 \%$. All variables are defined in Appendix 2 .
} 


\section{TABLE 19}

Multivariate Analysis for the Association between Analyst Forecast Dispersion and the Use of Uncertain and Weak Modal Words in 10-K Filings: Fog Replacement

DV: Dispersion
Uncertain
Weak_Modal
Fog
Pos_Tone
Neg_Tone
Firm_Size
Growth
Segments
\%_Inst
$10-K \_N e w s$
Adv
R\&D

\begin{tabular}{|c|c|c|c|}
\hline \multirow[b]{2}{*}{ Prediction } & \multicolumn{3}{|c|}{ Uncertain } \\
\hline & Model 1 & Model 2 & $\underline{\text { Model } 3}$ \\
\hline$?$ & & $\begin{array}{c}-0.5170 * * * \\
(-5.91)\end{array}$ & $\begin{array}{c}-0.4895 * * * \\
(-5.69)\end{array}$ \\
\hline$?$ & & & \\
\hline+ & $\begin{array}{c}0.0001 \\
(0.97)\end{array}$ & $\begin{array}{c}-0.0000 \\
(-0.14)\end{array}$ & $\begin{array}{c}0.0000 \\
(0.25)\end{array}$ \\
\hline+ & $\begin{array}{c}-0.1134 \\
(-0.77)\end{array}$ & $\begin{array}{c}0.0362 \\
(0.24)\end{array}$ & \\
\hline+ & $\begin{array}{c}0.2514 * * * \\
(3.87)\end{array}$ & $\begin{array}{c}0.2815^{* * *} \\
(4.32)\end{array}$ & \\
\hline- & $\begin{array}{c}-0.0061 * * * \\
(-26.60)\end{array}$ & $\begin{array}{c}-0.0062 * * * \\
(-26.97)\end{array}$ & $\begin{array}{c}-0.0062 * * * \\
(-27.49)\end{array}$ \\
\hline - & $\begin{array}{c}-0.0019 * * * \\
(-3.64)\end{array}$ & $\begin{array}{c}-0.0017 * * * \\
(-3.30)\end{array}$ & $\begin{array}{c}-0.0018 * * * \\
(-3.54)\end{array}$ \\
\hline+ & $\begin{array}{c}0.0023 * * * \\
(4.10)\end{array}$ & $\begin{array}{c}0.0020 * * * \\
(3.50)\end{array}$ & $\begin{array}{c}0.0020 * * * \\
(3.56)\end{array}$ \\
\hline - & $\begin{array}{c}-0.0176^{* * *} * \\
(-15.89)\end{array}$ & $\begin{array}{c}-0.0174 * * * \\
(-15.73)\end{array}$ & $\begin{array}{c}-0.0172 * * * \\
(-15.61)\end{array}$ \\
\hline+ & $\begin{array}{c}0.0379 * * * \\
(6.13)\end{array}$ & $\begin{array}{c}0.0384 * * * \\
(6.22)\end{array}$ & $\begin{array}{c}0.0390 * * * \\
(6.32)\end{array}$ \\
\hline+ & $\begin{array}{c}0.0337 * * * \\
(4.51)\end{array}$ & $\begin{array}{c}0.0351 * * * \\
(4.70)\end{array}$ & $\begin{array}{c}0.0377 * * * \\
(5.06)\end{array}$ \\
\hline+ & $\begin{array}{c}0.0055^{* * * *} \\
(3.37)\end{array}$ & $\begin{array}{c}0.0062 * * * \\
(3.82)\end{array}$ & $\begin{array}{c}0.0066^{* * * *} \\
(4.23)\end{array}$ \\
\hline
\end{tabular}

\begin{tabular}{ccc}
\multicolumn{3}{c}{ Weak_Modal } \\
\hline Model 4 & $\underline{\text { Model 5 }}$ & $\underline{\text { Model 6 }}$ \\
& & \\
& $-1.5384 * * *$ & $-1.2926 * * *$ \\
& $(-9.23)$ & $(-8.03)$ \\
0.0001 & 0.0001 & 0.0002 \\
$(0.97)$ & $(0.71)$ & $(1.22)$ \\
-0.1134 & 0.0367 & \\
$(-0.77)$ & $(0.25)$ & \\
$0.2514 * * *$ & $0.4049 * * *$ & \\
$(3.87)$ & $(6.06)$ & \\
$-0.0061 * * *$ & $-0.0063 * * *$ & $-0.0064 * * *$ \\
$(-26.60)$ & $(-27.59)$ & $(-28.04)$ \\
$-0.0019 * * *$ & $-0.0014 * * *$ & $-0.0016^{* * *}$ \\
$(-3.64)$ & $(-2.75)$ & $(-3.18)$ \\
$0.0023 * * *$ & $0.0015 * * *$ & $0.0017 * * *$ \\
$(4.10)$ & $(2.68)$ & $(2.96)$ \\
$-0.0176 * * *$ & $-0.0173^{* * *}$ & $-0.0171^{* * *}$ \\
$(-15.89)$ & $(-15.73)$ & $(-15.55)$ \\
$0.0379 * * *$ & $0.0387 * * *$ & $0.0395^{* * *}$ \\
$(6.13)$ & $(6.30)$ & $(6.41)$ \\
$0.0337 * * *$ & $0.0385^{* * *}$ & $0.0413^{* * *}$ \\
$(4.51)$ & $(5.16)$ & $(5.55)$ \\
$0.0055^{* * * *}$ & $0.0093 * * *$ & $0.0093^{* * *}$ \\
$(3.37)$ & $(5.58)$ & $(5.71)$ \\
& &
\end{tabular}


TABLE 19 (Continued)

\begin{tabular}{|c|c|c|c|c|c|c|c|}
\hline \multirow{2}{*}{$\begin{array}{l}\text { DV: Dispersion } \\
\text { IV }\end{array}$} & \multirow[b]{2}{*}{ Prediction } & \multicolumn{3}{|c|}{ Uncertain } & \multicolumn{3}{|c|}{ Weak_Modal } \\
\hline & & Model 1 & Model 2 & Model 3 & Model 4 & Model 5 & Model 6 \\
\hline Std_Ret & + & $\begin{array}{c}0.0841 * * * \\
(24.01)\end{array}$ & $\begin{array}{c}0.0847 * * * \\
(24.20)\end{array}$ & $\begin{array}{c}0.0873 * * * \\
(25.31)\end{array}$ & $\begin{array}{c}0.0841 * * * \\
(24.01)\end{array}$ & $\begin{array}{c}0.0858 * * * \\
(24.53)\end{array}$ & $\begin{array}{c}0.0891 * * * \\
(25.76)\end{array}$ \\
\hline \#Analysts & + & $\begin{array}{c}0.0009 * * * \\
(17.76)\end{array}$ & $\begin{array}{c}0.0009 * * * \\
(17.79)\end{array}$ & $\begin{array}{c}0.0010 * * * \\
(18.33)\end{array}$ & $\begin{array}{c}0.0009 * * * \\
(17.76)\end{array}$ & $\begin{array}{c}0.0009 * * * \\
(17.98)\end{array}$ & $\begin{array}{c}0.0010 * * * \\
(18.63)\end{array}$ \\
\hline Intercept & & $\begin{array}{c}0.0319 * * * \\
(3.51)\end{array}$ & $\begin{array}{c}0.0393 * * * \\
(4.30)\end{array}$ & $\begin{array}{c}0.0419 * * * \\
(4.62)\end{array}$ & $\begin{array}{c}0.0319 * * * \\
(3.51)\end{array}$ & $\begin{array}{c}0.0365^{* * * *} \\
(4.03)\end{array}$ & $\begin{array}{c}0.0397 * * * \\
(4.42)\end{array}$ \\
\hline Year/Ind. Fixed Effects & & Yes & Yes & Yes & Yes & Yes & Yes \\
\hline$n$ & & 11,820 & 11,820 & 11,820 & 11,820 & 11,820 & 11,820 \\
\hline Adjusted R-Squared & & 0.3151 & 0.317 & 0.3161 & 0.3151 & 0.3199 & 0.3179 \\
\hline
\end{tabular}

The $t$-statistics in parentheses. *, $* *, * * *$ stands for $\mathrm{p}<0.1, \mathrm{p}<0.05, \mathrm{p}<0.01$, respectively, two-tailed $\mathrm{t}$-tests. All continuous variables are winsorized at $1 \%$ and 99\%. Variables are defined in the Appendix 2. 


\section{TABLE 20}

\section{Correlation Matrix for the Association between Analyst Forecast Accuracy and the Use of Uncertain and Weak Modal} Words in 10-K Filings: Fog replacement

\begin{tabular}{|c|c|c|c|c|c|c|c|c|c|c|c|c|c|c|c|}
\hline & 1 & 2 & 3 & 4 & 5 & 6 & 7 & 8 & 9 & 10 & 11 & 12 & 13 & 14 & 15 \\
\hline 1 Accuracy & & -0.0173 & 0.0118 & -0.0065 & $-0.0540^{*}$ & $0.0637 *$ & $-0.1967 *$ & $-0.0964 *$ & -0.0063 & $-0.0843 *$ & $0.1071 *$ & $-0.0655^{*}$ & $-0.0465^{*}$ & $0.2702 *$ & $-0.1164 *$ \\
\hline 2 Uncertain & $-0.0390 *$ & & $0.6639 *$ & $-0.0606^{*}$ & $0.2203^{*}$ & $0.1698 *$ & $-0.1270^{*}$ & $0.0488^{*}$ & $-0.1739 *$ & $0.0267 *$ & $0.0492 *$ & $0.0399 *$ & $0.2334 *$ & $0.1471^{*}$ & $-0.0409 *$ \\
\hline 3 Weak_Modal & $-0.0275^{*}$ & $0.6742 *$ & & $0.1090 *$ & $0.1842 *$ & $0.3743 *$ & $-0.2503^{*}$ & $0.1073^{*}$ & $-0.3072 *$ & $-0.0494 *$ & $0.1344 *$ & $0.0523 *$ & $0.4042 *$ & $0.3126^{*}$ & $-0.0793 *$ \\
\hline 4 Fog & 0.0108 & $-0.1027 *$ & $0.0739 *$ & & 0.0121 & $0.1479 *$ & 0.011 & 0.0013 & -0.002 & $0.0552 *$ & -0.0184 & 0.0003 & $0.0667 *$ & 0.0033 & $0.0420 *$ \\
\hline 5 Pos_Tone & $-0.0567 *$ & $0.2034 *$ & $0.2112 *$ & -0.0098 & & $0.0733 *$ & $-0.0285^{*}$ & -0.0006 & $-0.0686^{*}$ & $-0.0541 *$ & -0.0119 & $0.0330 *$ & $0.3755^{*}$ & $0.0686^{*}$ & $-0.0336 *$ \\
\hline 6 Neg_Tone & $0.0647 *$ & $0.1778 *$ & $0.3797 *$ & $0.1310^{*}$ & $0.0413^{*}$ & & $-0.1266^{*}$ & $-0.0805^{*}$ & $-0.0800 *$ & -0.0129 & $0.1020 *$ & $0.0956^{*}$ & $0.3320^{*}$ & $0.2562 *$ & 0.0071 \\
\hline 7 Firm_Size & $-0.1509 *$ & $-0.1223^{*}$ & $-0.2389 *$ & $0.0317 *$ & -0.0133 & $-0.1015^{*}$ & & $0.0524 *$ & $0.2652 *$ & $0.3949 *$ & $-0.2389 *$ & $0.0320^{*}$ & $-0.0938 *$ & $-0.5011^{*}$ & $0.7030 *$ \\
\hline 8 Growth & $-0.0247 *$ & $0.0487^{*}$ & $0.1398 *$ & 0.0002 & $0.0503 *$ & -0.0155 & $-0.0235^{*}$ & & $-0.1072 *$ & 0.0133 & 0.0099 & -0.0139 & $0.0717 *$ & 0.0145 & -0.0111 \\
\hline 9 Segments & -0.0023 & $-0.1764^{*}$ & $-0.3075^{*}$ & 0.0126 & $-0.0785^{*}$ & $-0.0798 *$ & $0.2724 *$ & $-0.1105^{*}$ & & $0.0859 *$ & $-0.1206^{*}$ & $-0.0506^{*}$ & $-0.1633^{*}$ & $-0.2254^{*}$ & $0.0901 *$ \\
\hline $10 \%$ Inst & $-0.1049^{*}$ & 0.0129 & $-0.0743 *$ & $0.0579 *$ & $-0.0518^{*}$ & & $34^{*}$ & $-0.0735^{*}$ & 0.1 & & $-0.1469^{*}$ & 0.0167 & $-0.1295^{*}$ & $-0.3043^{*}$ & $0.3591 *$ \\
\hline 11 10K_News & $0.0705^{*}$ & $0.0489 *$ & $0.1245^{*}$ & -0.0163 & 0.012 & $0.0897 *$ & $-0.2235^{*}$ & $0.0619 *$ & $-0.1048^{*}$ & $-0.1679 *$ & & -0.0135 & $0.0848 *$ & $0.3750^{*}$ & $-0.1488 *$ \\
\hline $12 A d v$ & 02 & $0.0287^{*}$ & $0.0531 *$ & $-0.0282 *$ & 0.0143 & $0.0615^{*}$ & $0.0805^{*}$ & $0.0386^{*}$ & $-0.0259 *$ & $-0.0374 *$ & 0.0032 & & $0.0248 *$ & -0.003 & $0.0738 *$ \\
\hline $13 R \& D$ & $-0.0221 *$ & $0.1823 *$ & $0.4374 *$ & $0.0669 *$ & $0.4006^{*}$ & $0.2256^{*}$ & $-0.1188^{*}$ & $0.1897 *$ & $-0.2665^{*}$ & $-0.1474 *$ & $0.1072 *$ & $-0.0647 *$ & & $0.2412 *$ & -0.0122 \\
\hline 14 Std_Ret & $0.1989 *$ & $0.1067 *$ & $0.2646^{*}$ & $-0.0211^{*}$ & $0.0841 *$ & $0.2148^{*}$ & $-0.4303^{*}$ & $0.1314^{*}$ & $-0.2040^{*}$ & $-0.3573 *$ & $0.4074 *$ & 0.0139 & $0.2553 *$ & & $-0.2918 *$ \\
\hline 15 \#Analysts & $-0.0411^{*}$ & $-0.0509 *$ & $-0.0792 *$ & $0.0490 *$ & $-0.0399 *$ & $0.0269 *$ & $0.7113 *$ & $-0.0507^{*}$ & $0.0869^{*}$ & $0.2956^{*}$ & $-0.1294 *$ & $0.1000 *$ & $-0.0217 *$ & $-0.2359 *$ & \\
\hline
\end{tabular}

\footnotetext{
This table reports the Pearson (below the diagonal) and Spearman (above the diagonal) correlation coefficients for the variables used in the regression analysis

* stands for $\mathrm{p}<0.05$ two-tailed t-tests. All continuous variables are winsorized at $1 \%$ and $99 \%$. All variables are defined in Appendix 2 .
} 


\section{TABLE 21}

Multivariate Analysis for the Association between Analyst Forecast Accuracy and the Use of Uncertain and Weak Modal Words in 10-K Filings: Fog replacement

DV:Accuracy
$\frac{\text { IV }}{\text { Uncertain }}$
Weak_Modal
Fog
Pos_Tone
Neg_Tone
Firm_Size
Growth
Segments
R\&_Inst

\begin{tabular}{|c|c|c|c|}
\hline \multirow[b]{2}{*}{ Prediction } & \multicolumn{3}{|c|}{ Uncertain } \\
\hline & Model 1 & Model 2 & Model 3 \\
\hline$?$ & & $\begin{array}{c}-3.3171 * * * \\
(-5.59)\end{array}$ & $\begin{array}{c}-3.3191 * * * \\
(-5.66)\end{array}$ \\
\hline$?$ & & & \\
\hline+ & $\begin{array}{c}0.0011 \\
(1.11)\end{array}$ & $\begin{array}{c}0.0000 \\
(0.04)\end{array}$ & $\begin{array}{c}0.0004 \\
(0.45)\end{array}$ \\
\hline+ & $\begin{array}{c}-2.6441 * * * \\
(-2.65)\end{array}$ & $\begin{array}{c}-1.7887 * * * \\
(-1.77)\end{array}$ & \\
\hline+ & $\begin{array}{c}1.6933 * * * \\
(3.84)\end{array}$ & $\begin{array}{c}1.8746 * * * \\
(4.24)\end{array}$ & \\
\hline- & $\begin{array}{c}-0.0180 * * * \\
(-11.52)\end{array}$ & $\begin{array}{c}-0.0185^{* * *} \\
(-11.84)\end{array}$ & $\begin{array}{c}-0.0192 * * * \\
(-12.38)\end{array}$ \\
\hline- & $\begin{array}{c}-0.0084 * * \\
(-2.44)\end{array}$ & $\begin{array}{c}-0.0074 * * \\
(-2.15)\end{array}$ & $\begin{array}{c}-0.0078 * * \\
(-2.29)\end{array}$ \\
\hline+ & $\begin{array}{c}0.0149 * * * \\
(3.96)\end{array}$ & $\begin{array}{c}0.0127 * * * \\
(3.37)\end{array}$ & $\begin{array}{c}0.0132 * * * \\
(3.48)\end{array}$ \\
\hline- & $\begin{array}{c}-0.0326 * * * \\
(-4.34)\end{array}$ & $\begin{array}{c}-0.0313 * * * \\
(-4.17)\end{array}$ & $\begin{array}{c}-0.0296 * * * \\
(-3.94)\end{array}$ \\
\hline+ & $\begin{array}{l}-0.0495 \\
(-1.11)\end{array}$ & $\begin{array}{l}-0.0464 \\
(-1.04)\end{array}$ & $\begin{array}{l}-0.0412 \\
(-0.93)\end{array}$ \\
\hline+ & $\begin{array}{c}0.0279 \\
(0.53)\end{array}$ & $\begin{array}{c}0.0397 \\
(0.76)\end{array}$ & $\begin{array}{c}0.0604 \\
(1.16)\end{array}$ \\
\hline- & $\begin{array}{c}-0.0396 * * * \\
(-3.59)\end{array}$ & $\begin{array}{c}-0.0348 * * * \\
(-3.15)\end{array}$ & $\begin{array}{c}-0.0365 * * * \\
(-3.40)\end{array}$ \\
\hline
\end{tabular}

\begin{tabular}{|c|c|c|}
\hline \multicolumn{3}{|c|}{ Weak_Modal } \\
\hline Model 4 & Model 5 & Model 6 \\
\hline & $\begin{array}{c}-9.9156 * * * \\
(-8.74)\end{array}$ & $\begin{array}{c}-8.5436 * * * \\
(-7.75)\end{array}$ \\
\hline 0.0011 & 0.0009 & 0.0014 \\
\hline (1.11) & $(0.90)$ & $(1.47)$ \\
\hline$-2.6441^{* * *} *$ & -1.8753 & \\
\hline$(-2.65)$ & $(-1.88)$ & \\
\hline $1.6933 * * *$ & $2.6260 * * *$ & \\
\hline (3.84) & $(5.81)$ & \\
\hline$-0.0180 * * *$ & $-0.0196 * * *$ & $-0.0204 * * *$ \\
\hline$(-11.52)$ & $(-12.53)$ & $(-13.03)$ \\
\hline$-0.0084 * *$ & -0.0056 & $-0.0066^{*}$ \\
\hline$(-2.44)$ & $(-1.63)$ & $(-1.93)$ \\
\hline $0.0149 * * *$ & $0.0098 * *$ & $0.0110 * * *$ \\
\hline (3.96) & $(2.57)$ & (2.91) \\
\hline$-0.0326 * * *$ & $-0.0307 * * *$ & $-0.0288 * * *$ \\
\hline$(-4.34)$ & $(-4.09)$ & $(-3.84)$ \\
\hline-0.0495 & -0.0449 & $-0.0390 * * *$ \\
\hline$(-1.11)$ & $(-1.01)$ & $(-0.88)$ \\
\hline 0.0279 & 0.0637 & $0.0863 *$ \\
\hline$(0.53)$ & $(1.22)$ & $(1.65)$ \\
\hline$-0.0396 * * *$ & -0.0144 & $-0.0191 *$ \\
\hline$(-3.59)$ & $(-1.27)$ & $(-1.72)$ \\
\hline
\end{tabular}


TABLE 21 (Continued)

\begin{tabular}{|c|c|c|c|c|c|c|c|}
\hline \multirow{2}{*}{$\begin{array}{l}\text { DV: Accuracy } \\
\text { IV }\end{array}$} & \multirow[b]{2}{*}{ Prediction } & \multicolumn{3}{|c|}{ Uncertain } & \multicolumn{3}{|c|}{ Weak_Modal } \\
\hline & & Model 1 & Model 2 & Model 3 & Model 4 & Model 5 & Model 6 \\
\hline Std_Ret & + & $\begin{array}{c}0.3413 * * * \\
(13.89)\end{array}$ & $\begin{array}{c}0.3481 * * * \\
(14.17)\end{array}$ & $\begin{array}{c}0.3642 * * * \\
(15.01)\end{array}$ & $\begin{array}{c}0.3413 * * * \\
(13.89)\end{array}$ & $\begin{array}{c}0.3573 * * * \\
(14.55)\end{array}$ & $\begin{array}{c}0.3768 * * * \\
(15.49)\end{array}$ \\
\hline \#Analysts & + & $\begin{array}{c}0.0031 * * * \\
(9.08)\end{array}$ & $\begin{array}{c}0.0031 * * * \\
(9.10)\end{array}$ & $\begin{array}{c}0.0032 * * * \\
(9.67)\end{array}$ & $\begin{array}{c}0.0031 * * * \\
(9.08)\end{array}$ & $\begin{array}{c}0.0031 * * * \\
(9.30)\end{array}$ & $\begin{array}{c}0.0033 * * * \\
\quad(9.99)\end{array}$ \\
\hline Intercept & & $\begin{array}{l}0.0912 \\
(1.44)\end{array}$ & $\begin{array}{c}0.1348 \\
(2.11)\end{array}$ & $\begin{array}{c}0.1378 * * * \\
(2.17)\end{array}$ & $\begin{array}{l}0.0912 \\
(1.44)\end{array}$ & $\begin{array}{c}0.1202 * \\
(1.90)\end{array}$ & $\begin{array}{c}0.1230^{*} \\
(1.95)\end{array}$ \\
\hline Year/Ind Fixed Effects & & Yes & Yes & Yes & Yes & Yes & Yes \\
\hline $\mathrm{n}$ & & 9,640 & 9,640 & 9,640 & 9,640 & 9,640 & 9,640 \\
\hline Adjusted R-Squared & & 0.1092 & 0.1120 & 0.1101 & 0.1092 & 0.1162 & 0.1127 \\
\hline
\end{tabular}

The $t$-statistics in parentheses. *, **, *** stands for $\mathrm{p}<0.1, \mathrm{p}<0.05, \mathrm{p}<0.01$, respectively, two-tailed t-tests. All continuous variables are winsorized at $1 \%$ and 99\%. Variables are defined in the Appendix 2. 


\section{TABLE 22}

\section{Correlation Matrix for the Association between Uncertainty in Analysts' Overall Information Environment and the Use of Uncertain and Weak Modal Words in 10-K Filings: Fog replacement}

\begin{tabular}{|c|c|c|c|c|c|c|c|c|c|c|c|c|c|c|c|c|}
\hline & & 1 & 2 & 3 & 4 & 5 & 6 & 7 & 8 & 9 & 10 & 1 & 2 & 13 & 14 & 15 \\
\hline & ncertainty_Overall & & $218^{*}$ & $0.0925^{*}$ & 0.0071 & $-0.0535^{*}$ & $0.1386^{*}$ & $-0.2834 *$ & $-0.1479 *$ & $-0.0442 *$ & $-0.1329 *$ & $0.1749 *$ & $-0.0809 *$ & 0.0091 & $902 *$ & $14 *$ \\
\hline & Uncertain & $-0.0372 *$ & & $0.6601 *$ & $-0.0721 *$ & $0.2174 *$ & $0.1684 *$ & $-0.1474 *$ & $0.0476^{*}$ & $-0.1810^{*}$ & $0.0285^{*}$ & $0.0500^{*}$ & $0.0407 *$ & $0.2315^{*}$ & $0.1503^{*}$ & $-0.0604 *$ \\
\hline & Weak_Modal & -0.0139 & $0.6702 *$ & & $44 *$ & $0.1792 *$ & $0.3716^{*}$ & -0.2 & $0.1073 *$ & $-0.3144 *$ & $-0.0476^{*}$ & $0.1373^{*}$ & $0.0543 *$ & $0.4019 *$ & $0.3179 *$ & $-0.1059 *$ \\
\hline & Pos_Tone & $-0.0610^{*}$ & $0.1994 *$ & $0.2072 *$ & -0.0068 & & $0.0736^{*}$ & $-0.0325^{*}$ & -0.0035 & $-0.0638 *$ & $-0.0578^{*}$ & -0.0166 & $0.0358 *$ & $0.3750 *$ & $0.0641 *$ & $-0.0441 *$ \\
\hline & Neg_Tone & $0.0787 *$ & $0.1774 *$ & $0.3772 *$ & $0.1344^{*}$ & $0.0408 *$ & & $-0.1460 *$ & $-0.0840^{*}$ & $-0.0879 *$ & $-0.0216^{*}$ & $0.1104 *$ & $0.0990 *$ & $0.3368^{*}$ & $0.2645^{*}$ & -0.0072 \\
\hline & Firm_Size & $-0.1650 *$ & $-0.1411 *$ & $-0.2667 *$ & $0.0334 *$ & -0.0194 & $-0.1183 *$ & & $0.0465^{*}$ & $0.2694 *$ & $0.3314^{*}$ & $-0.2313^{*}$ & $0.0267 *$ & $-0.1016^{*}$ & $-0.5028 *$ & $0.6825^{*}$ \\
\hline & Segments & -0.0095 & $-0.1829 *$ & $-0.3147 *$ & 0.0158 & $-0.0751 *$ & $-0.0880 *$ & $0.2760^{*}$ & $-0.1103 *$ & & $0.0670^{*}$ & $-0.1207 *$ & $-0.0527 *$ & $-0.1611 *$ & $-0.2226^{*}$ & $0.0845^{*}$ \\
\hline & $\%$ Inst & $-0.1131 *$ & 0.0148 & $-0.0754 *$ & $0.0600 *$ & $-0.0595 *$ & $-0.0279 *$ & $0.3409 *$ & $-0.0762 *$ & $0.0860 *$ & & $-0.1310 *$ & 0.01100 & $-0.1338 *$ & $-0.2811 *$ & $0.2939 *$ \\
\hline & 10K_News & $0.0889 *$ & $0.0503 *$ & $0.1289 *$ & -0.0191 & 0.0102 & $0.0995 *$ & $-0.2216^{*}$ & $0.0663 *$ & $-0.1037 *$ & $-0.1658 *$ & & -0.013 & $0.0862 *$ & $0.3743 *$ & -0.1327 * \\
\hline & $A d v$ & 0.0101 & $0.0295 *$ & $.0543 *$ & $-0.0258 *$ & 0.0145 & $0.0666 *$ & $0.0804 *$ & $0.0439 *$ & $-0.0240 *$ & $-0.0441 *$ & 0.0056 & & $0.0283 *$ & 0.0015 & $0.0643 *$ \\
\hline & $R \& D$ & -0.0077 & $0.1797 *$ & $0.4374 *$ & $0.0703 *$ & $0.4004 *$ & $0.2289 *$ & $-0.1275^{*}$ & $0.1823 *$ & $-0.2668 *$ & $-0.1488^{*}$ & $0.1100 *$ & $-0.0618 *$ & & $0.2409 *$ & $-0.0218 *$ \\
\hline & Std_Ret & $0.2381 *$ & $0.1059 *$ & $0.2675^{*}$ & -0.0197 & $0.0766^{*}$ & $0.2241 *$ & $-0.4350 *$ & $0.1281 *$ & $-0.2005^{*}$ & $-0.3471^{*}$ & $0.4136^{*}$ & 0.0139 & $0.2481 *$ & & $-0.2810 *$ \\
\hline & \#Analysts & $-0.0251 *$ & $-0.0645^{*}$ & $-0.0954 *$ & $0.0509 *$ & $-0.0500 *$ & 0.0199 & $0.6959 *$ & $-0.0559 *$ & $0.0807 *$ & $0.2384 *$ & $-0.1206^{*}$ & $0.0988^{*}$ & $-0.0246^{*}$ & $.2253^{*}$ & \\
\hline
\end{tabular}

This table reports the Pearson (below the diagonal) and Spearman (above the diagonal) correlation coefficients for the variables used in the regression analysis.
$*$ stands for $\mathrm{p}<0.05$ two-tailed t-tests. All continuous variables are winsorized at $1 \%$ and $99 \%$. All variables are defined in Appendix 2 . 


\section{TABLE 23}

Multivariate Analysis for the Association between Uncertainty in Analysts' Overall Information Environment and the Use of Uncertain and Weak Modal Words in 10-K Filings: Fog replacement

\begin{tabular}{|c|c|c|c|c|c|c|c|}
\hline \multicolumn{2}{|c|}{ DV: Uncertainty_Overall } & \multicolumn{3}{|c|}{ Uncertain } & \multicolumn{3}{|c|}{ Weak_Modal } \\
\hline IV & Prediction & Model 1 & Model 2 & Model 3 & Model 4 & Model 5 & Model 6 \\
\hline$\overline{\text { Uncertain }}$ & + & & $\begin{array}{c}-3.0118 * * * \\
(-5.61)\end{array}$ & $\begin{array}{c}-3.0567 * * * \\
(-5.76)\end{array}$ & & & \\
\hline Weak_Modal & + & & & & & $\begin{array}{c}-8.9429 * * * \\
(-8.69)\end{array}$ & $\begin{array}{c}-7.7987 * * * \\
(-7.78)\end{array}$ \\
\hline Fog & + & $\begin{array}{c}0.0008 \\
(0.89)\end{array}$ & $\begin{array}{l}-0.0002 \\
(-0.25)\end{array}$ & $\begin{array}{c}0.0001 \\
(0.17)\end{array}$ & $\begin{array}{c}0.0008 \\
(0.89)\end{array}$ & $\begin{array}{c}0.0006 \\
(0.65)\end{array}$ & $\begin{array}{c}0.0011 \\
(1.24)\end{array}$ \\
\hline Pos_Tone & - & $\begin{array}{c}-2.8336 * * * \\
(-3.16)\end{array}$ & $\begin{array}{c}-2.0775^{* *} \\
(-2.29)\end{array}$ & & $\begin{array}{c}-2.8336 * * * \\
(-3.16)\end{array}$ & $\begin{array}{c}-2.1854 * * \\
(-2.44)\end{array}$ & \\
\hline Neg_Tone & + & $\begin{array}{c}1.5763 * * * \\
(3.94)\end{array}$ & $\begin{array}{c}1.7332 * * * \\
(4.32)\end{array}$ & & $\begin{array}{c}1.5763 * * * \\
(3.94)\end{array}$ & $\begin{array}{c}2.3727 * * * \\
(5.80)\end{array}$ & \\
\hline Firm_Size & - & $\begin{array}{c}-0.0190 * * * \\
(-13.43)\end{array}$ & $\begin{array}{c}-0.0195 * * * \\
(-13.79)\end{array}$ & $\begin{array}{c}-0.0202 * * * \\
(-14.39)\end{array}$ & $\begin{array}{c}-0.0190 * * * \\
(-13.43)\end{array}$ & $\begin{array}{c}-0.0206^{* * *} * \\
(-14.53)\end{array}$ & $\begin{array}{c}-0.0213 * * * \\
(-15.07)\end{array}$ \\
\hline Growth & - & $\begin{array}{c}-0.0051 \\
(-1.58)\end{array}$ & $\begin{array}{c}-0.0041 \\
(-1.27)\end{array}$ & $\begin{array}{c}-0.0045 \\
(-1.41)\end{array}$ & $\begin{array}{c}-0.0051 \\
(-1.58)\end{array}$ & $\begin{array}{c}-0.0023 \\
(-0.71)\end{array}$ & $\begin{array}{c}-0.0033 \\
(-1.02)\end{array}$ \\
\hline Segments & + & $\begin{array}{c}0.0139 * * * \\
(4.10)\end{array}$ & $\begin{array}{c}0.0119 * * * \\
(3.49)\end{array}$ & $\begin{array}{c}0.0122 * * * \\
(3.58)\end{array}$ & $\begin{array}{c}0.0139 * * * \\
(4.10)\end{array}$ & $\begin{array}{c}0.0093 * * * \\
(2.71)\end{array}$ & $\begin{array}{c}0.0103 * * * \\
(3.01)\end{array}$ \\
\hline$\% \_I n s t$ & - & $\begin{array}{c}-0.0331 * * * \\
(-4.71)\end{array}$ & $\begin{array}{c}-0.0320 * * * \\
(-4.57)\end{array}$ & $\begin{array}{c}-0.0306^{* * *} \\
(-4.36)\end{array}$ & $\begin{array}{c}-0.0331 * * * \\
(-4.71)\end{array}$ & $\begin{array}{c}-0.0320 * * * \\
(-4.58)\end{array}$ & $\begin{array}{c}-0.0305 * * * \\
(-4.35)\end{array}$ \\
\hline $10 K \_N e w s$ & + & $\begin{array}{c}-0.0478 \\
(-1.16)\end{array}$ & $\begin{array}{c}-0.0444 \\
(-1.08)\end{array}$ & $\begin{array}{c}-0.0379 * * * \\
(-0.92)\end{array}$ & $\begin{array}{c}-0.0478 \\
(-1.16)\end{array}$ & $\begin{array}{c}-0.0438 \\
(-1.07)\end{array}$ & $\begin{array}{c}-0.0363 \\
(-0.88)\end{array}$ \\
\hline$A d v$ & + & $\begin{array}{c}0.0749 \\
(1.58)\end{array}$ & $\begin{array}{c}0.08560 * \\
(1.82)\end{array}$ & $\begin{array}{c}0.1071 * * \\
(2.27)\end{array}$ & $\begin{array}{c}0.0749 \\
(1.58)\end{array}$ & $\begin{array}{c}0.1072 * * \\
(2.27)\end{array}$ & $\begin{array}{c}0.1304 * * * \\
(2.76)\end{array}$ \\
\hline$R \& D$ & - & $\begin{array}{c}-0.0318 * * * \\
(-3.18)\end{array}$ & $\begin{array}{c}-0.0279 * * * \\
(-2.79)\end{array}$ & $\begin{array}{c}-0.0307 * * * \\
(-3.16)\end{array}$ & $\begin{array}{c}-0.0318 * * * \\
(-3.18)\end{array}$ & $\begin{array}{c}-0.0095 \\
(-0.92)\end{array}$ & $\begin{array}{c}-0.0149 \\
(-1.49)\end{array}$ \\
\hline
\end{tabular}


TABLE 23 (Continued)

\begin{tabular}{|c|c|c|c|c|c|c|c|}
\hline \multirow{2}{*}{$\begin{array}{l}\text { DV: Uncertainty_Overall } \\
\text { IV }\end{array}$} & \multirow[b]{2}{*}{ Prediction } & \multicolumn{3}{|c|}{ Uncertain } & \multicolumn{3}{|c|}{ Weak_Modal } \\
\hline & & Model 1 & Model 2 & Model 3 & Model 4 & Model 5 & Model 6 \\
\hline$S t d \_R e t$ & + & $\begin{array}{c}0.3590 * * * \\
(15.53)\end{array}$ & $\begin{array}{c}0.3652 * * * \\
(15.8)\end{array}$ & $\begin{array}{c}0.3807 * * * \\
(16.69)\end{array}$ & $\begin{array}{c}0.3590 * * * \\
(15.53)\end{array}$ & $\begin{array}{c}0.3732 * * * \\
(16.17)\end{array}$ & $\begin{array}{c}0.3919 * * * \\
(17.14)\end{array}$ \\
\hline \#Analysts & + & $\begin{array}{c}0.0035^{* * * *} \\
(11.43)\end{array}$ & $\begin{array}{c}0.0035^{* * * *} \\
(11.45)\end{array}$ & $\begin{array}{c}0.0036^{* * *} \\
(12.08)\end{array}$ & $\begin{array}{c}0.0035^{* * * *} \\
(11.43)\end{array}$ & $\begin{array}{l}0.0035^{* * * *} \\
(11.67)\end{array}$ & $\begin{array}{c}0.0037 * * * \\
(12.41)\end{array}$ \\
\hline Intercept & & $\begin{array}{c}0.1307 * * \\
(2.17)\end{array}$ & $\begin{array}{c}0.1717 * * * \\
(2.84)\end{array}$ & $\begin{array}{l}0.1729 * * * \\
\quad(2.87)\end{array}$ & $\begin{array}{c}0.1307 * * \\
(2.17)\end{array}$ & $\begin{array}{c}0.1600 * * * \\
(2.67)\end{array}$ & $\begin{array}{c}0.1601 * * * \\
(2.68)\end{array}$ \\
\hline $\begin{array}{l}\text { Year/Ind Fixed Effects } \\
\mathrm{n}\end{array}$ & & $\begin{array}{c}\text { Yes } \\
8,989\end{array}$ & $\begin{array}{c}\text { Yes } \\
8,989\end{array}$ & $\begin{array}{c}\text { Yes } \\
8,989\end{array}$ & $\begin{array}{c}\text { Yes } \\
8,989\end{array}$ & $\begin{array}{c}\text { Yes } \\
8,989\end{array}$ & $\begin{array}{c}\text { Yes } \\
8,989\end{array}$ \\
\hline Adjusted R-Squared & & 0.1439 & 0.1545 & 0.1445 & 0.1439 & 0.151 & 0.1471 \\
\hline
\end{tabular}

The $t$-statistics in parentheses. *, **,*** stands for $\mathrm{p}<0.1, \mathrm{p}<0.05, \mathrm{p}<0.01$, respectively, two-tailed $\mathrm{t}$-tests. All continuous variables are winsorized at $1 \%$ and 99\%. Variables are defined in the Appendix 2. 


\section{TABLE 24}

\section{Correlation Matrix for the Association between Uncertainty in Analysts' Common Information Environment and the Use} of Uncertain and Weak Modal Words in 10-K Filings: For Replacement

\begin{tabular}{|c|c|c|c|c|c|c|c|c|c|c|c|c|c|c|c|}
\hline & 1 & 2 & 3 & 4 & 5 & 6 & 7 & 8 & 9 & 10 & 11 & 12 & 13 & 14 & 15 \\
\hline 1 Uncertainty_Common & & $-0.0740 *$ & $-0.0976 *$ & $-0.0293 *$ & $-0.0530 *$ & $-0.0223 *$ & $0.0875^{*}$ & -0.0117 & $0.0756^{*}$ & $0.0820 *$ & $-0.0212 *$ & -0.0017 & $-0.1040 *$ & $0.0292 *$ & $.1092 *$ \\
\hline 2 Uncertain & $-0.0722 *$ & & $0.6599 *$ & $-0.0719 *$ & $0.2175^{*}$ & $0.1680^{*}$ & $-0.1471 *$ & $0.0474 *$ & $-0.1808 *$ & $0.0286^{*}$ & $0.0503^{*}$ & $0.0406^{*}$ & $0.2315^{*}$ & $0.1500 *$ & $-0.0599 *$ \\
\hline 3 Weak_Modal & $-0.0987 *$ & $0.6700 *$ & & $0.1046 *$ & $0.1793^{*}$ & $0.3712 *$ & $-0.2808 *$ & $0.1071 *$ & $-0.3143 *$ & $-0.0475 *$ & $0.1377 *$ & $0.0541 *$ & $0.4020^{*}$ & $0.3176^{*}$ & $-0.1054 *$ \\
\hline 4 Fog & $-0.0305^{*}$ & $-0.1154 *$ & $0.0697 *$ & & 0.0146 & $0.1508^{*}$ & 0.0144 & -0.0004 & 0.0015 & $0.0578^{*}$ & $-0.0226 *$ & 0.0043 & $0.0716^{*}$ & 0.0016 & $0.0482 *$ \\
\hline 5 Pos_Tone & $-0.0564 *$ & $0.1995 *$ & $0.2073 *$ & -0.0068 & & $0.0738^{*}$ & $-0.0326 *$ & -0.0036 & $-0.0638 *$ & $-0.0575^{*}$ & -0.0165 & $0.0359 *$ & $0.3750 *$ & $0.0642 *$ & $-0.0442 *$ \\
\hline 6 Neg_Tone & -0.0143 & $0.1769^{*}$ & $0.3768^{*}$ & $0.1346^{*}$ & $0.0409 *$ & & $-0.1455^{*}$ & $-0.0842 *$ & $-0.0877^{*}$ & $-0.0216^{*}$ & $0.1107 *$ & $0.0988^{*}$ & $0.3369^{*}$ & $0.2642 *$ & -0.0066 \\
\hline 7 Firm_Size & $0.0885^{*}$ & $-0.1407 *$ & $-0.2663 *$ & $0.0333^{*}$ & -0.0196 & $-0.1178 *$ & & $0.0467 *$ & $0.2692 *$ & $0.3315^{*}$ & $-0.2316^{*}$ & $0.0269 *$ & $-0.1016^{*}$ & $-0.5025^{*}$ & $0.6823^{*}$ \\
\hline 8 Growth & -0.0018 & $0.0509 *$ & $0.1422 *$ & 0 & $0.0511 *$ & -0.0189 & $-0.0285^{*}$ & & $-0.1084 *$ & 0.0148 & 0.0085 & -0.0109 & $0.0676^{*}$ & 0.0055 & -0.02 \\
\hline 9 Segment. & $0751^{*}$ & $-0.1827 *$ & $-0.3146^{*}$ & 0.0158 & $-0.0752 *$ & $-0.0877^{*}$ & $0.2758^{*}$ & $-0.1103^{*}$ & & $0.0670^{*}$ & $-0.1209 *$ & $-0.0526^{*}$ & $-0.1611 *$ & $-0.2224 *$ & $0.0842 *$ \\
\hline $10 \%$ _Inst & $0.0993 *$ & 0.0149 & $-0.0753 *$ & $0.0600 *$ & $-0.0593 *$ & $-0.0279 *$ & $0.3411^{*}$ & $-0.0762 *$ & $0.0860^{*}$ & & $-0.1312 *$ & 0.0158 & $-0.1337 *$ & $-0.2812 *$ & $0.2940^{*}$ \\
\hline 11 10K_News & $-0.0241 *$ & $0.0505^{*}$ & $0.1292 *$ & -0.0191 & 0.0103 & $0.0996^{*}$ & $-0.2217 *$ & $0.0663^{*}$ & $-0.1037 *$ & $-0.1659 *$ & & -0.0129 & $0.0863^{*}$ & $0.3746^{*}$ & $-0.1331 *$ \\
\hline $12 A d v$ & 0.0058 & $0.0296 *$ & $0.0544 *$ & $-0.0258 *$ & 0.0145 & $0.0666^{*}$ & $0.0805^{*}$ & $0.0439 *$ & $-0.0240 *$ & $-0.0442 *$ & 0.0056 & & $0.0283^{*}$ & 0.0013 & $0.0646 *$ \\
\hline $13 R \& D$ & $-0.1139 *$ & $0.1798 *$ & $0.4377 *$ & $0.0703 *$ & $0.4005 *$ & $0.2290^{*}$ & $-0.1275^{*}$ & $0.1823^{*}$ & $-0.2668 *$ & $-0.1489 *$ & $0.1100 *$ & $-0.0618 *$ & & $0.2410^{*}$ & $-0.0218 *$ \\
\hline $14 S t d \_R$ & $0.0294 *$ & $0.1057 *$ & $0.2673 *$ & -0.0196 & $0.0767 *$ & $0.2238^{*}$ & $-0.4348 *$ & $0.1280 *$ & $-0.2004 *$ & $-0.3472 *$ & $0.4137 *$ & 0.0139 & $0.2482 *$ & & $-0.2806^{*}$ \\
\hline 15 \#Analysts & $0.1094 *$ & $-0.0641 *$ & $-0.0949 *$ & $0.0508 *$ & $-0.0502 *$ & 0.0205 & $0.6958 *$ & $-0.0559 *$ & $0.0804 *$ & $0.2386^{*}$ & $-0.1207 *$ & $0.0989 *$ & $-0.0246^{*}$ & $-0.2251 *$ & \\
\hline
\end{tabular}

\footnotetext{
This table reports the Pearson (below the diagonal) and Spearman (above the diagonal) correlation coefficients for the variables used in the regression analysis

* stands for $\mathrm{p}<0.05$ two-tailed t-tests. All continuous variables are winsorized at $1 \%$ and $99 \%$. All variables are defined in Appendix 2 .
} 


\section{TABLE 25}

Multivariate Analysis for the Association between Uncertainty in Analysts' Common Information Environment and the Use of Uncertain and Weak Modal Words in 10-K Filings: Fog replacement

\begin{tabular}{|c|c|c|c|c|c|c|c|}
\hline \multicolumn{2}{|c|}{ DV: Uncertainty_Common } & \multicolumn{3}{|c|}{ Uncertainty } & \multicolumn{3}{|c|}{ Weak Modal } \\
\hline IV & Prediction & Model 1 & Model 2 & $\underline{\text { Model } 3}$ & Model 4 & Model 5 & Model 6 \\
\hline Uncertain & + & & $\begin{array}{c}-8.5482 * * * \\
(-4.61)\end{array}$ & $\begin{array}{c}-8.5315 * * * \\
(-4.66)\end{array}$ & & & \\
\hline Weak_Modal & + & & & & & $\begin{array}{c}-16.4710 * * * \\
(-4.63)\end{array}$ & $\begin{array}{c}-14.9049 * * * \\
(-4.30)\end{array}$ \\
\hline File_Size & + & $\begin{array}{c}-0.0056^{*} \\
(-1.88)\end{array}$ & $\begin{array}{c}-0.0084 * * * \\
(-2.77)\end{array}$ & $\begin{array}{c}-0.0079 * * * \\
(-2.63)\end{array}$ & $\begin{array}{c}-0.0056^{*} \\
(-1.88)\end{array}$ & $\begin{array}{c}-0.0060 * * \\
(-2.02)\end{array}$ & $\begin{array}{c}-0.0053^{*} \\
(-1.79)\end{array}$ \\
\hline Pos_Tone & - & $\begin{array}{c}-3.8991 \\
(-1.26)\end{array}$ & $\begin{array}{c}-1.7528 \\
(-0.56)\end{array}$ & & $\begin{array}{c}-3.8991 \\
(-1.26)\end{array}$ & $\begin{array}{c}-2.7059 \\
(-0.87)\end{array}$ & \\
\hline Neg_Tone & + & $\begin{array}{l}1.7555 \\
(1.27)\end{array}$ & $\begin{array}{c}2.1980 \\
(1.59)\end{array}$ & & $\begin{array}{l}1.7555 \\
(1.27)\end{array}$ & $\begin{array}{c}3.2190 * * \\
(2.27)\end{array}$ & \\
\hline Firm_Size & - & $\begin{array}{c}0.0000 \\
(0.01)\end{array}$ & $\begin{array}{c}-0.0014 \\
(-0.29)\end{array}$ & $\begin{array}{c}-0.0023 \\
(-0.47)\end{array}$ & $\begin{array}{c}0.0000 \\
(0.01)\end{array}$ & $\begin{array}{c}-0.0030 \\
(-0.61)\end{array}$ & $\begin{array}{c}-0.0040 \\
(-0.81)\end{array}$ \\
\hline Growth & - & $\begin{array}{l}0.0177 \\
(1.59)\end{array}$ & $\begin{array}{c}0.0206^{*} \\
(1.85)\end{array}$ & $\begin{array}{c}0.0199 * \\
(1.79)\end{array}$ & $\begin{array}{c}0.0177 \\
(1.59)\end{array}$ & $\begin{array}{c}0.0228 * * \\
(2.05)\end{array}$ & $\begin{array}{c}0.0214^{*} \\
(1.93)\end{array}$ \\
\hline Segments & + & $\begin{array}{c}0.0360 * * * \\
(3.08)\end{array}$ & $\begin{array}{c}0.0302 * * \\
(2.57)\end{array}$ & $\begin{array}{c}0.0306^{* * *} * \\
(2.60)\end{array}$ & $\begin{array}{c}0.0360 * * * \\
(3.08)\end{array}$ & $\begin{array}{c}0.0275 * * \\
(2.32)\end{array}$ & $\begin{array}{c}0.0288^{* * *} \\
(2.44)\end{array}$ \\
\hline$\%$ Inst & + & $\begin{array}{c}0.1878 * * * \\
(7.75)\end{array}$ & $\begin{array}{c}0.1908 * * * \\
(7.88)\end{array}$ & $\begin{array}{c}0.1922 * * * \\
(7.95)\end{array}$ & $\begin{array}{c}0.1878 * * * \\
(7.75)\end{array}$ & $\begin{array}{c}0.1898 * * * \\
(7.84)\end{array}$ & $\begin{array}{c}0.1918 * * * \\
(7.93)\end{array}$ \\
\hline $10 K \_N e w s$ & + & $\begin{array}{c}-0.5008 * * * \\
(-3.53)\end{array}$ & $\begin{array}{c}-0.4909 * * * \\
(-3.46)\end{array}$ & $\begin{array}{c}-0.4835 * * * \\
(-3.41)\end{array}$ & $\begin{array}{c}-0.5008 * * * \\
(-3.53)\end{array}$ & $\begin{array}{c}-0.4931 * * * \\
(-3.48)\end{array}$ & $\begin{array}{c}-0.4831 * * * \\
(-3.41)\end{array}$ \\
\hline$A d v$ & + & $\begin{array}{c}-0.0764 \\
(-0.47)\end{array}$ & $\begin{array}{c}-0.0449 \\
(-0.27)\end{array}$ & $\begin{array}{c}-0.0186 \\
(-0.11)\end{array}$ & $\begin{array}{c}-0.0764 \\
(-0.47)\end{array}$ & $\begin{array}{c}-0.0167 \\
(-0.10)\end{array}$ & $\begin{array}{c}0.0146 \\
(0.09)\end{array}$ \\
\hline$R \& D$ & - & $\begin{array}{c}-0.2269 * * * \\
(-6.58)\end{array}$ & $\begin{array}{c}-0.2158 * * * \\
(-6.25)\end{array}$ & $\begin{array}{c}-0.2172^{* * *} \\
(-6.47)\end{array}$ & $\begin{array}{c}-0.2269 * * * \\
(-6.58)\end{array}$ & $\begin{array}{c}-0.1857 * * * \\
(-5.22)\end{array}$ & $\begin{array}{c}-0.1925 * * * \\
(-5.54)\end{array}$ \\
\hline
\end{tabular}


TABLE 25 (Continued)

\begin{tabular}{|c|c|c|c|c|c|c|c|}
\hline \multicolumn{2}{|l|}{ DV: Uncertainty_Common } & \multicolumn{3}{|c|}{ Uncertainty } & \multicolumn{3}{|c|}{ Weak Modal } \\
\hline IV & Prediction & Model 1 & Model 2 & Model 3 & Model 4 & Model 5 & Model 6 \\
\hline$\overline{S t d} \_R e t$ & + & $\begin{array}{c}0.5806 * * * \\
(7.28)\end{array}$ & $\begin{array}{c}0.5980 * * * \\
(7.50)\end{array}$ & $\begin{array}{c}0.6181 * * * \\
(7.86)\end{array}$ & $\begin{array}{c}0.5806 * * * \\
(7.28)\end{array}$ & $\begin{array}{c}0.6066 * * * \\
(7.59)\end{array}$ & $\begin{array}{c}0.6321 * * * \\
(8.00)\end{array}$ \\
\hline \#Analysts & + & $\begin{array}{c}0.0069 * * * \\
(6.64)\end{array}$ & $\begin{array}{c}0.0069 * * * \\
(6.65)\end{array}$ & $\begin{array}{c}0.0071 * * * \\
(6.88)\end{array}$ & $\begin{array}{c}0.0069 * * * \\
(6.64)\end{array}$ & $\begin{array}{c}0.0070 * * * \\
(6.75)\end{array}$ & $\begin{array}{c}0.0073^{* * *} * \\
(7.06)\end{array}$ \\
\hline Intercept & & $\begin{array}{c}0.6485^{* * *} \\
(3.13)\end{array}$ & $\begin{array}{c}0.7651 * * * \\
(3.67)\end{array}$ & $\begin{array}{c}0.7719 * * * \\
(3.72)\end{array}$ & $\begin{array}{c}0.6485^{* * *} \\
\quad(3.13)\end{array}$ & $\begin{array}{c}0.7025 * * * \\
(3.38)\end{array}$ & $\begin{array}{c}0.7046^{* * * *} \\
\quad(3.42)\end{array}$ \\
\hline Year/Ind Fixed Effects & & Yes & Yes & Yes & Yes & Yes & Yes \\
\hline $\mathrm{n}$ & & 8,987 & 8,987 & 8,987 & 8,987 & 8,987 & 8,987 \\
\hline Adjusted R-Squared & & 0.0653 & 0.0674 & 0.0673 & 0.0653 & 0.0674 & 0.0670 \\
\hline
\end{tabular}

The $t$-statistics in parentheses. *, **, *** stands for $\mathrm{p}<0.1, \mathrm{p}<0.05, \mathrm{p}<0.01$, respectively, two-tailed t-tests. All continuous variables are winsorized at $1 \%$ and 99\%. Variables are defined in the Appendix 2. 
VITA

\section{MYUNG SUB KIM}

Born, Seoul, Korea

1996-2002

Bachelor of Business Administration

Dankook University

Seoul, Korea

2002-2003

Junior Accountant

Stryker

Seoul, Korea

2004-2007

Senior Accountant

Emerson Process Management

Seoul, Korea

2008-2009

Assistant Manager in Finance and Accounting bioMérieux

Seoul, Korea

2009-2012

Master of Professional Accountancy

Georgia State University

Atlanta, Georgia

2014-2018

Ph.D. Business Administration

Florida International University

Miami, Florida

\section{PUBLICATIONS AND PRESENTATIONS}

Kim, M., (2018, January). "Market Reaction to the OTCQX International Market Listing" Paper presented at American Accounting Association International Accounting Section Midyear Meeting, Long Beach, California. 